Argonne

\title{
Technical Letter Report on the Cracking of Irradiated Cast Stainless Steels with Low Ferrite Content
}

Nuclear Engineering Division 


\title{
About Argonne National Laboratory
}

Argonne is a U.S. Department of Energy laboratory managed by UChicago Argonne, LLC under contract DE-AC02-06CH11357. The Laboratory's main facility is outside Chicago, at 9700 South Cass Avenue, Argonne, Illinois 60439. For information about Argonne and its pioneering science and technology programs, see www.anl.gov.

\section{DOCUMENT AVAILABILITY}

Online Access: U.S. Department of Energy (DOE) reports produced after 1991 and a growing number of pre-1991 documents are available free via DOE's SciTech Connect (http://www.osti.gov/scitech/)

\author{
Reports not in digital format may be purchased by the public from the \\ National Technical Information Service (NTIS): \\ U.S. Department of Commerce \\ National Technical Information Service \\ 5301 Shawnee Rd \\ Alexandria, VA 22312 \\ www.ntis.gov \\ Phone: (800) 553-NTIS (6847) or (703) 605-6000 \\ Fax: (703) 605-6900 \\ Email: orders@ntis.gov
}

Reports not in digital format are available to DOE and DOE contractors from the Office of Scientific and Technical Information (OSTI):

U.S. Department of Energy

Office of Scientific and Technical Information

P.O. Box 62

Oak Ridge, TN 37831-0062

www.osti.gov

Phone: (865) 576-8401

Fax: (865) 576-5728

Email: reports@osti.gov 
ANL-14/16

\section{Technical Letter Report on the Cracking of Irradiated Cast Stainless Steels with Low Ferrite Content}

prepared by

Y. Chen, B. Alexandreanu, and K. Natesan

Nuclear Engineering Division, Argonne National Laboratory

November 2014 



\section{ABSTRACT}

Crack growth rate and fracture toughness J-R curve tests were performed on CF-3 and CF-8 cast austenite stainless steels (CASS) with $13-14 \%$ of ferrite. The tests were conducted at $\sim 320^{\circ} \mathrm{C}$ in either high-purity water with low dissolved oxygen or in simulated PWR water. The cyclic crack growth rates of CF-8 were higher than that of CF-3, and the differences between the aged and unaged specimens were small. No elevated SCC susceptibility was observed among these samples, and the SCC CGRs of these materials were comparable to those of CASS alloys with $>23 \%$ ferrite. The fracture toughness values of unirradiated CF-3 were similar between unaged and aged specimens, and neutron irradiation decreased the fracture toughness significantly. The fracture toughness of CF-8 was reduced after thermal aging, and declined further after irradiation. It appears that while lowering ferrite content may help reduce the tendency of thermal aging embrittlement, it is not very effective to mitigate irradiation-induced embrittlement. Under a combined condition of thermal aging and irradiation, neutron irradiation plays a dominant role in causing embrittlement in CASS alloys. 
Cast austenitic stainless steels (CASSs) are widely used in the cooling systems of light water reactors (LWRs) thanks to their excellent corrosion and mechanical properties. Cast components are formed directly from liquid phase and have a characteristic two-phase microstructure containing austenite and delta ferrite. While austenite is the main phase in CASS alloys, delta ferrite is critical for the strength and corrosion resistance of CASS materials. Despite its beneficial effects, delta ferrite can also exert a negative impact on the fracture resistance of CASS alloys. Exposed to LWR environments at elevated temperatures and neutron irradiations, CASS alloys can experience hardening and embrittlement. Precipitation and growth of carbides and G-phase, and the formation of Cr-rich alpha prime phase are believed to be responsible for the observed thermal aging embrittlement. A previous study also showed that the degree of embrittlement may be higher for the irradiated and thermally aged CASS materials, suggesting a combined effect of thermal aging and irradiation embrittlement. While thermal aging embrittlement is sensitive to the fraction of ferrite in CASS, the effect of ferrite content has not been evaluated carefully for irradiation-induce embrittlement.

In the current study, crack growth rate (CGR) and fracture toughness J-R curve tests were performed on neutron-irradiated CASS specimens with $13-14 \%$ delta ferrite. The tests were conducted at $\sim 320^{\circ} \mathrm{C}$ in either simulated PWR water or high-purity water with low dissolvedoxygen (DO). The specimens were in unaged and thermally aged conditions, and were irradiated to 0.08 dpa at Halden reactor. All samples were precracked in the test environments, and cyclic and SCC CGRs were measured. The cyclic CGRs of CF-8 were higher than that of CF-3, and the differences between the aged and unaged specimens were small. No elevated SCC susceptibility was seen among the samples, and the SCC CGRs of these materials were comparable to the previous results on CASS with $>23 \%$ ferrite.

After each CGR test, a fracture toughness J-R curve test was conducted on the same sample in the test environment. A J-R curve was then re-constructed by fitting the calculated $\mathrm{J}$ values and corresponding crack lengths to a power law relationship. The $\mathrm{J}$ value at the $0.2-\mathrm{mm}$ offset line was obtained and compared with the previous tests on CASS with higher ferrite contents $(>23 \%)$. The fracture toughness values of unirradiated CF-3 were similar between the unaged and aged specimens, and neutron irradiation reduced the fracture toughness significantly. The fracture toughness of CF-8 was reduced after thermal aging, and declined further after irradiation. It appears that while lowering ferrite content may help reduce the tendency of thermal aging embrittlement, it is not very effective to mitigate irradiation-induced embrittlement. Under a combined condition of thermal aging and irradiation, neutron irradiation plays a dominant role in causing embrittlement. 


\section{TABLE OF CONTENTS}

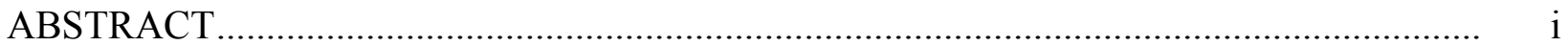

EXECUTIVE SUMMARY …................................................................................. iii

TABLE OF CONTENTS ............................................................................... v

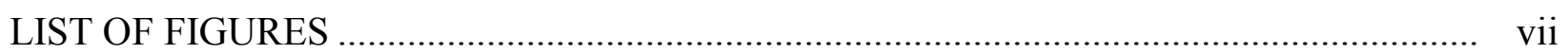

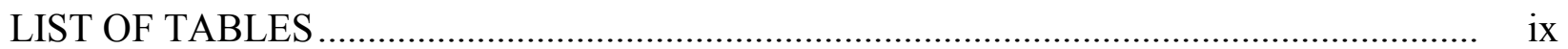

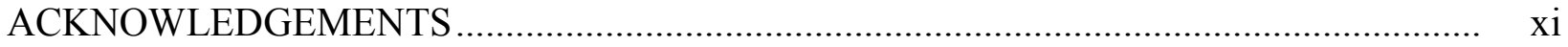

ACRONYMS AND ABBREVATIONS ....................................................................... xiii

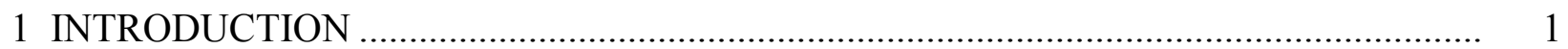

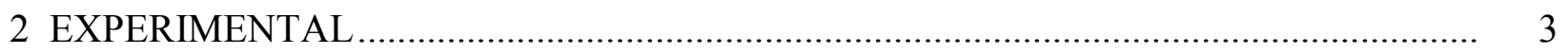

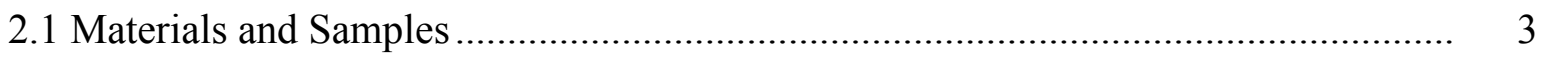

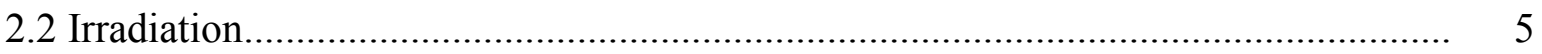

2.3 Crack Growth Rate Test ..................................................................................... 5

2.4 Fracture Toughness J-R Curve Test.................................................................. 6

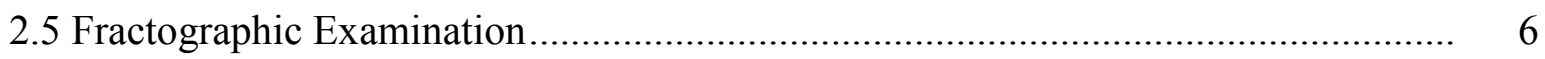

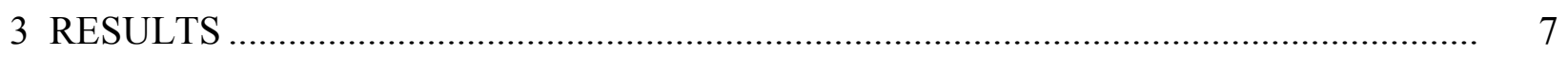

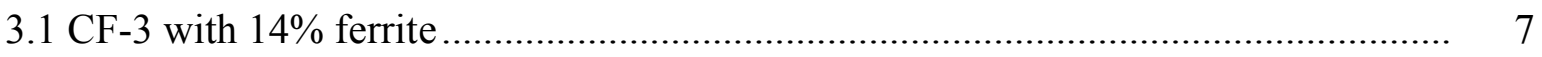

3.1.1 Unaged Specimen, C-1 ................................................................. 7

3.1.2 Aged Specimen, D-1 ...................................................................... 18

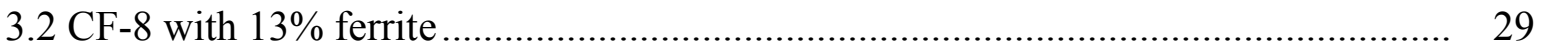

3.2.1 Unaged Specimen, G-1 ............................................................... 29

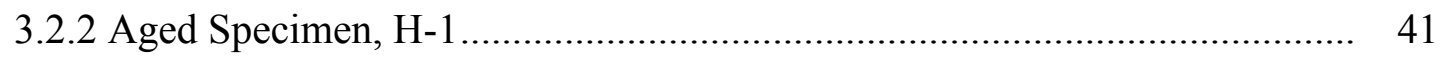

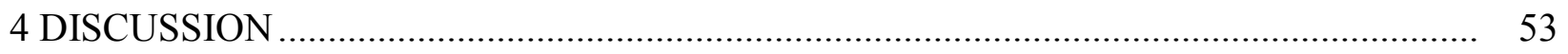

4.1 Crack Growth Behavior of the Low-Ferrite CASS Specimens ............................. 53

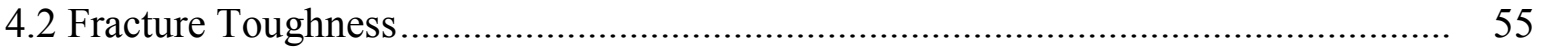

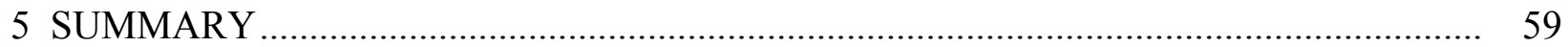





\section{LIST OF FIGURES}

1. Metallurgical images of the CASS materials..................................................................... 4

2. 1/4T-CT specimen used in this study......................................................................... 4

3. Crack-length-vs.-time plot of specimen C-1 (unaged 0.08-dpa CF-3 with $14 \%$ ferrite): test periods (a) a-c, (b) d-f, (c) g-i, (d) j-1, (e) m-n, and (f) 1a-1c. .................................... 8

4. Cyclic CGRs of Specimen C-1, an unaged 0.08-dpa CF-3 with 14\% ferrite tested in simulated PWR water.

5. J-R curve of Specimen C-1, an unaged 0.08-dpa CF-3 with 14\% ferrite tested in PWR water.

6. Fracture surface of specimen C-1, an 0.08-dpa unaged CF-3 with $14 \%$ ferrite tested in PWR water.

7. Fracture surface of specimen $\mathrm{C}-1$ along the sample central line.

8. Cyclic fatigue cracking at the machine notch.

9. Flat transgranular cracking region with visible ferrite.

10. The transition region from CGR test to J-R curve test.

11. Ductile dimple fracture in the J-R curve test.

12. Crack-length-vs.-time plot of specimen D-1 (aged 0.08-dpa CF-3 with $14 \%$ ferrite): test periods (a) a-c, (b) d-f, (c) g-i, (d) j-l, (e) m-o, (f) p-s, (g) t-v, and (h) la-1b.

13. Cyclic CGRs of Specimen D-1, an aged 0.08-dpa CF-3 with $14 \%$ ferrite tested in simulated PWR water

14. J-R curve of Specimen D-1, an aged 0.08-dpa CF-3 with $14 \%$ ferrite tested in PWR water.

15. Fracture surface of specimen D-1, an 0.08-dpa aged CF-3 with $14 \%$ ferrite tested in low-DO high-purity water.

16. Cyclic fatigue cracking near the machine notch.

17. Near the end of CGR test, relatively flat fracture surface with visible ferrite................... 26

18. The transition region from CGR test to J-R curve test. ................................................... 27

19. Ductile dimple and mixed mode fracture in the J-R curve test..................................... 28

20. Crack-length-vs.-time plot of specimen G-1 (unaged 0.08-dpa CF-8 with 13\% ferrite): test periods (a) a-e, (b) f-h, (c) i-l, (d) m-o, (e) p-r, (f) 1a, (g) v-w, (h) 1b-1c.

21. Cyclic CGRs of Specimen G-1, an unaged 0.08-dpa CF-8 with 13\% ferrite tested in low-DO high-purity water.

22. J-R curve of Specimen G-1, an unaged 0.08-dpa CF-8 with $13 \%$ ferrite tested in lowDO high-purity water.

23. Fracture surface of specimen G-1, an 0.08-dpa unaged CF-8 with 13\% ferrite tested in low-DO high-purity water.

24. Cyclic fatigue cracking near the machine notch.

25. Relatively flat transgranular cracking region with visible ferrite.

26. The transition region from CGR test to J-R curve test.

27. Ductile dimple fracture in the J-R curve test. 
28. Crack-length-vs.-time plot of specimen H-1 (aged 0.08-dpa CF-8 with 13\% ferrite): test periods (a) a-c, (b) d-g, (c) 1-n, (d) h-k, and (e) 1a-1b.

29. Cyclic CGRs of Specimen H-1, an aged 0.08-dpa CF-8 with $13 \%$ ferrite tested in low-DO high-purity water.

30. J-R curve of Specimen H-1, an aged 0.08-dpa CF-8 with 13\% ferrite tested in lowDO high-purity water.

31. Fracture surface of specimen $\mathrm{H}-1$, an 0.08 -dpa aged CF-8 with $13 \%$ ferrite tested in low-DO high-purity water.

32. Fracture surface of specimen $\mathrm{H}-1$ along the sample central line.

33. Cyclic fatigue cracking near the machine notch. 48

34. Relatively flat transgranular cracking region with visible ferrite. 49

35. The transition region from CGR test to J-R curve test. 50

36. Ductile dimple fracture in the J-R curve test. 51

37. Best fit curves for cyclic CGR data with a superposition model. 53

38. SCC crack growth rates of CASS alloys tested in low-DO high-purity water or PWR water at $\sim 320^{\circ} \mathrm{C}$

39. $\mathrm{J}_{0.2}$ values of high- and low-ferrite CASS: (a) for CF-3, and (b) CF-8. 


\section{LIST OF TABLES}

1. Chemical compositions of the CASS Samples used in this study ................................... 3

2. Thermal aging condition prior to irradiation. ............................................................ 3

3. Crack growth rates of specimen C-1 (unaged CF-3 with 14\% ferrite) in PWR water. ........ 7

4. Crack growth rates of specimen D-1 (aged CF-3 with 14\% ferrite) in PWR water............ 18

5. Crack growth rates of specimen G-1 (unaged CF-8 with 13\% ferrite) in low-DO high-

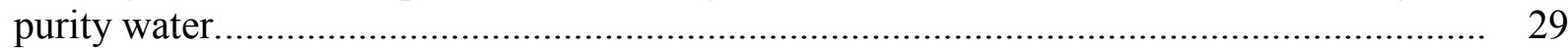

6. Crack growth rates of specimen H-1 (aged CF-8 with 13\% ferrite) in low-DO high-

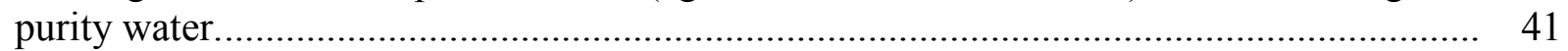

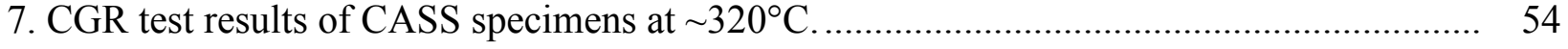

8. Fracture toughness J-R curve test results for CASS alloys......................................... 56 


\section{ACKNOWLEDGEMENTS}

The authors would like to thank Drs. O. K. Chopra and W. J. Shack for their invaluable contribution to this project. Our special thank go out to Ms. T. M. Karlsen, OECD Halden Reactor Project, Halden, Norway, for reactor irradiation experiments and sample transfer. L. A. Knoblich, E. E. Gruber, R. Clark, and E. J. Listwan of Argonne, and M. Okubo of University of Fukui are acknowledged for their contributions to the experimental effort. This work is sponsored by the Office of Nuclear Regulatory Research, U.S. Nuclear Regulatory Commission, under Job Code V6454; Program Manager: A. S. Rao. 


\section{ACRONYMS AND ABBREVATIONS}

$\begin{array}{ll}\text { ANL } & \text { Argonne National Laboratory } \\ \text { BWR } & \text { Boiling Water Reactor } \\ \text { CASS } & \text { Cast Austenitic Stainless Steel } \\ \text { CGR } & \text { Crack Growth Rate } \\ \text { CT } & \text { Compact Tension } \\ \text { DCPD } & \text { Direct Current Potential Drop } \\ \text { DO } & \text { Dissolved Oxygen } \\ \text { dpa } & \text { Displacement per atom } \\ \text { ECP } & \text { Electrochemical Potential } \\ \text { HWC } & \text { Hydrogen Water Chemistry } \\ \text { J-R } & \text { J-Integral Resistance } \\ \text { LWR } & \text { Light Water Reactor } \\ \text { PPU } & \text { Periodical Partial Unloading } \\ \text { PWR } & \text { Pressurized Water Reactor } \\ \text { SCC } & \text { Stress Corrosion Cracking } \\ \text { SEM } & \text { Scanning Electron Microscopy } \\ \text { SS } & \text { Stainless Steel } \\ \text { TG } & \text { Transgranular }\end{array}$




\section{INTRODUCTION}

Cast austenitic stainless steels (CASSs) are an important class of engineering materials used in the cooling system of light water reactors (LWRs). Many reactor components with complex shapes at the pressure-boundary and inside the reactor core internals are made of CASS alloys, such as pump casings, valve bodies, coolant piping, elbows, and control rod guide tube spacers. ${ }^{1}$ The CF grade CASS alloys are essentially the cast version of 300-series austenitic stainless steels (SSs) and possess excellent corrosion resistance in reactor coolant environments. ${ }^{2}$ At room temperature, the yield and tensile strengths of CF-3 and CF-8 grades are greater than $200 \mathrm{MPa}$ and $480 \mathrm{MPa}$, respectively, similar to those of solution-annealed SSs. ${ }^{3}$ The fracture toughness values of CF-3 and CF-8 range from $200 \mathrm{~kJ} / \mathrm{m}^{2}$ to $1000 \mathrm{~kJ} / \mathrm{m}^{2}$, also comparable to those of wrought SSs. ${ }^{4,5}$ Because of their excellent corrosion and mechanical properties, CASS alloys are used alongside with wrought SSs in the current LWRs.

Cast components are formed directly from liquid phase and have a characteristic solidification microstructure consisting of two phases, austenite and delta ferrite. While austenite is the main phase in CASS alloys, delta ferrite is very important for the soundness of castings. A minimum amount of delta ferrite is often required to avoid "hot cracking" during solidification. In the solidified microstructure, the retained ferrite phase also plays a crucial role in strengthening the austenite matrix, ${ }^{6,7}$ and to improve the resistance of CASS alloys to sensitization and stress corrosion cracking (SCC). ${ }^{8,9}$ These beneficial effects of delta ferrite contribute to the successful applications of CASS alloys in LWRs with relatively few degradation modes in their service lifetimes.

Despite its positive effects on the strength and corrosion resistance, delta ferrite can have a negative impact on the fracture resistance of CASS alloys. Exposed to LWR environments at elevated temperatures and neutron irradiations, CASS alloys can experience hardening and embrittlement. It is well accepted that the ferrite phase is vulnerable to thermal aging embrittlement due to its inherent instability. ${ }^{10,11}$ An increased tensile strength and reduced ductility can be observed after long-term exposure at $300-500^{\circ} \mathrm{C}^{12}$ The upper-shelf impact energies of ferritic materials are also reduced, and their ductile-to-brittle transition temperatures shift higher. ${ }^{13}$ The mechanisms of thermal aging embrittlement of CASS are attributed to the precipitation and growth of carbides and G-phase and the formation of Cr-rich alpha prime phase through spinodal decomposition. ${ }^{11,12}$ In addition to thermal aging, neutron irradiation can also induce displacement damages and microchemical changes, ${ }^{14}, 15$ leading to deteriorated ductility and fracture toughness of CASS alloys. The possible interplay between the two degradation mechanisms, i.e. thermal aging and neutron irradiation, should be carefully evaluated. A previous study showed that the degree of embrittlement may be higher than expected for the irradiated and thermally aged CASS materials, suggesting a combined effect of thermal aging and irradiation embrittlement. ${ }^{16}$

Based on the previous thermal aging study, the extent of embrittlement is sensitive to the ferrite content in CASS alloys. ${ }^{4}$ A similar effect of ferrite content on irradiation-induced embrittlement may also exist, but has not been evaluated carefully in CASS materials. In the current study, neutron-irradiated CASS specimens with 13-14\% delta ferrite were tested. The ferrite content of these alloys was lower than that of the previous materials $(24-28 \%) .{ }^{16} \mathrm{Crack}$ growth rates (CGRs) and fracture toughness values of the CASS specimens were measured in 
low-corrosion-potential environments. The specimens were unaged and thermally-aged CF-3 and CF-8 irradiated to a low dose. The fracture morphologies of the tested samples were examined. Based on the results of this study, the effect of ferrite content on the embrittlement of irradiated CASS was assessed under a combination of thermal aging and neutron irradiation. 


\section{EXPERIMENTAL}

\subsection{Materials and Samples}

Two CASS alloys with different carbon contents (a low-carbon CF-3, and a high-carbon CF-8) were selected for this study. The specimens were cut from static casted Keel blocks and their chemical compositions are given in Table 1. A ferrite scope measurement performed in a previous study showed that the heats CF-3 and CF-8 contained approximately $14 \%$ and $13 \%$ delta ferrite, respectively. ${ }^{4}$ The thermal aging conditions are shown in Table 2.

Table 1. Chemical compositions of the CASS Samples used in this study

\begin{tabular}{|c|c|c|c|c|c|c|c|c|c|c|c|c|}
\hline \multirow{2}{*}{$\begin{array}{c}\text { Cast } \\
\text { Grade }\end{array}$} & \multirow{2}{*}{$\begin{array}{c}\text { Heat } \\
\text { ID }\end{array}$} & \multicolumn{2}{|c|}{ Ferrite content $(\%)$} & \multicolumn{9}{|c|}{ Composition (wt. \%) } \\
\hline & & Measured $^{\mathrm{a}}$ & Calculated $^{\mathrm{b}}$ & $\mathrm{Mn}$ & $\mathrm{Si}$ & $\mathrm{P}$ & $\mathrm{S}$ & Mo & $\mathrm{Cr}$ & $\mathrm{Ni}$ & $\mathrm{N}$ & $\mathrm{C}$ \\
\hline CF-3 & 52 & $14 \%$ & $10 \%$ & 0.57 & 0.92 & 0.012 & 0.005 & 0.35 & 19.49 & 9.4 & 0.052 & 0.009 \\
\hline CF-8 & 61 & $13 \%$ & $10 \%$ & 0.65 & 1.01 & 0.007 & 0.007 & 0.32 & 20.65 & 8.86 & 0.080 & 0.054 \\
\hline
\end{tabular}

a. Measured with a ferrite scope, Ref. [4].

b. Calculated with Hull's equations, Ref. [4]

Table 2. Thermal aging condition prior to irradiation.

\begin{tabular}{|c|c|c|c|}
\hline Material & Heat ID & Ferrite content $^{\mathbf{a}}, \mathbf{\%}$ & Thermal Aging Condition \\
\hline CF-3 & 52 & 14 & Unaged \\
\hline CF-3 & 52 & 14 & $55,000 \mathrm{hr}$, at $320^{\circ} \mathrm{C}$ \\
\hline CF-8 & 61 & 13 & Unaged \\
\hline CF-8 & 61 & 13 & $5,900 \mathrm{hr}$, at $400^{\circ} \mathrm{C}$ \\
\hline
\end{tabular}

a. Measured with a ferrite scope, Ref. [4].

Figure 1 shows the metallurgical images of the CASS materials in this study. The samples were polished with $\mathrm{SiC}$ papers up to 1200 grit. After a final finish with $3 \mu \mathrm{m}$ diamond slurry, the polished surfaces were etched with ferric chloride. A vermicular morphology of delta ferrite can be seen in both unaged and aged specimens as shown in Figure 1.

Sub-sized compact tension (CT) specimens were used in this study. The sample was about 6.5$\mathrm{mm}$ thick (i.e., 1/4T-CT) and $14 \mathrm{~mm}$ high. The starter notch size was about $6 \mathrm{~mm}$. To ensure an in-plane crack growth, side grooves approximately $5 \%$ of the thickness were machined on both sides of the sample. Figure 2 shows a picture of the 1/4T-CT specimen. 


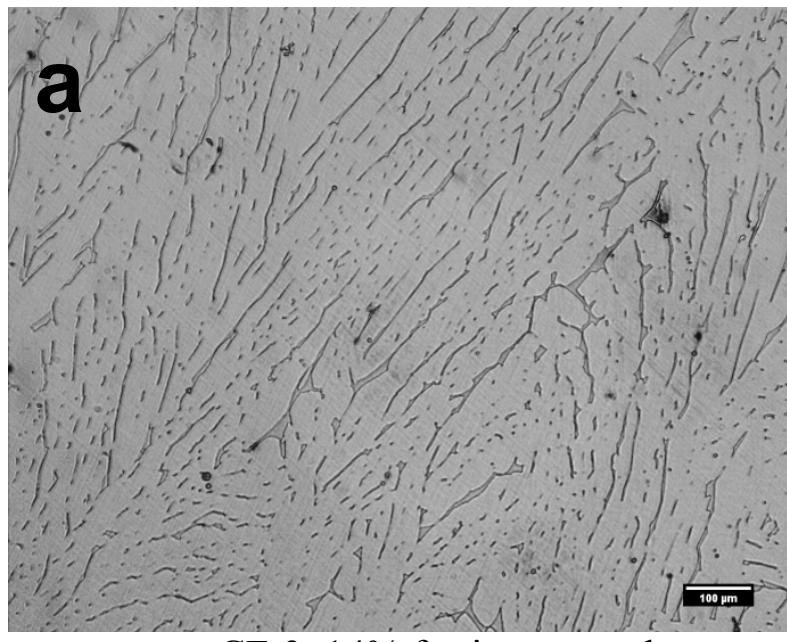

CF-3, 14\% ferrite, unaged

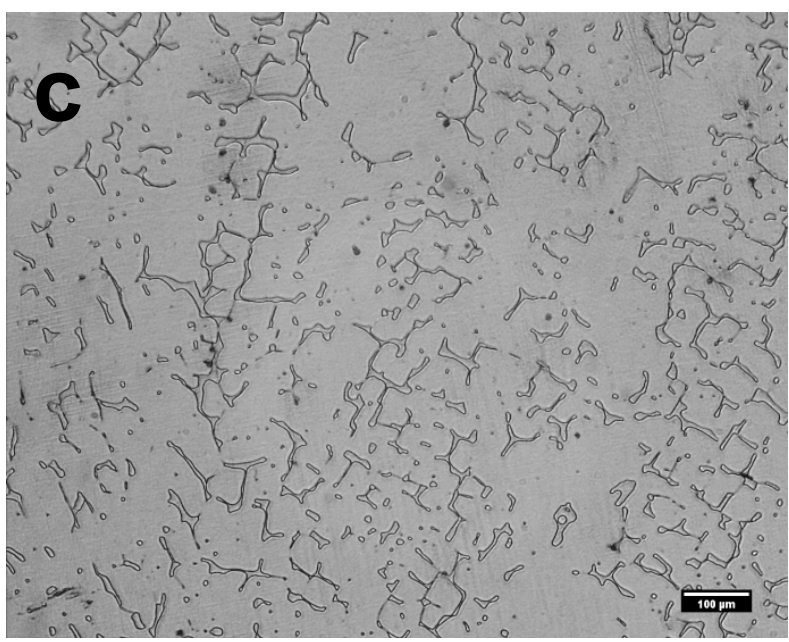

CF-8, 13\% ferrite, unaged

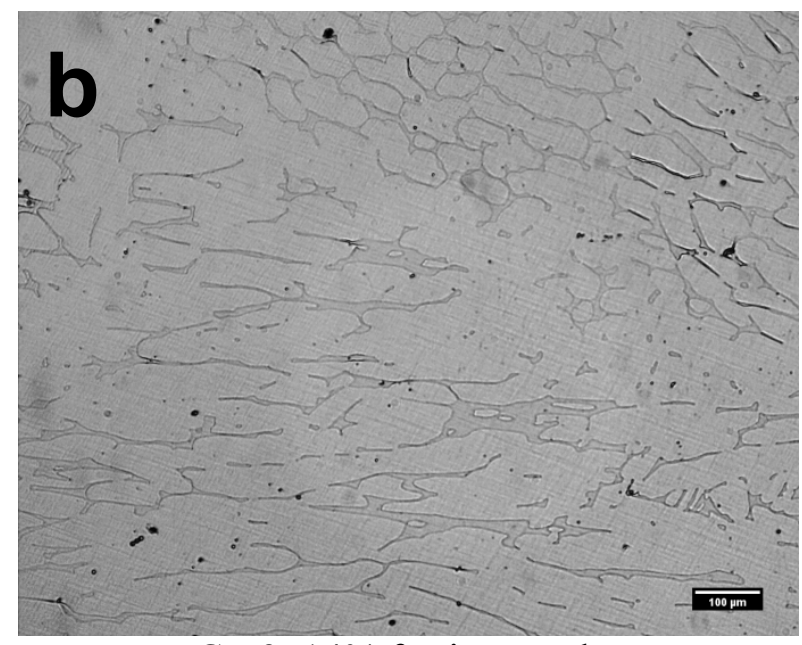

CF-3, 14\% ferrite, aged

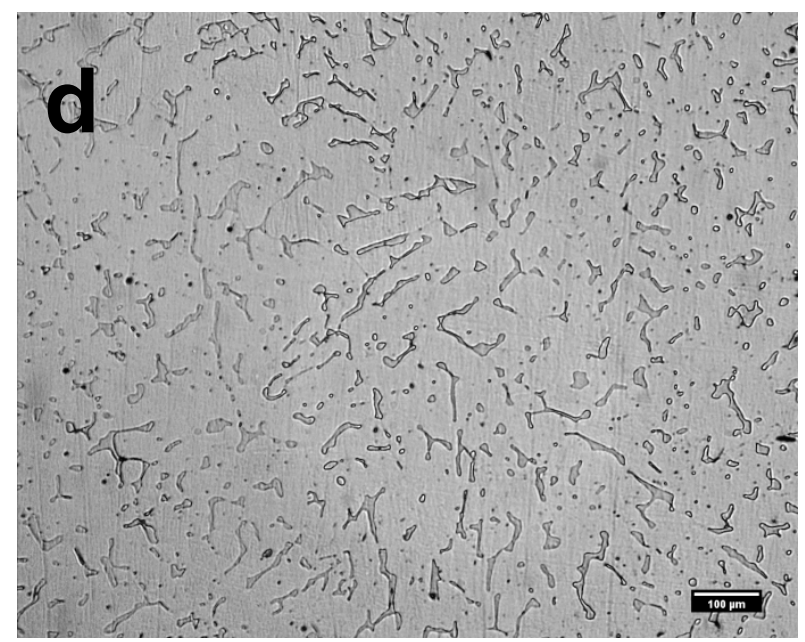

CF-8, 13\% ferrite, aged

Figure 1. Metallurgical images of the CASS materials.

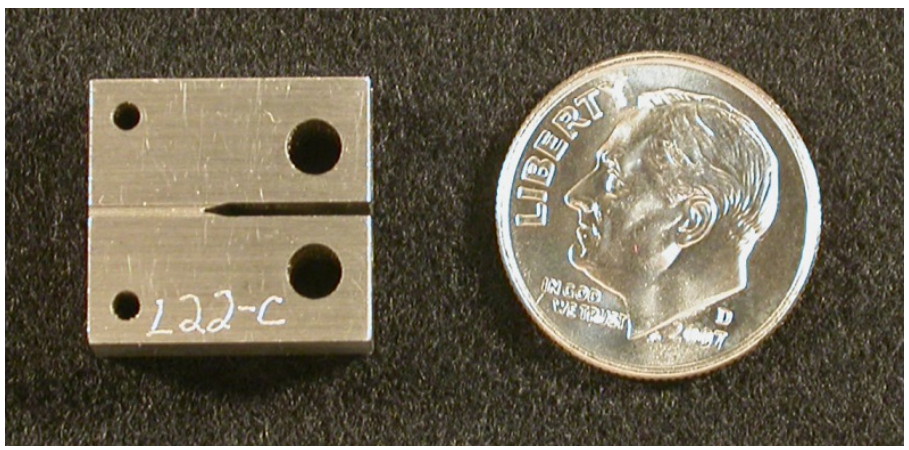

Figure 2. 1/4T-CT specimen used in this study. 


\subsection{Irradiation}

The specimens were irradiated in a helium-filled capsule in the Halden reactor. The irradiation experiment was conducted at $\sim 315^{\circ} \mathrm{C}$, and two sets of melting alloy temperature monitor were installed on the irradiation capsule. Multiple neutron fluence monitor wires (Fe, $\mathrm{Ni}$ and $\mathrm{Al} / \mathrm{Co}$ alloy) were placed outside the irradiation capsule during the irradiation experiment. These neutron fluence wires were analyzed for dosimetry by Halden researchers after irradiation. The accumulated fast neutron fluence $(\mathrm{E}>1 \mathrm{MeV})$ was about $5.6 \times 10^{19} \mathrm{n} / \mathrm{cm}^{2}$, corresponding to a displacement damage of 0.08 displacement per atom (dpa) for the SS samples.

\subsection{Crack Growth Rate Test}

Crack growth rate tests were conducted at $\sim 320^{\circ} \mathrm{C}$ and $\sim 1800$ psig either in simulated PWR water or in high-purity water with low dissolved-oxygen (DO). Both test environments have low corrosion potentials, which are known to reduce the sensitivity of SSs to SCC. ${ }^{17}$ The simulated PWR water contained $\sim 2 \mathrm{ppm}$ lithium, $\sim 1000$ ppm boron, and $\sim 2 \mathrm{ppm}$ hydrogen. The conductivity was about $20 \mu \mathrm{S} / \mathrm{cm}$. The low-DO high-purity water contained less than $10 \mathrm{ppb}$ dissolved oxygen and the conductivity was kept below $0.07 \mu \mathrm{S} / \mathrm{cm}$. During the tests, the water was circulated through the autoclave (1-liter volume) at a rate of $20-30 \mathrm{~mL} / \mathrm{min}$.

In a CGR test, the crack extension of the specimen was monitored with a direct current potential drop (DCPD) method. A constant current was passed through the sample, and the potential drop across the crack mouth was measured and related to the crack extension with a calibrated correlation curve. Before each test, the sample was soaked in the test environment for six to ten days to stabilize test conditions. All specimens were pre-cracked in the test environments with fatigue cyclic loading. A load ratio around 0.2-0.3, frequency of $1-2 \mathrm{~Hz}$, and maximum stress intensity factor $\left(\mathrm{K}_{\max }\right)$ between 14 and $16 \mathrm{MPa} \mathrm{m}{ }^{1 / 2}$ were used for pre-cracking. Once a fatigue crack was initiated, a series of test steps was carried out with gradually increased rise times and load ratios. The measured CGRs in these test steps included the contributions from both mechanical fatigue and corrosion-fatigue. With the change in loading conditions, the contribution of mechanical fatigue was gradually reduced while the environmental effect is enhanced. The cyclic CGR test was transitioned to a SCC CGR test when a significant environmental enhancement was observed.

Following the cyclic CGR test, a SCC test was conducted at one or two stress intensity factors on the specimen with or without periodic partial unloading (PPU). As the crack advances during a SCC test, the applied load was reduced periodically to maintain an approximately constant K at the crack tip. With PPU, the specimen was unloaded and reloaded briefly $(\sim 24 \mathrm{~s})$ to a load ratio of $\sim 0.5$ at a regular interval $(2 \mathrm{hr})$. Because of the beneficial effects of ferrite and low-corrosion potential environments used, relatively low CGRs were observed in these tests. To measure SCC CGRs at such low growth rates, a considerable amount of time is needed to collect data for adequate measurements. Since the embrittlement (i.e., loss of facture toughness) rather than the SCC behavior of CASS alloys was the focus in this study, the SCC CGR tests were intentionally shortened. Nonetheless, environmentally enhanced cracking was indeed established in these samples before the start of fracture toughness J-R curve tests. 


\subsection{Fracture Toughness J-R Curve Test}

After a SCC CGR test is completed, a fracture toughness J-R curve test was conducted on the same sample in the test environment. The test was performed with a constant stain rate of 0.43 $\mu \mathrm{m} / \mathrm{s}$, and the load and sample extension were recorded continuously outside the autoclave. The load-line displacement was determined by subtracting the extension of the load train, which had been measured prior to the test. During a J-R curve test, the loading was interrupted periodically, and the specimen was held at a constant extension to measure crack length with the DCPD method. Before each DCPD measurement, the sample stress was allowed to relax at a constant displacement for $30 \mathrm{~s}$. After the test, a J-R curve was re-constructed by fitting the calculated $\mathrm{J}$ values and corresponding crack lengths to a power law relationship. The $\mathrm{J}$ value at the intersection of the power law curve and the $0.2 \mathrm{~mm}$ offset blunting line, $\mathrm{J}_{0.2}$, was reported.

\subsection{Fractographic Examination}

After each CGR/J-R test, the final crack front was marked with fatigue cycling in air at room temperature. The specimen was then broken, and the fracture surface was examined with a scanning electron microscope (SEM). The CGR test and J-R test regions were identified, and their fracture morphologies were analyzed. The physical crack length was measured on the SEM images, and a $9 / 8$ averaging technique was used to account for the uneven extensions at the crack front. With this technique, nine measurements were taken along the crack front across the width of the sample at equal intervals. The two near-surface measurements were averaged, and the resultant value was averaged with the remaining seven measurements. All crack extensions determined from the DCPD method were then scaled proportionately to match the final crack length measured by SEM. All test results reported in the report have been corrected with the corresponding SEM measurements. 


\section{RESULTS}

\subsection{CF-3 with $14 \%$ ferrite}

\subsubsection{Unaged Specimen, C-1}

$\underline{\text { Crack growth rate test }}$

Specimen C-1 was a CF-3 CASS with 14\% ferrite irradiated to 0.08 dpa. The sample was unaged and was tested in PWR water. The test conditions and results are summarized in Table 3 , and a crack-length history plot is shown in Figure 3.

Table 3. Crack growth rates of specimen C-1 (unaged CF-3 with 14\% ferrite) in PWR water.

\begin{tabular}{|c|c|c|c|c|c|c|c|c|c|c|c|}
\hline $\begin{array}{l}\text { Test } \\
\text { Period }\end{array}$ & $\begin{array}{l}\text { Test } \\
\text { Time, } \\
\mathrm{h} \\
\end{array}$ & $\begin{array}{l}\text { Test } \\
\text { Temp., } \\
{ }^{\circ} \mathrm{C}\end{array}$ & $\begin{array}{l}\text { Load } \\
\text { Ratio }\end{array}$ & $\begin{array}{l}\text { Rise } \\
\text { Time, } \\
\text { s } \\
\end{array}$ & $\begin{array}{l}\text { Return } \\
\text { Time, } \\
\text { s }\end{array}$ & $\begin{array}{l}\text { Hold } \\
\text { Time, } \\
\text { s }\end{array}$ & $\begin{array}{l}\text { Kmax, } \\
\mathrm{MPa} \mathrm{m}^{1 / 2}\end{array}$ & $\begin{array}{l}\Delta \mathrm{K}, \\
\mathrm{MPa} \mathrm{m}^{1 / 2}\end{array}$ & $\begin{array}{l}\text { CGR in } \\
\text { Env., } \\
\mathrm{m} / \mathrm{s}\end{array}$ & $\begin{array}{l}\text { CGR } \\
\text { in Air, } \\
\mathrm{m} / \mathrm{s} \\
\end{array}$ & $\begin{array}{l}\text { Crack } \\
\text { Length, } \\
\mathrm{mm}\end{array}$ \\
\hline Start & 0.2 & & & & & & & & & & 5.909 \\
\hline$a^{a}$ & 4.9 & 317 & 0.21 & 0.43 & 0.43 & 0.07 & 14.9 & 11.8 & 5.92E-08 & 4.07E-08 & 6.253 \\
\hline $\mathrm{b}$ & 8.1 & 317 & 0.31 & 0.41 & 0.41 & 0.09 & 15.2 & 10.5 & 4.62E-08 & $3.21 \mathrm{E}-08$ & 6.467 \\
\hline $\mathrm{c}$ & 13 & 317 & 0.46 & 0.79 & 0.79 & 0.21 & 15.6 & 8.4 & $2.02 \mathrm{E}-08$ & $9.61 \mathrm{E}-09$ & 6.610 \\
\hline $\mathrm{d}$ & 24.1 & 317 & 0.61 & 3.62 & 3.62 & 1.38 & 15.2 & 5.9 & $3.15 \mathrm{E}-10$ & $7.59 \mathrm{E}-10$ & 6.619 \\
\hline $\mathrm{e}^{\mathrm{a}}$ & 37.7 & 317 & 0.56 & 1.49 & 1.49 & 0.51 & 15.8 & 6.9 & 8.92E-09 & $2.86 \mathrm{E}-09$ & 6.722 \\
\hline$f$ & 49.0 & 318 & 0.63 & 3.57 & 1.43 & 1.43 & 15.5 & 5.8 & $4.98 \mathrm{E}-10$ & $7.20 \mathrm{E}-10$ & 6.733 \\
\hline $\mathrm{g}$ & 56.8 & 317 & 0.60 & 3.65 & 1.46 & 1.35 & 15.9 & 6.4 & $3.27 \mathrm{E}-09$ & $9.46 \mathrm{E}-10$ & 6.783 \\
\hline $\mathrm{h}$ & 79.4 & 317 & 0.62 & 7.15 & 1.43 & 2.85 & 16.2 & 6.1 & $1.68 \mathrm{E}-09$ & $4.24 \mathrm{E}-10$ & 6.869 \\
\hline $\mathrm{i}$ & 119.5 & 317 & 0.62 & 21.5 & 3.59 & 8.46 & 16.5 & 6.3 & $6.98 \mathrm{E}-10$ & $1.55 \mathrm{E}-10$ & 6.932 \\
\hline $\mathrm{j}$ & 168.2 & 317 & 0.63 & 42.5 & 8.49 & 17.5 & 16.4 & 6.0 & $2.13 \mathrm{E}-10$ & $6.94 \mathrm{E}-11$ & 6.958 \\
\hline $\mathrm{k}$ & 218.5 & 318 & 0.63 & 85.1 & 8.51 & 34.9 & 16.3 & 6.1 & $1.62 \mathrm{E}-10$ & $3.59 \mathrm{E}-11$ & 6.978 \\
\hline 1 & 270.3 & 318 & 0.63 & 177.4 & 8.52 & 72.6 & 16.7 & 6.2 & $1.37 \mathrm{E}-10$ & $1.79 \mathrm{E}-11$ & 6.999 \\
\hline $\mathrm{m}$ & 317 & 318 & 0.63 & 355.0 & 8.52 & 145.0 & 16.7 & 6.2 & $7.99 \mathrm{E}-11$ & $9.06 \mathrm{E}-12$ & 7.008 \\
\hline $\mathrm{n}$ & 367.7 & 318 & 0.63 & 711.1 & 8.53 & 288.9 & 16.8 & 6.2 & $5.42 \mathrm{E}-11$ & $4.64 \mathrm{E}-12$ & 7.016 \\
\hline $1 \mathrm{a}$ & 459.5 & 318 & 0.62 & 12 & 12 & 7200 & 16.9 & 6.4 & $1.82 \mathrm{E}-11$ & $4.93 \mathrm{E}-13$ & 7.025 \\
\hline $1 \mathrm{~b}$ & 603.4 & 318 & 1.0 & - & - & - & 16.7 & - & negligible & - & 7.025 \\
\hline $1 \mathrm{c}$ & 792.2 & 318 & 0.62 & 12 & 12 & 7200 & 16.8 & 6.4 & $4.47 \mathrm{E}-12$ & $4.87 \mathrm{E}-13$ & 7.027 \\
\hline
\end{tabular}

a The CGR value was obtained from the later part of the test period.

Fatigue precracking was started with a triangle waveform of $1 \mathrm{~Hz}$ at a load ratio of $\sim 0.2$ and a stress intensity factor of $\sim 15 \mathrm{MPa} \mathrm{m}^{1 / 2}$. After an initial slow growth period, a CGR slightly above the fatigue growth rate in air was observed. After more than $340 \mu \mathrm{m}$ crack extension, the load ratio was increased to $\sim 0.3$ and $\sim 0.45$ in the following test periods while the $\mathrm{K}_{\max }$ was increased slightly. The measured CGRs continued to follow the trend of fatigue growth rate in air. After the load ratio was increased to $\sim 0.6$, the CGR dropped below the fatigue growth rate.

Next, the crack was re-activated by lowering the load ratio slightly. Environmentally enhanced cracking started to appear with a load ratio of $\sim 0.6$ and a rise time of $10 \mathrm{~s}$. The cyclic loading was continued with gradually increased rise times to stabilize the environmental enhancement. By the end of the cyclic CGR test, the measured CGR in water was about one order of magnitude higher than the expected fatigue growth rate in air. 
(a)

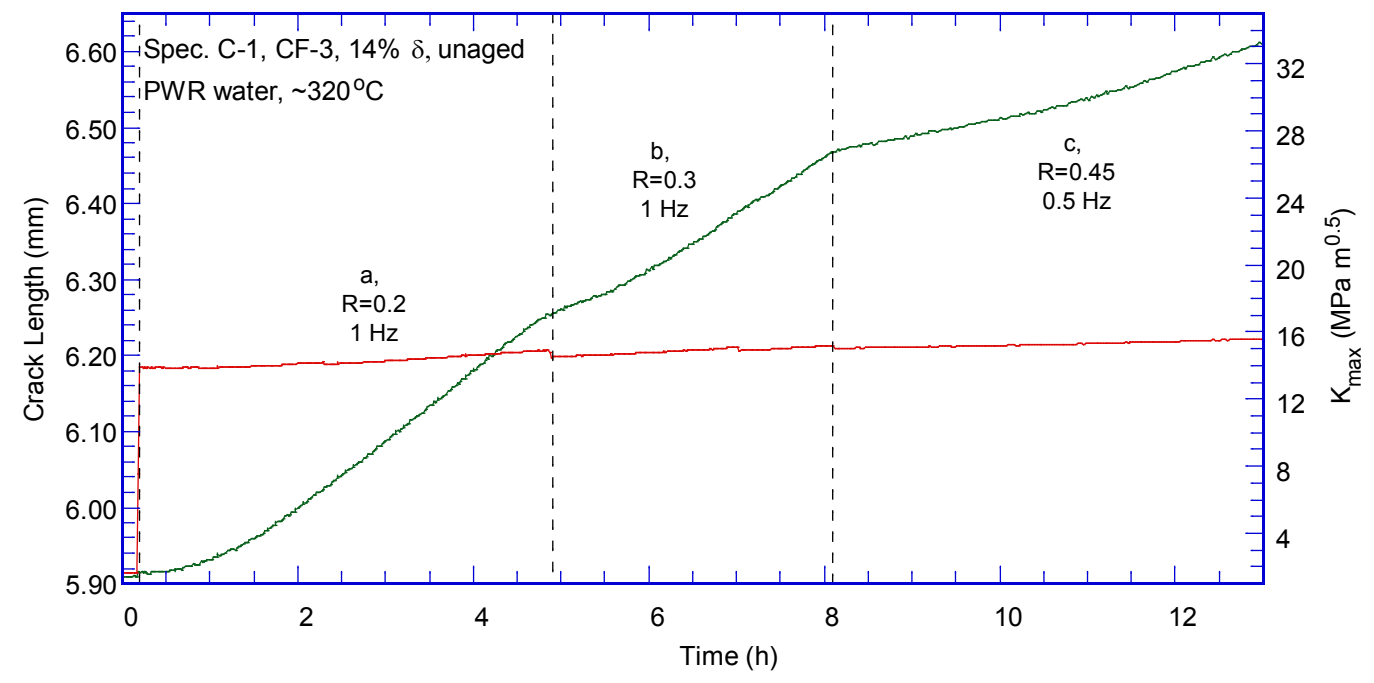

(b)

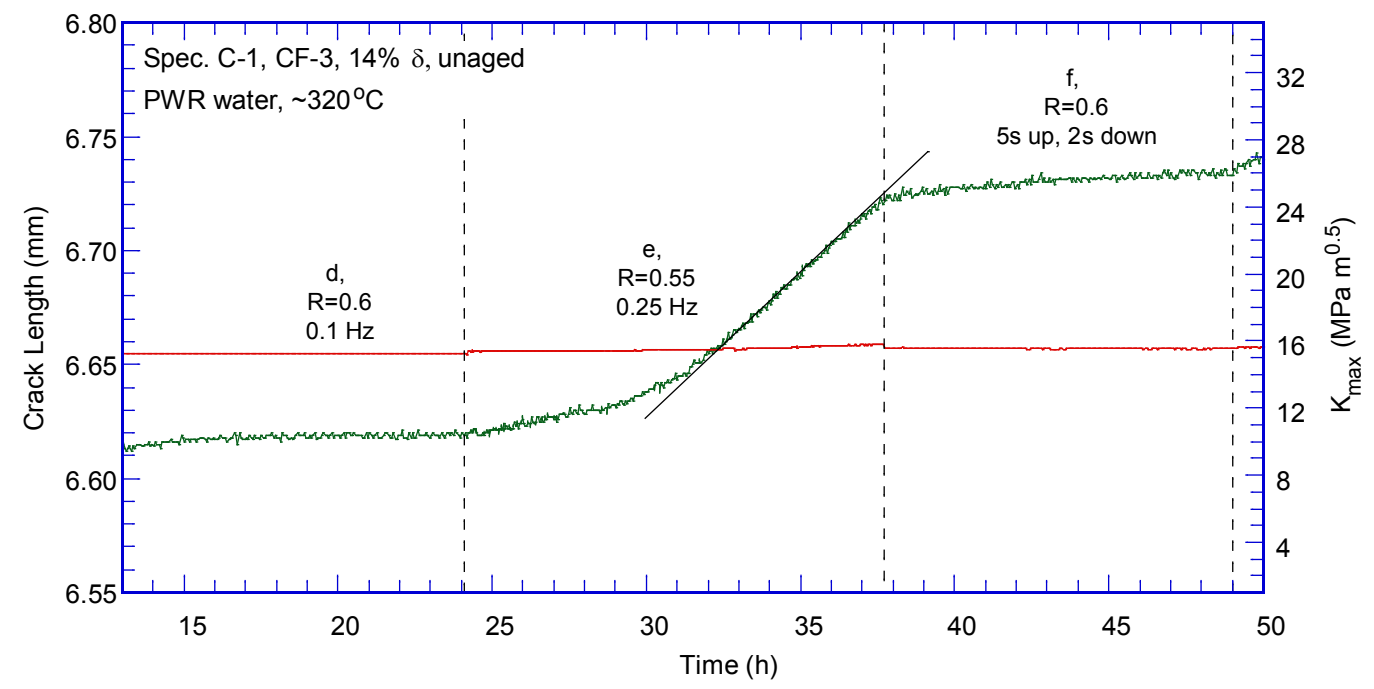

(c)

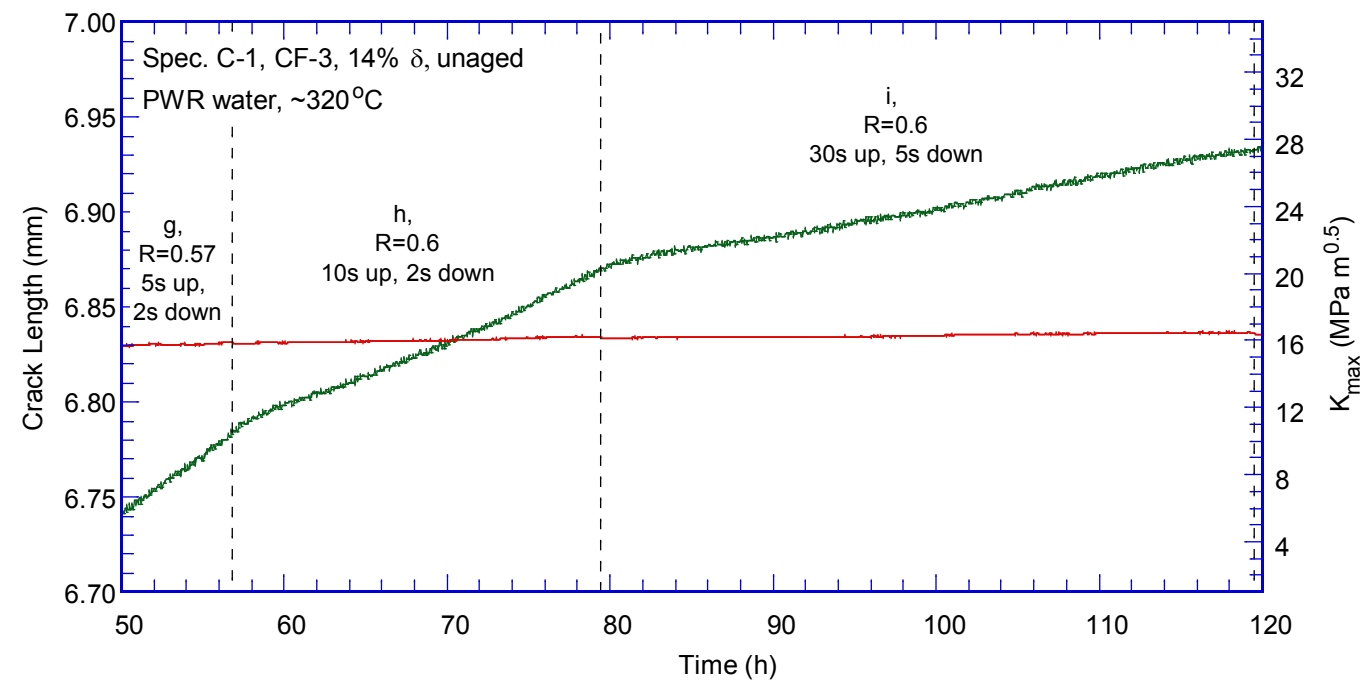

Figure 3. Crack-length-vs.-time plot of specimen C-1 (unaged 0.08-dpa CF-3 with 14\% ferrite): test periods (a) a-c, (b) d-f, (c) g-i, (d) j-1, (e) m-n, and (f) $1 \mathrm{a}-1 \mathrm{c}$. 
(d)

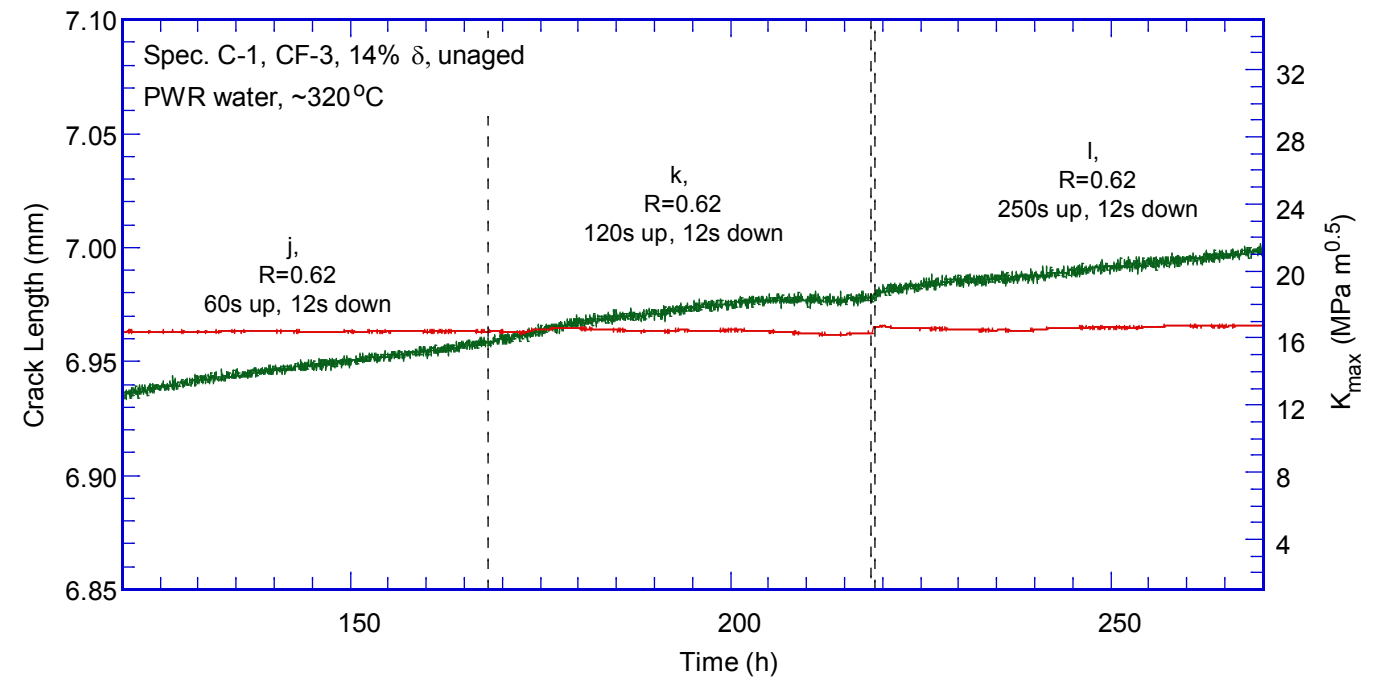

(e)

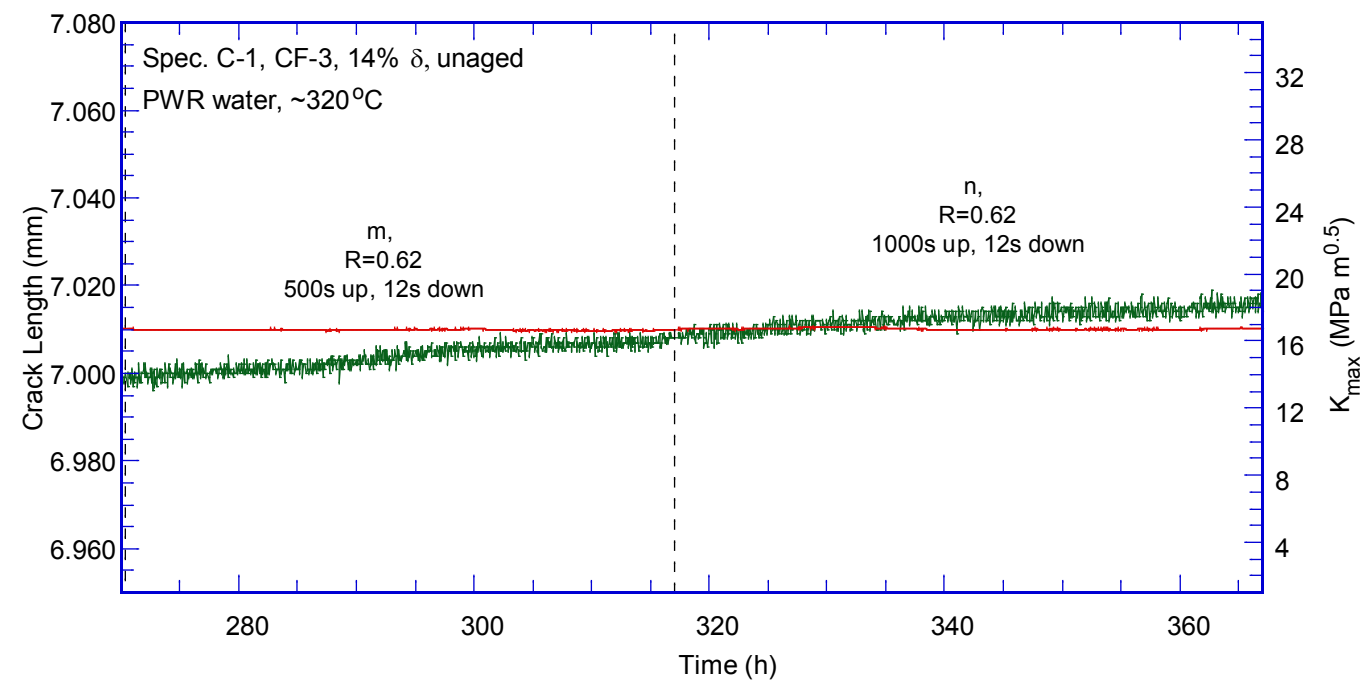

(f)

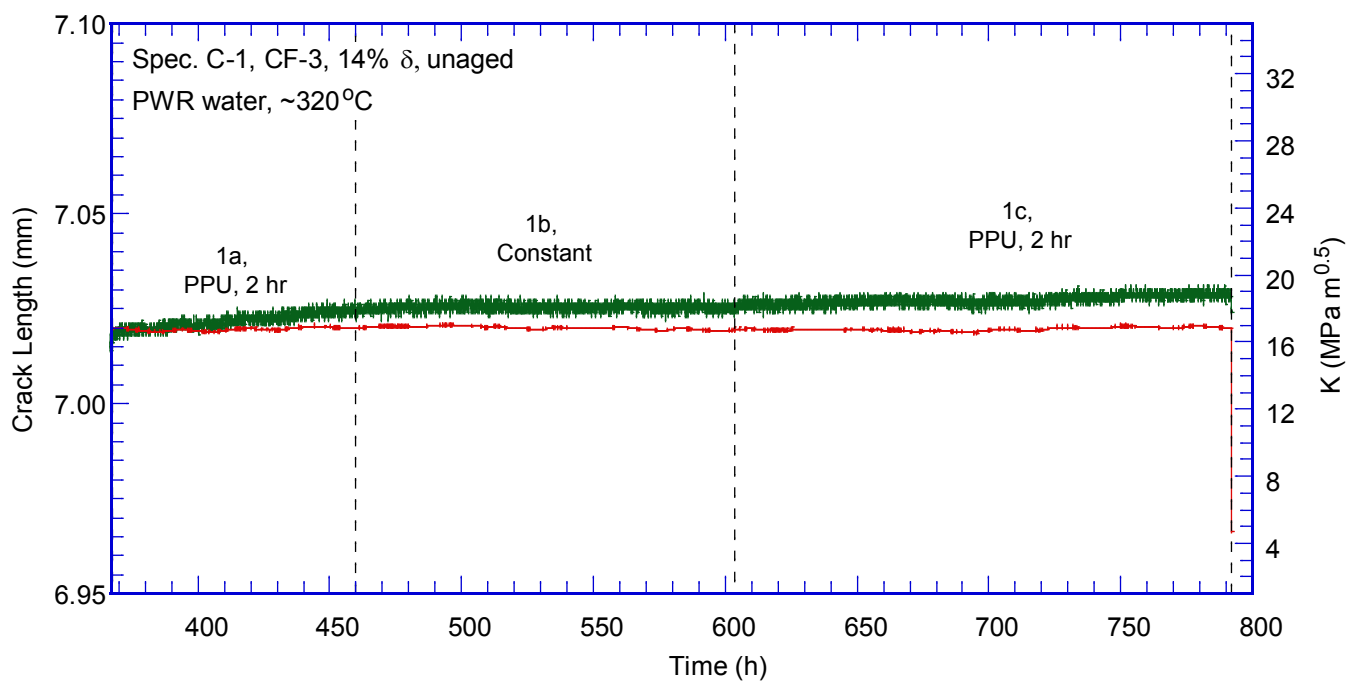

Figure 3. (Cont'd) 
The cyclic CGRs obtained from this test are plotted against the estimated fatigue CGRs in air in Figure 4. A corrosion-fatigue curve proposed by Shack and Kassner ${ }^{18}$ for unirradiated SSs in 0.2 -ppm DO water at $290^{\circ} \mathrm{C}$ is also included as a reference. Apparently, the corrosion-fatigue response of this irradiated CASS is better than that of typical SSs.

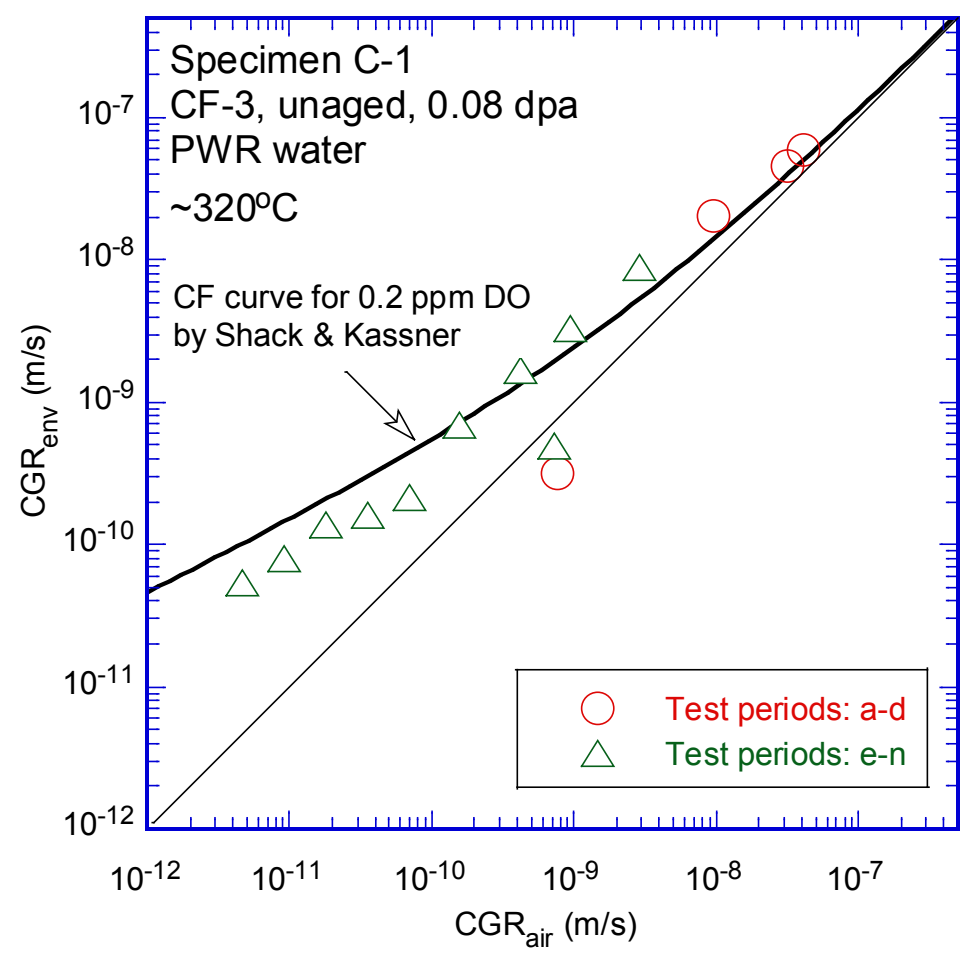

Figure 4. Cyclic CGRs of Specimen C-1, an unaged 0.08-dpa CF-3 with $14 \%$ ferrite tested in simulated PWR water.

After the cyclic CGR test, SCC CGR was measured at $\sim 17 \mathrm{MPa}{ }^{1 / 2}$ with PPU every $2 \mathrm{hr}$. The initial growth rate was high but gradually decreased after some $20 \mathrm{hr}$. An average CGR of 1.8E$11 \mathrm{~m} / \mathrm{s}$ was measured with $\sim 29 \mu \mathrm{m}$ crack extension. After the PPU was removed, the CGR dropped below the detection limit under a near constant-K condition. After the PPU was reapplied, a CGR of $4.5 \mathrm{E}-12 \mathrm{~m} / \mathrm{s}$ was observed. It is clear that SCC susceptibility of this heat is low in PWR water.

\section{Fracture toughness JR curve test}

After the CGR test, a fracture toughness J-R curve test was conducted on the specimen in the same test environment. The test was performed with a constant strain rate of $0.43 \mu \mathrm{m} / \mathrm{s}$, and the load and load-line displacement was recorded continuously. During the test, the loading was interrupted periodically, and the sample was held at a constant extension. After a 30-s stress relaxation, the crack extension was measured with DCPD method. The obtained J-R data are plotted in Figure 5. A correlation of $\mathrm{J}=347 \Delta \mathrm{a}^{0.65}$ was obtained with a curve fitting of the J-R data. The J value at the $0.2-\mathrm{mm}$ offset line is $\sim 168 \mathrm{~kJ} / \mathrm{m}^{2}$. Note that, the J-R curve cannot be 
validated since data points outside the maximum measurement capacity were used for curve fitting.

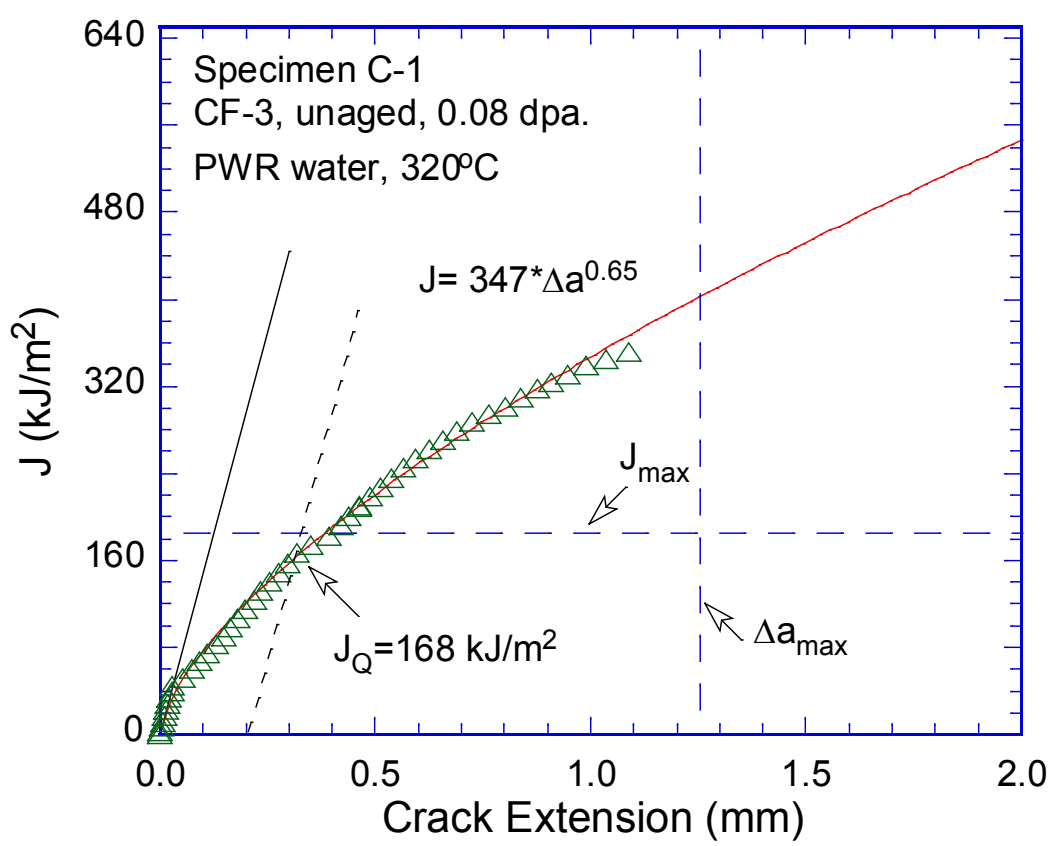

Figure 5. J-R curve of Specimen C-1, an unaged 0.08-dpa CF-3 with 14\% ferrite tested in PWR water.

\section{$\underline{\text { Fractographic examination }}$}

After the J-R curve test, the sample was fatigued at room temperature in air to break the remaining ligament. The fracture surface was then examined with replicas under a SEM. Figure 6 shows a global view of the entire fracture surface. The CGR and J-R curve test regions are clearly distinguishable. While the CGR region shows a transgranular morphology, the failure mode of the J-R curve test is ductile dimple. An enlarged view along the sample central line is shown in Figure 7. Compared with the initial fatigue region, the fracture surface of the later stage of the CGR test is much flatter, indicating an increasing trend of environmental contribution as the test progressing. Details of the fatigue and SCC cracking regions can be compared in Figure 8 and Figure 9. Figure 10 shows the transition region from the CGR to JR tests. A narrow band of brittle fracture is visible before ductile dimples become the dominant morphology. The fracture mode in the J-R curve test is fully ductile as shown in Figure 11. 


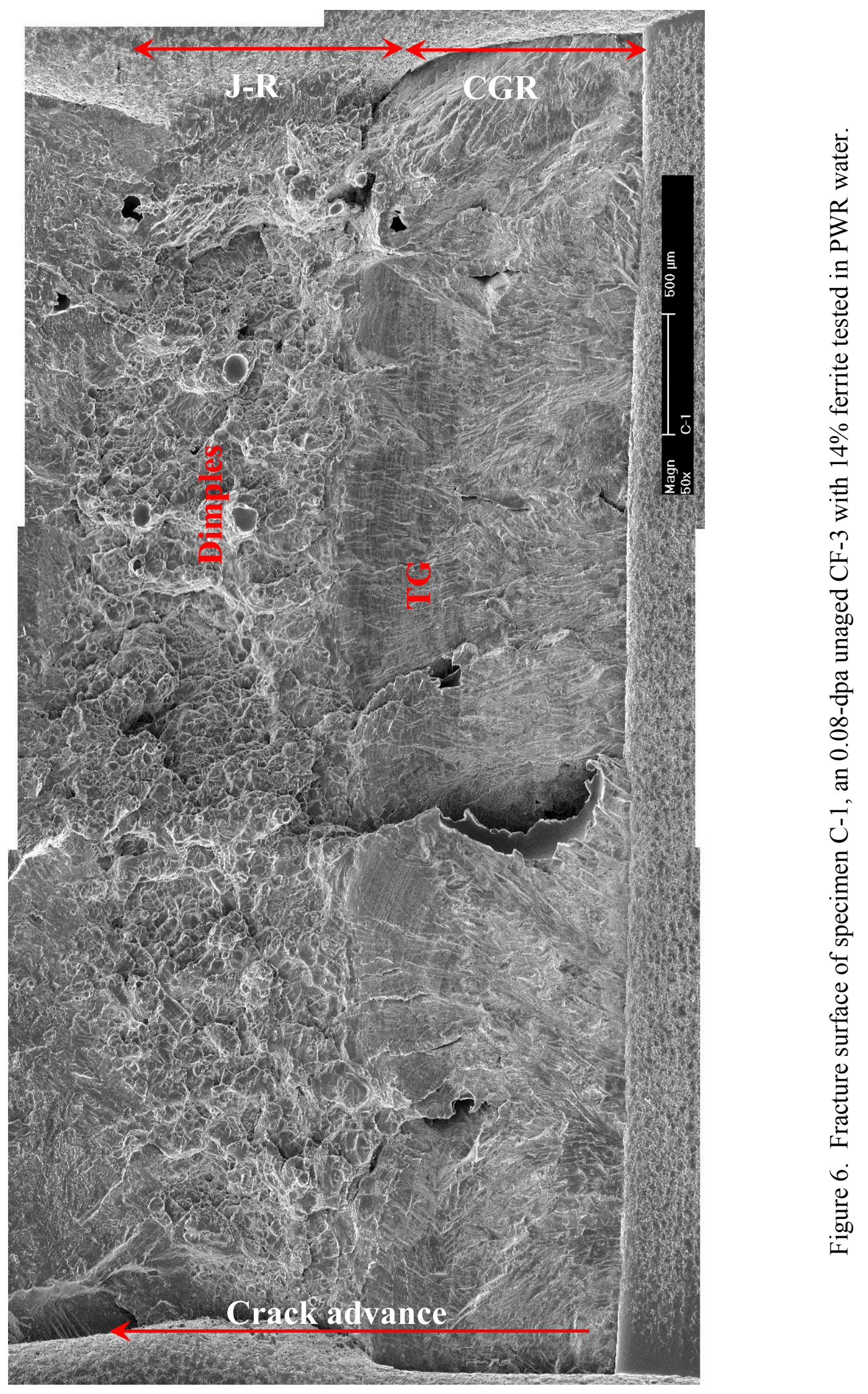




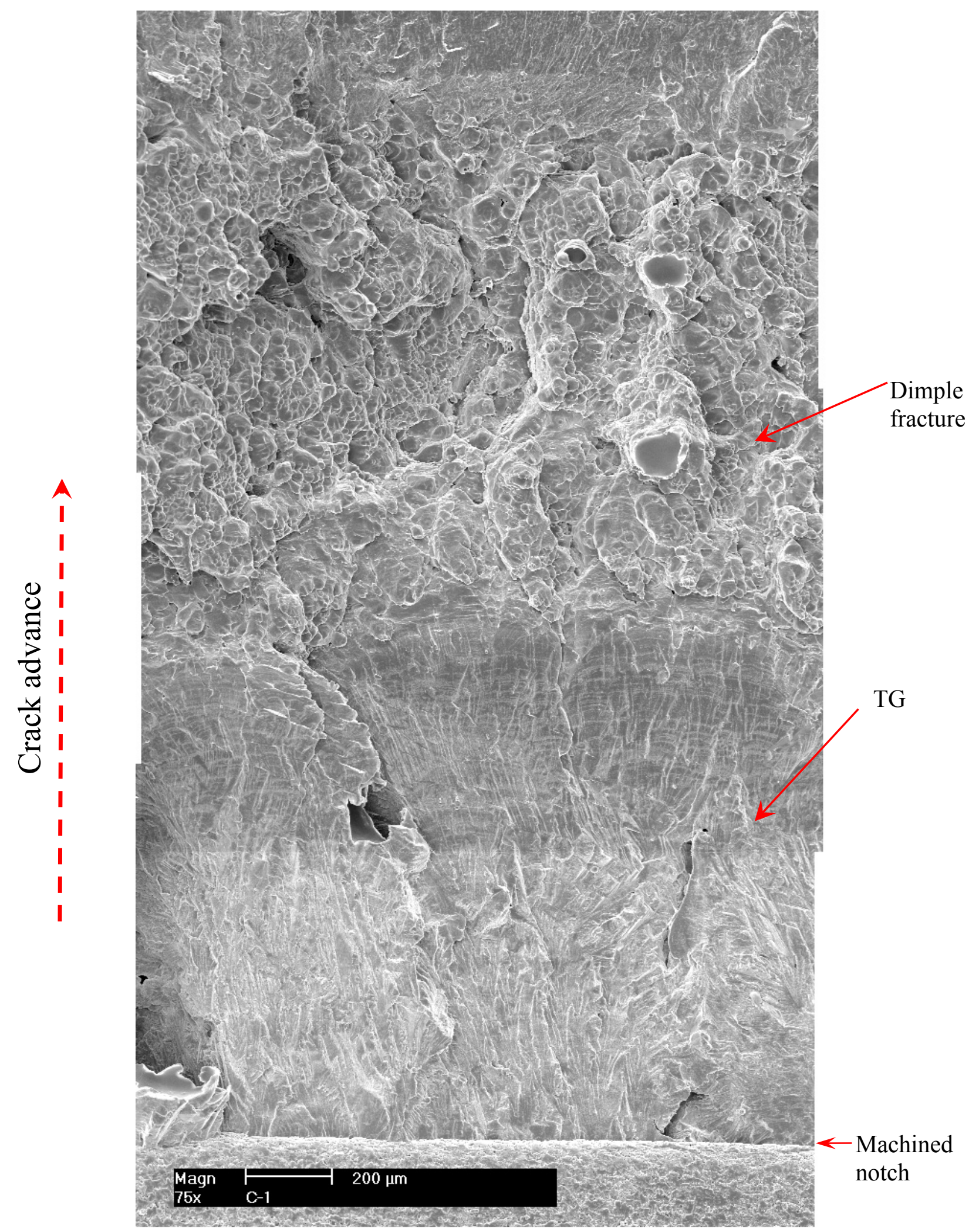

Figure 7. Fracture surface of specimen $\mathrm{C}-1$ along the sample central line. 


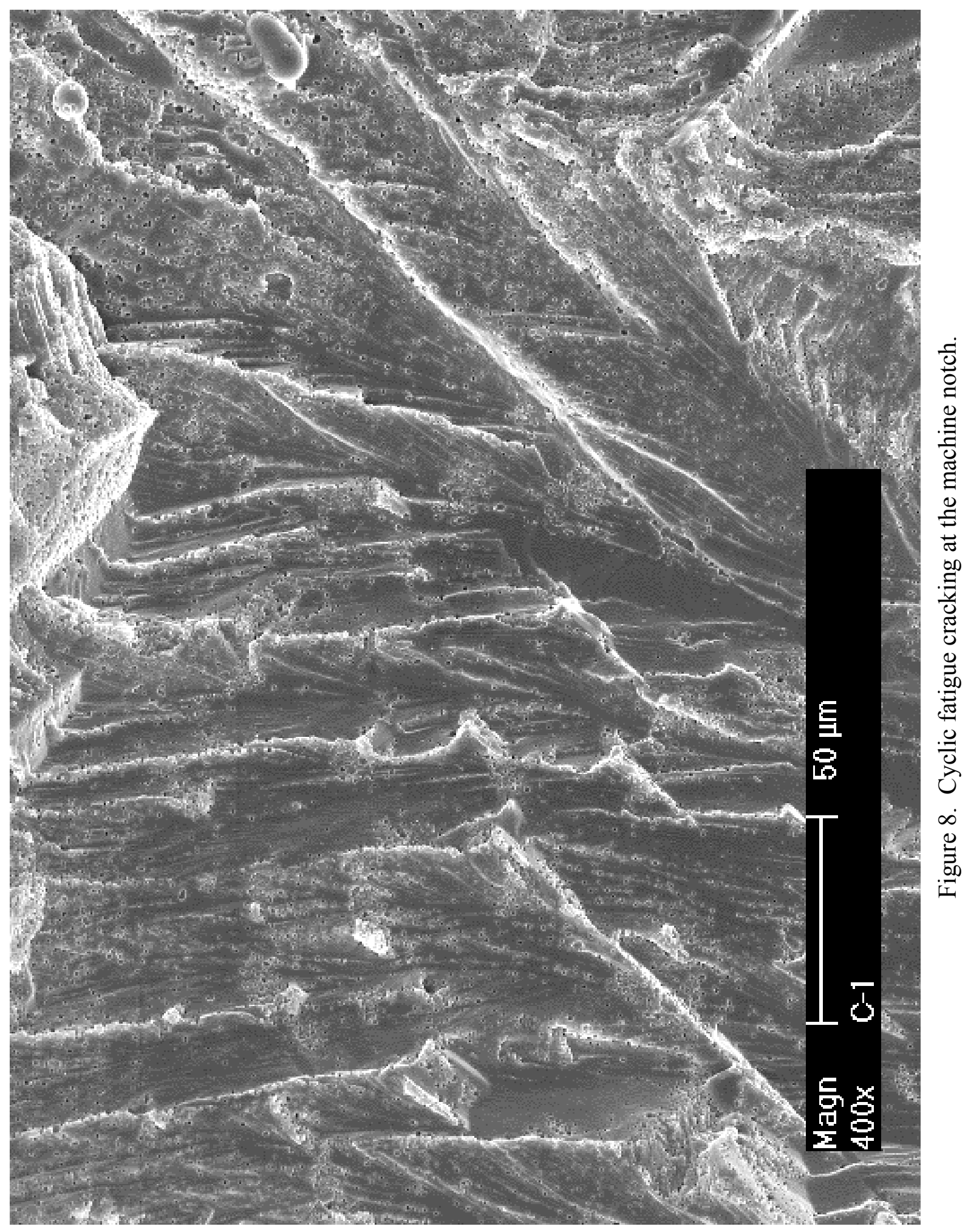




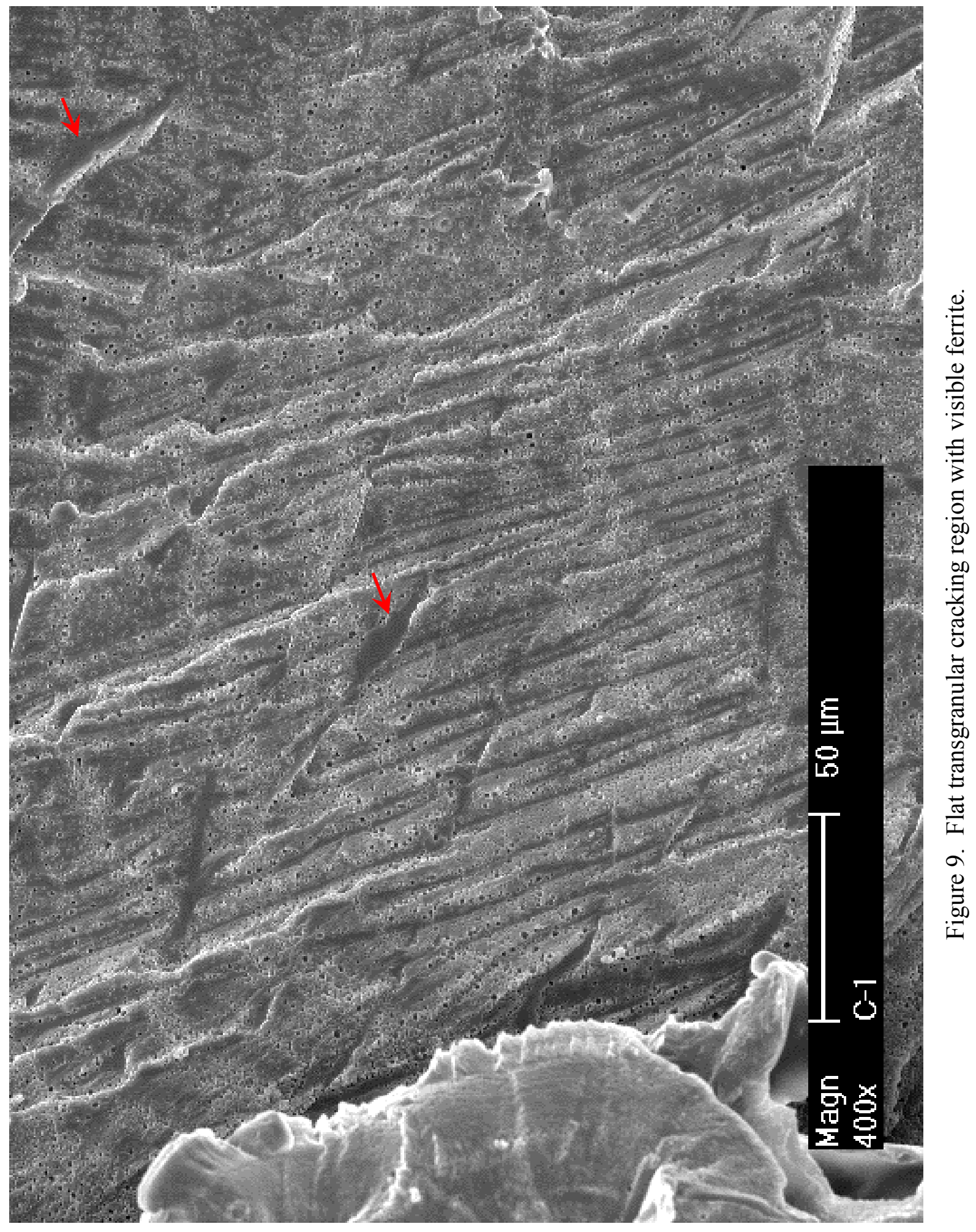




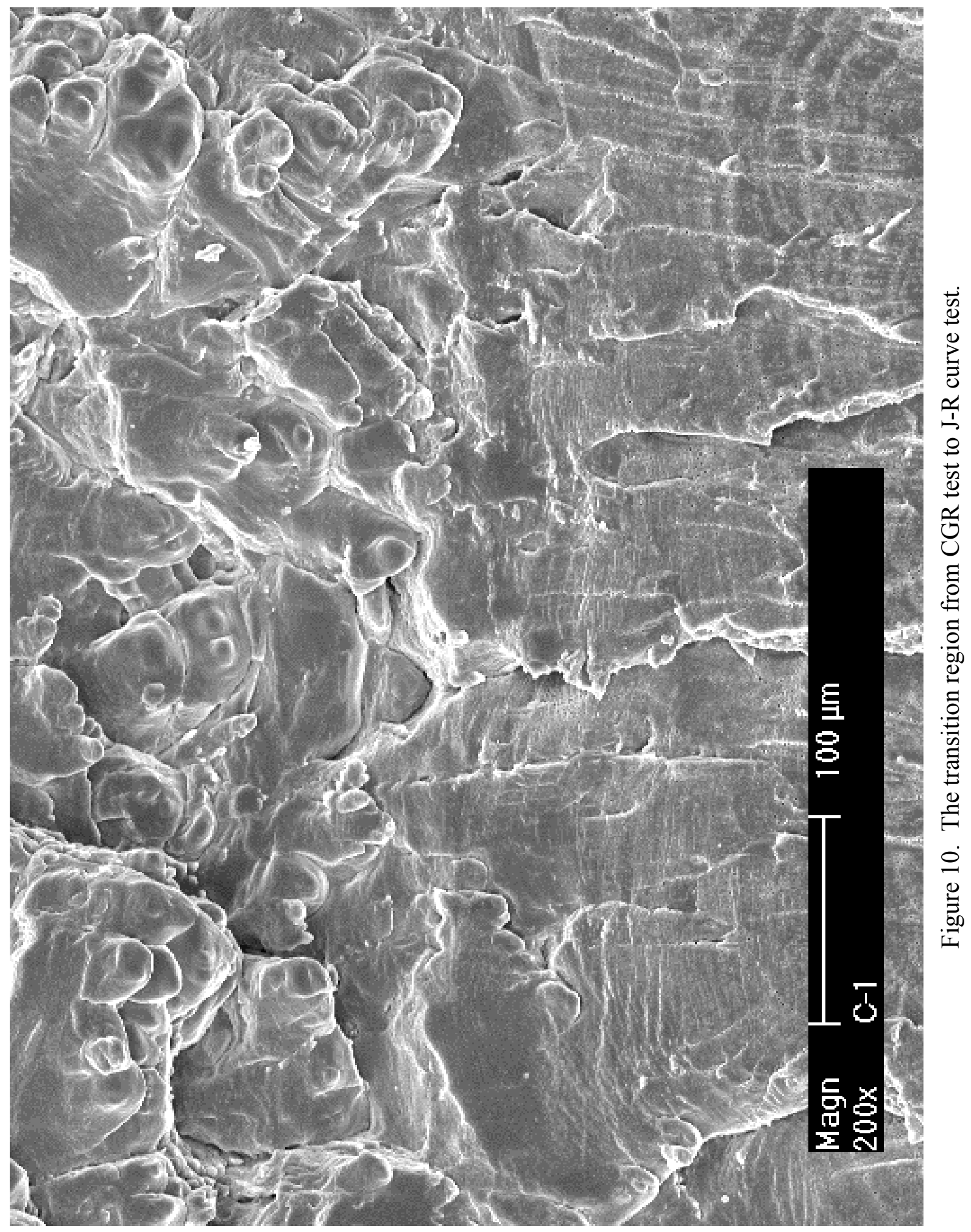




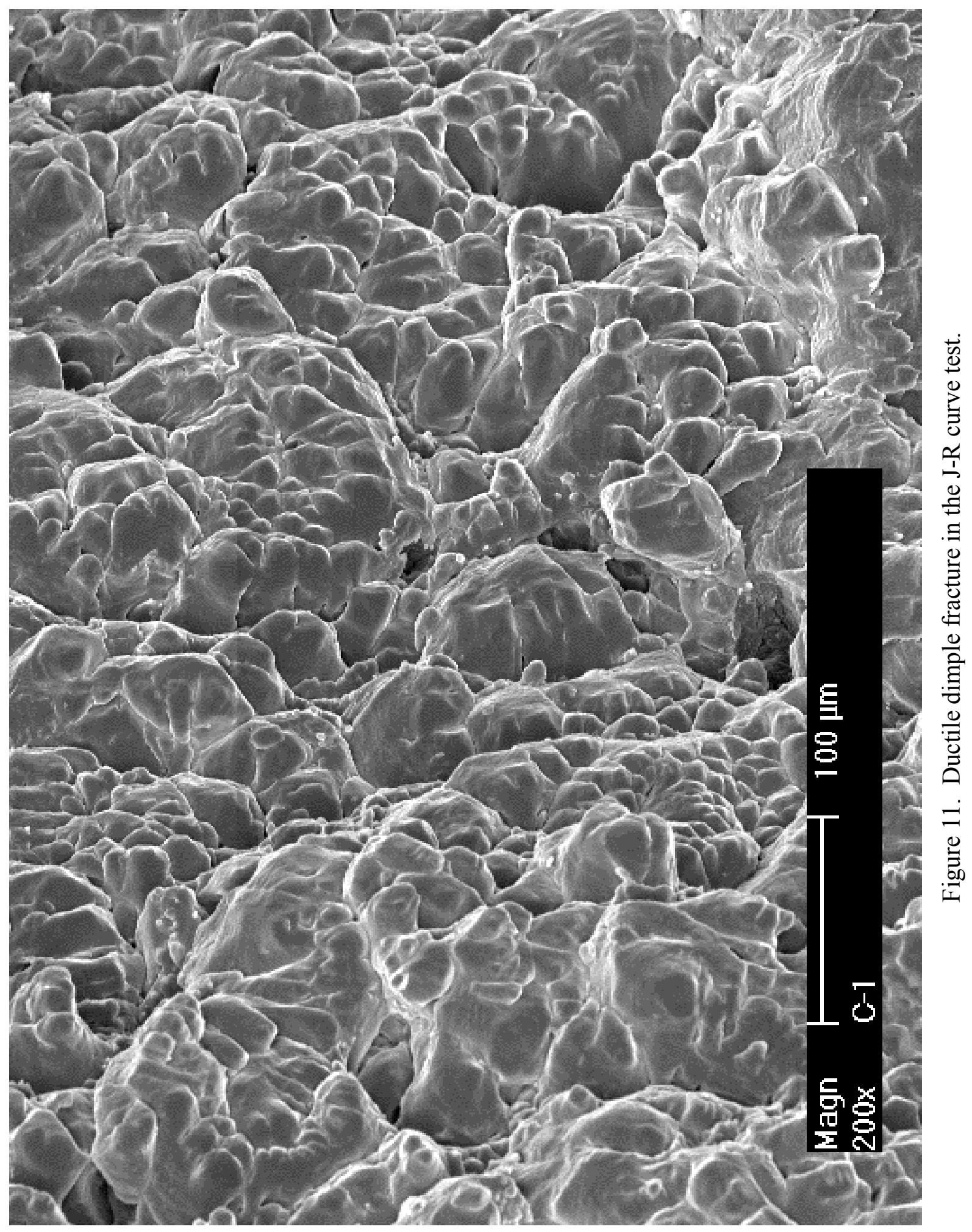




\subsubsection{Aged Specimen, $D-1$}

Crack growth rate test

Specimen D-1 was another CF-3 with $14 \%$ ferrite irradiated to 0.08 dpa. The sample was aged at $320^{\circ} \mathrm{C}$ for $55,000 \mathrm{hr}$ prior to the irradiation. The test was conducted in PWR water at $\sim 320^{\circ} \mathrm{C}$, identical to that of specimen $\mathrm{C}-1$. The test conditions and results are summarized in Table 4, and a crack-length history plot is shown in Figure 12.

Table 4. Crack growth rates of specimen D-1 (aged CF-3 with 14\% ferrite) in PWR water.

\begin{tabular}{|c|c|c|c|c|c|c|c|c|c|c|c|}
\hline $\begin{array}{l}\text { Test } \\
\text { Period }\end{array}$ & $\begin{array}{l}\text { Test } \\
\text { Time, } \\
\mathrm{h} \\
\end{array}$ & $\begin{array}{l}\text { Test } \\
\text { Temp., } \\
{ }^{\circ} \mathrm{C}\end{array}$ & $\begin{array}{l}\text { Load } \\
\text { Ratio }\end{array}$ & $\begin{array}{l}\text { Rise } \\
\text { Time, } \\
\mathrm{s} \\
\end{array}$ & $\begin{array}{l}\text { Return } \\
\text { Time, } \\
\text { s } \\
\end{array}$ & $\begin{array}{l}\text { Hold } \\
\text { Time, } \\
\mathrm{s} \\
\end{array}$ & $\begin{array}{l}\text { Kmax, } \\
\mathrm{MPa} \mathrm{m}^{1 / 2}\end{array}$ & $\begin{array}{l}\Delta \mathrm{K}, \\
\mathrm{MPa} \mathrm{m}^{1 / 2}\end{array}$ & $\begin{array}{l}\text { CGR in } \\
\text { Env., } \\
\mathrm{m} / \mathrm{s} \\
\end{array}$ & $\begin{array}{l}\text { CGR } \\
\text { in Air, } \\
\mathrm{m} / \mathrm{s} \\
\end{array}$ & $\begin{array}{l}\text { Crack } \\
\text { Length, } \\
\mathrm{mm}\end{array}$ \\
\hline Start & 15.1 & & & & & & & & & & 6.033 \\
\hline$a^{a}$ & 19.3 & 318 & 0.20 & 0.43 & 0.43 & 0.07 & 14.9 & 11.9 & $6.71 \mathrm{E}-08$ & $4.16 \mathrm{E}-08$ & 6.322 \\
\hline $\mathrm{b}$ & 21.8 & 318 & 0.31 & 0.42 & 0.42 & 0.08 & 15.2 & 10.6 & $4.47 \mathrm{E}-08$ & $3.29 \mathrm{E}-08$ & 6.490 \\
\hline $\mathrm{c}$ & 29.4 & 318 & 0.41 & 0.81 & 0.81 & 0.19 & 15.9 & 9.3 & $1.81 \mathrm{E}-08$ & $1.26 \mathrm{E}-08$ & 6.687 \\
\hline $\mathrm{d}$ & 38.1 & 318 & 0.50 & 3.88 & 3.88 & 1.12 & 15.5 & 7.8 & $1.60 \mathrm{E}-10$ & $1.58 \mathrm{E}-09$ & 6.691 \\
\hline $\mathrm{e}$ & 44 & 318 & 0.45 & 1.59 & 1.59 & 0.41 & 15.5 & 8.6 & $1.13 \mathrm{E}-10$ & $5.01 \mathrm{E}-09$ & 6.692 \\
\hline$f$ & 50.8 & 318 & 0.44 & 0.79 & 0.79 & 0.21 & 15.5 & 8.6 & $9.97 \mathrm{E}-11$ & $1.01 \mathrm{E}-08$ & 6.692 \\
\hline $\mathrm{g}^{\mathrm{a}}$ & $\begin{array}{c}111.8- \\
123.5 \\
\end{array}$ & 318 & 0.40 & 0.81 & 0.81 & 0.19 & 15.8 & 9.5 & 7.57E-09 & $1.31 \mathrm{E}-08$ & 6.737 \\
\hline $\mathrm{h}$ & 137.5 & 318 & 0.45 & 3.96 & 3.96 & 1.04 & 15.9 & 8.8 & $1.61 \mathrm{E}-09$ & $2.15 \mathrm{E}-09$ & 6.773 \\
\hline $\mathrm{i}$ & 158.2 & 318 & 0.47 & 7.83 & 3.91 & 2.17 & 15.6 & 8.3 & $5.37 \mathrm{E}-10$ & $9.41 \mathrm{E}-10$ & 6.796 \\
\hline $\mathrm{j}$ & 182.1 & 318 & 0.46 & 23.5 & 3.92 & 6.47 & 15.8 & 8.5 & $3.96 \mathrm{E}-10$ & $3.32 \mathrm{E}-10$ & 6.822 \\
\hline $\mathrm{k}$ & 215.5 & 318 & 0.49 & 46.5 & 3.88 & 13.5 & 16.0 & 8.1 & $9.93 \mathrm{E}-11$ & $1.47 \mathrm{E}-10$ & 6.830 \\
\hline 1 & 279.7 & 318 & 0.49 & 116.5 & 9.32 & 33.5 & 15.9 & 8.2 & $4.20 \mathrm{E}-11$ & $6.01 \mathrm{E}-11$ & 6.838 \\
\hline $\mathrm{m}$ & 331.9 & 318 & 0.49 & 232.9 & 9.32 & 67.1 & 16.1 & 8.2 & $5.95 \mathrm{E}-11$ & $3.03 \mathrm{E}-11$ & 6.847 \\
\hline $\mathrm{n}$ & 375 & 318 & 0.48 & 388.9 & 9.33 & 111.1 & 16.0 & 8.2 & $1.15 \mathrm{E}-11$ & $1.85 \mathrm{E}-11$ & 6.848 \\
\hline 0 & 473 & 318 & 0.49 & 777.9 & 9.34 & 222.1 & 16.2 & 8.2 & 4.42E-12 & $9.34 \mathrm{E}-12$ & 6.850 \\
\hline$p$ & 481.2 & 318 & 0.39 & 80.6 & 9.67 & 19.4 & 16.1 & 9.8 & $2.59 \mathrm{E}-10$ & $1.44 \mathrm{E}-10$ & 6.856 \\
\hline$q$ & 496.7 & 318 & 0.39 & 161.3 & 9.68 & 38.7 & 16.2 & 9.8 & $2.32 \mathrm{E}-10$ & $7.34 \mathrm{E}-11$ & 6.866 \\
\hline $\mathrm{r}$ & 504.4 & 318 & 0.39 & 40.3 & 9.67 & 9.72 & 16.3 & 9.9 & $1.21 \mathrm{E}-09$ & $2.96 \mathrm{E}-10$ & 6.886 \\
\hline $\mathrm{s}$ & 527 & 318 & 0.42 & 119.6 & 9.57 & 30.4 & 16.2 & 9.4 & $3.24 \mathrm{E}-10$ & $8.84 \mathrm{E}-11$ & 6.907 \\
\hline $\mathrm{t}$ & 566.2 & 318 & 0.44 & 237.6 & 9.50 & 62.4 & 16.4 & 9.2 & $2.13 \mathrm{E}-10$ & $4.14 \mathrm{E}-11$ & 6.929 \\
\hline $\mathrm{u}$ & 626.6 & 318 & 0.47 & 392.0 & 9.41 & 108.0 & 16.7 & 8.8 & $1.18 \mathrm{E}-10$ & $2.27 \mathrm{E}-11$ & 6.950 \\
\hline $\mathrm{V}$ & 662.7 & 318 & 0.49 & 777.3 & 9.33 & 222.7 & 16.7 & 8.5 & 5.83E-11 & $1.03 \mathrm{E}-11$ & 6.955 \\
\hline $1 \mathrm{a}$ & 736.2 & 318 & 0.50 & 12 & 12 & 7200 & 16.8 & 8.4 & $2.37 \mathrm{E}-11$ & $1.08 \mathrm{E}-12$ & 6.965 \\
\hline $1 \mathrm{~b}$ & 886 & 318 & 1.00 & - & - & & 16.5 & - & negligible & - & 6.965 \\
\hline
\end{tabular}

a The CGR value was obtained from the later part of the test period.

The test was started with cyclic loading of $1 \mathrm{~Hz}$ at a load ratio of $\sim 0.2$ and a maximum stress intensity factor of $\sim 15 \mathrm{MPa} \mathrm{m}^{1 / 2}$. After about 1 hour of slow growth, a CGR slightly above the fatigue growth rate in air was obtained. After nearly $290 \mu \mathrm{m}$ crack extension, the load ratio was increased to $\sim 0.3$ and then to $\sim 0.4$ in the next two test periods. The measured CGRs continued to follow closely to the fatigue growth rate in air. After the load ratio was increased to $\sim 0.5$, the CGR dropped significantly below the fatigue growth rate. Reducing the load ratio did not reactivate the crack growth in the following test periods, and the test was paused and held at a low stress intensity factor $\left(\sim 4 \mathrm{MPa} \mathrm{m}{ }^{1 / 2}\right)$ for about 60 hours.

After the test was restarted with a load ratio of 0.4 and $0.5 \mathrm{~Hz}$, the crack was re-activated successfully. Next, the load ratio and rise time were slowly increased to induce environmentally 
enhanced cracking. The observed CGR continued to follow the fatigue growth behavior as expected. In the following test periods, however, the crack propagation slowed down with increasing rise time, and environmental enhancement was diminishing. By the end of test period $o$, we had to re-active the crack again by repeating several steps with shorter rise times. The crack responded to the loading changes, and environmental enhancement became evident and was stabilized in the following test periods. By the end of the cyclic CGR test, the measured CGR was about 5.7 times higher than that of fatigue growth rate in air. The cyclic CGRs obtained from this test are plotted against the estimated fatigue CGRs in Figure 13.

(a)

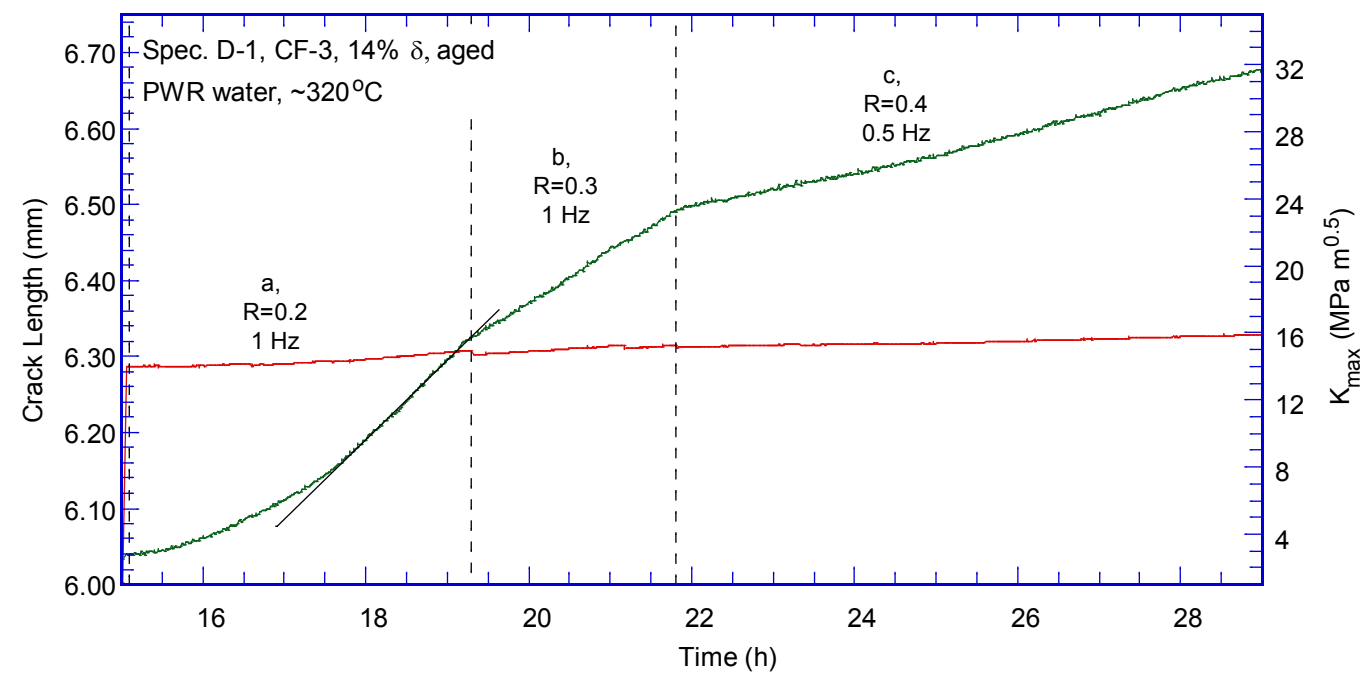

(b)

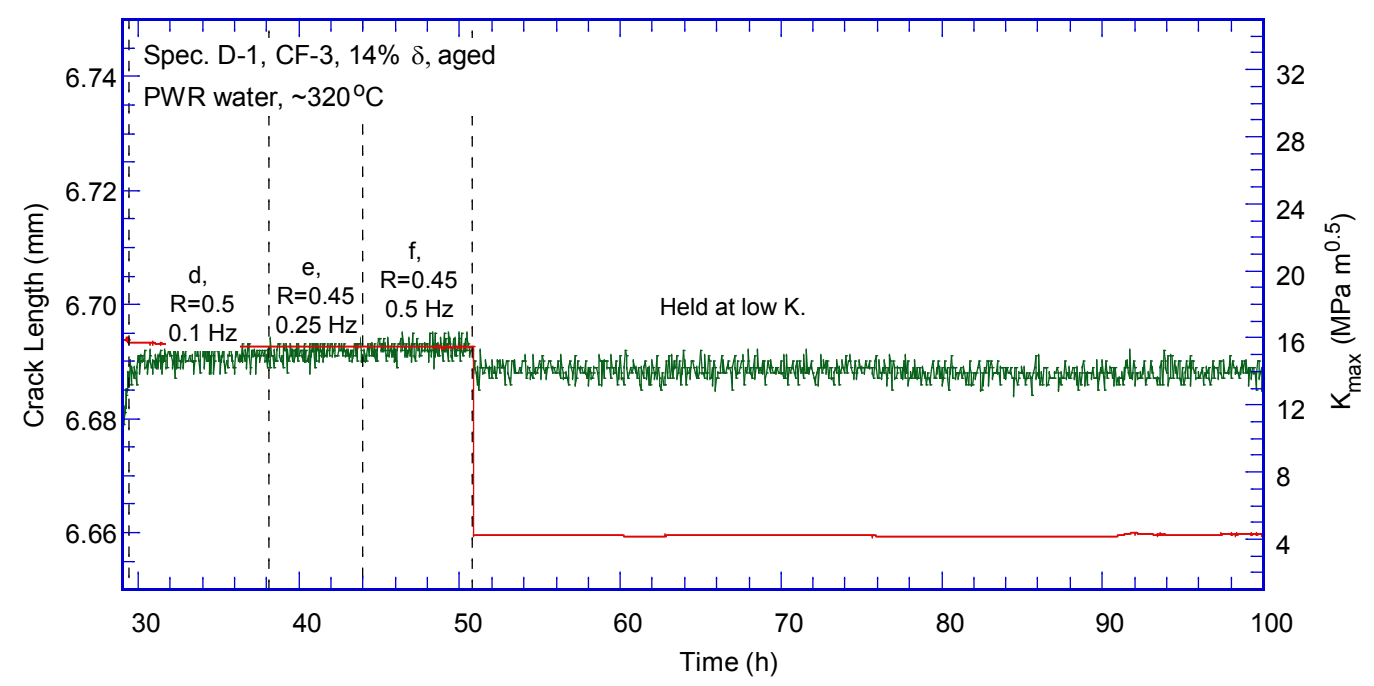

Figure 12. Crack-length-vs.-time plot of specimen D-1 (aged 0.08-dpa CF-3 with 14\% ferrite): test periods (a) a-c, (b) d-f, (c) g-i, (d) j-l, (e) m-o, (f) p-s, (g) t-v, and (h) 1a-1b. 
(c)

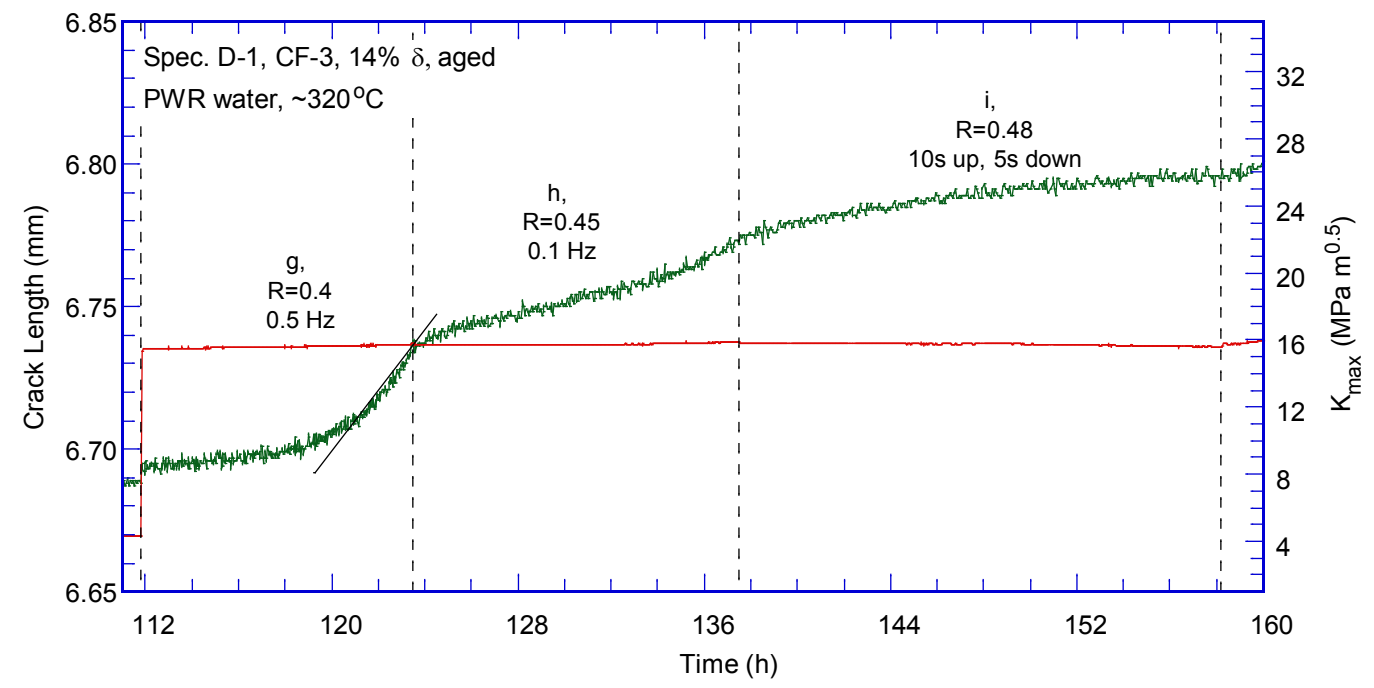

(d)

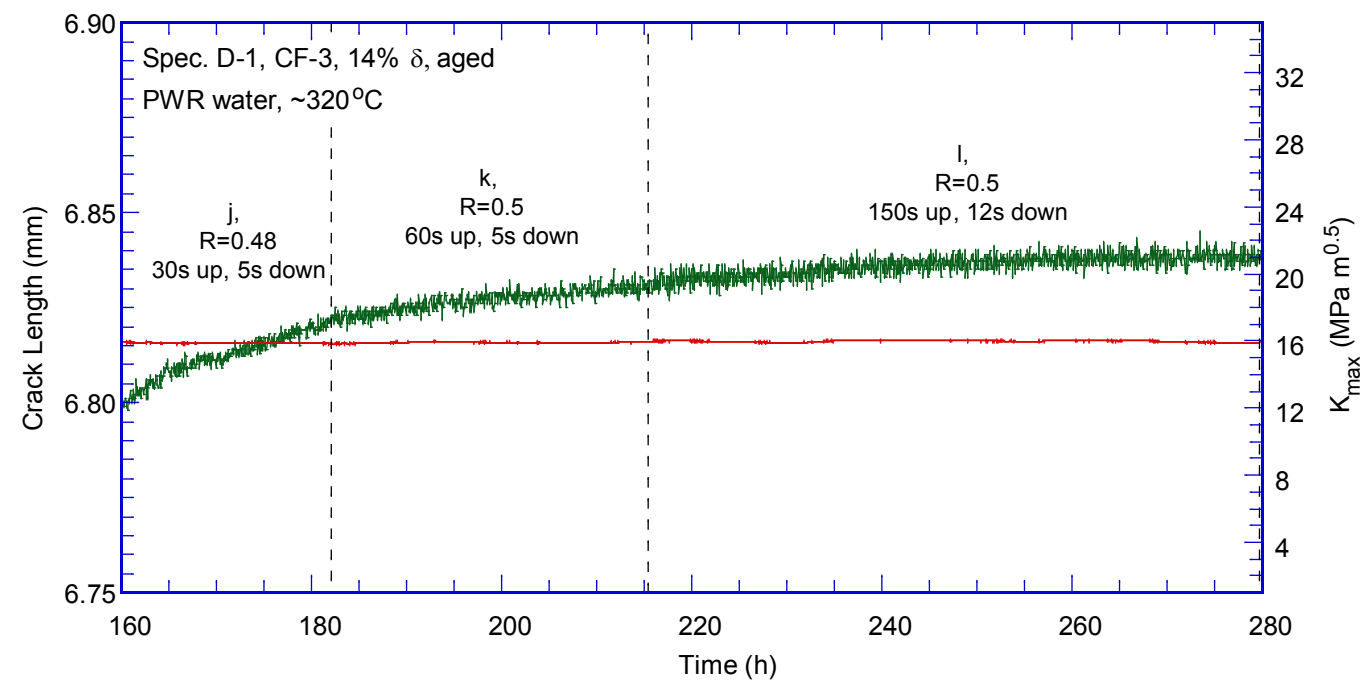

(e)

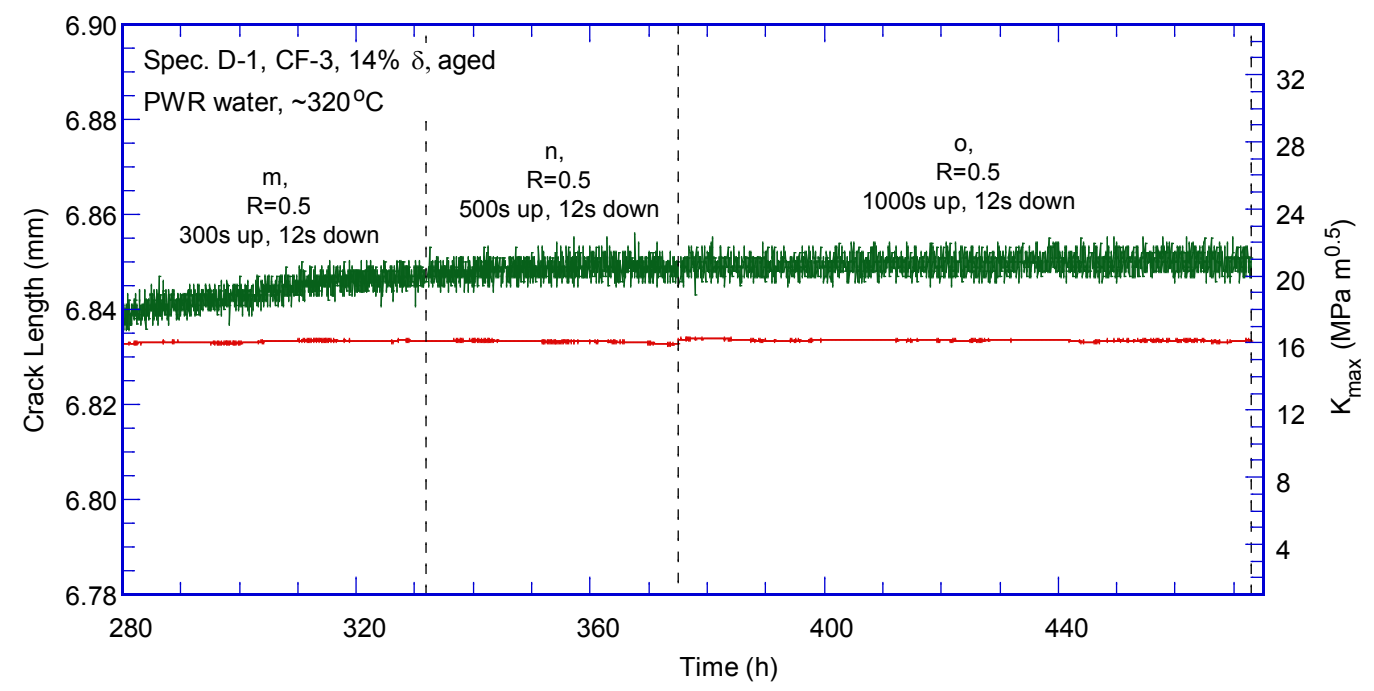

Figure 12. (Cont'd) 
(f)

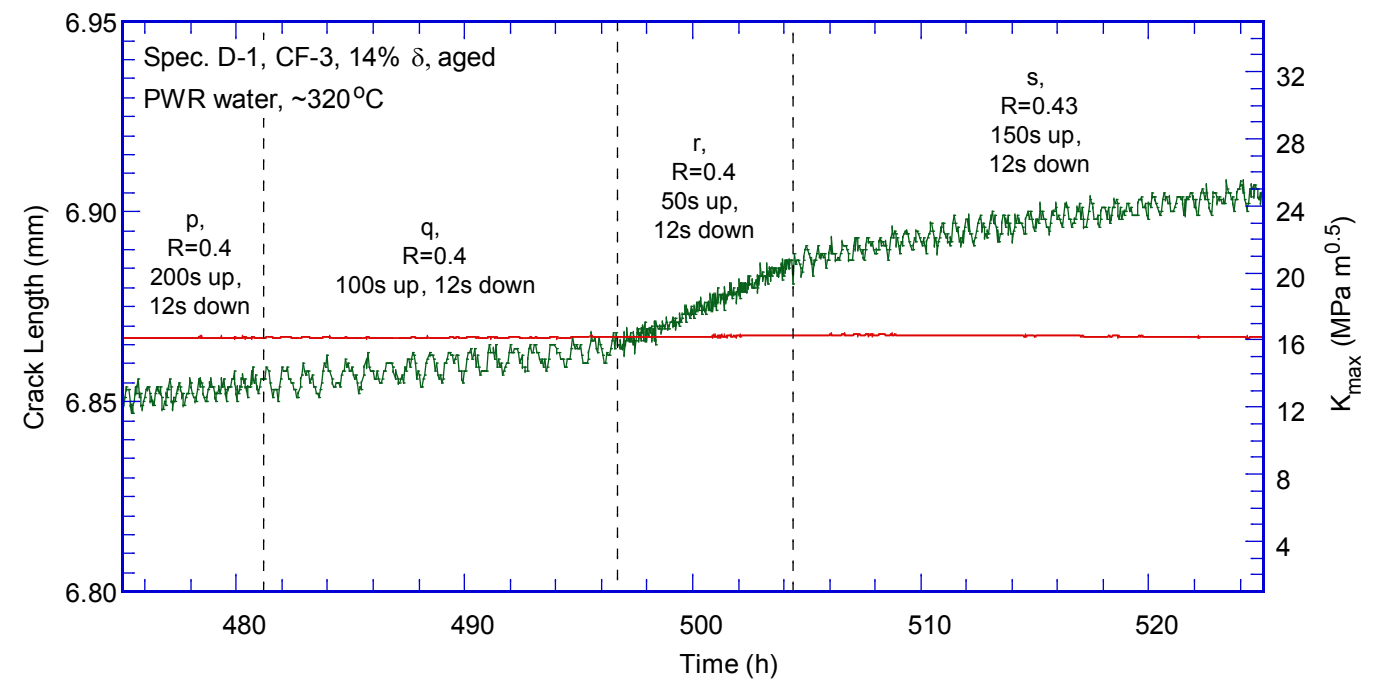

(g)

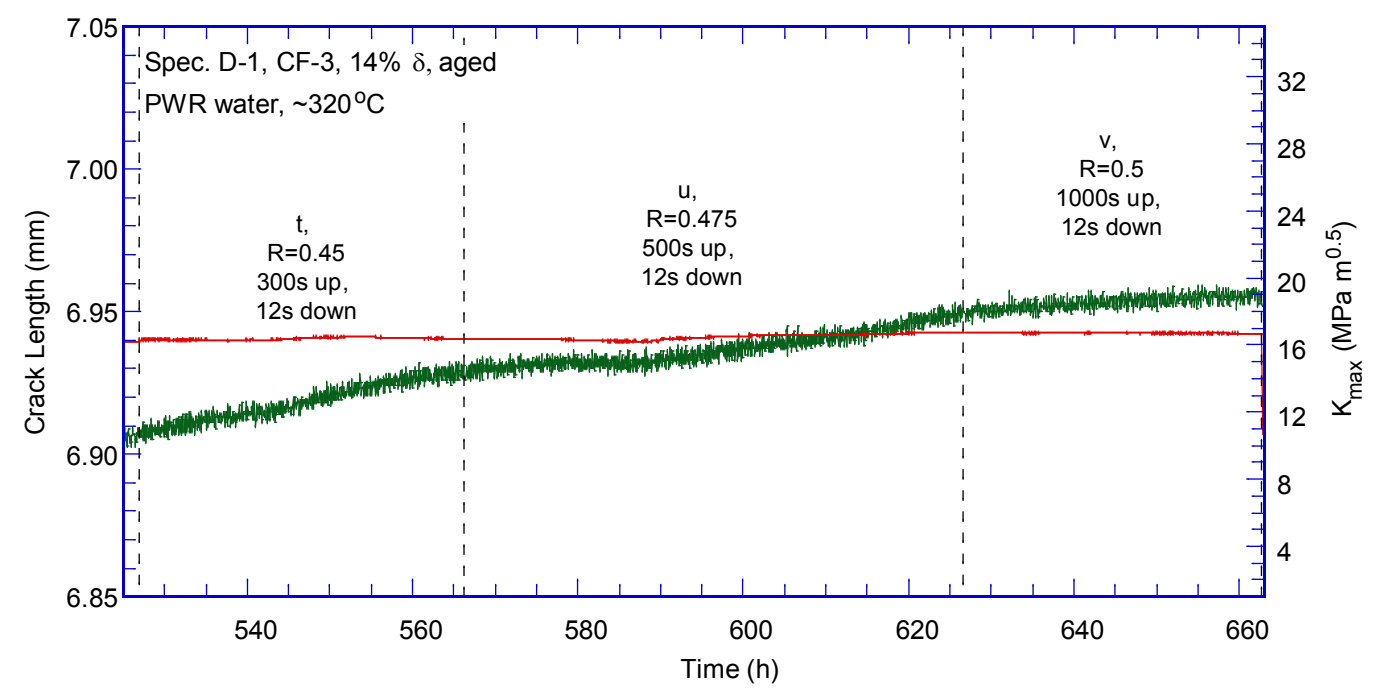

(h)

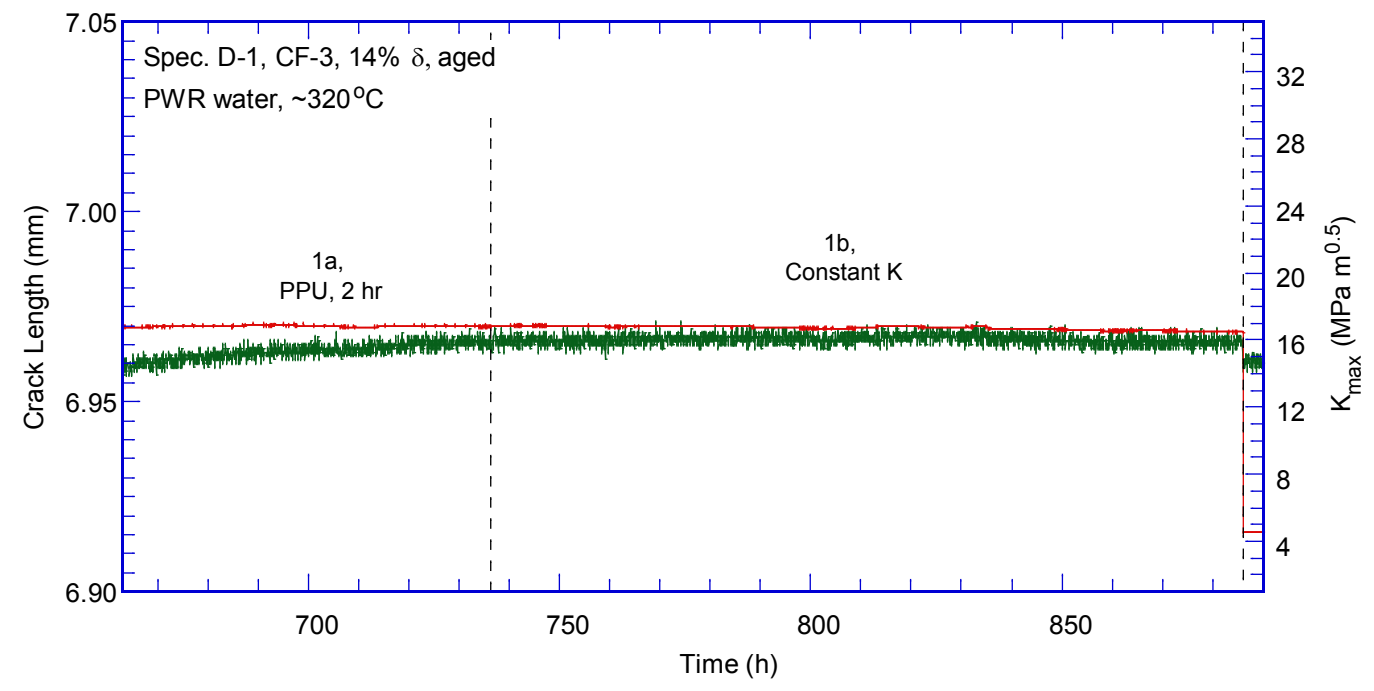

Figure 12. (Cont'd) 


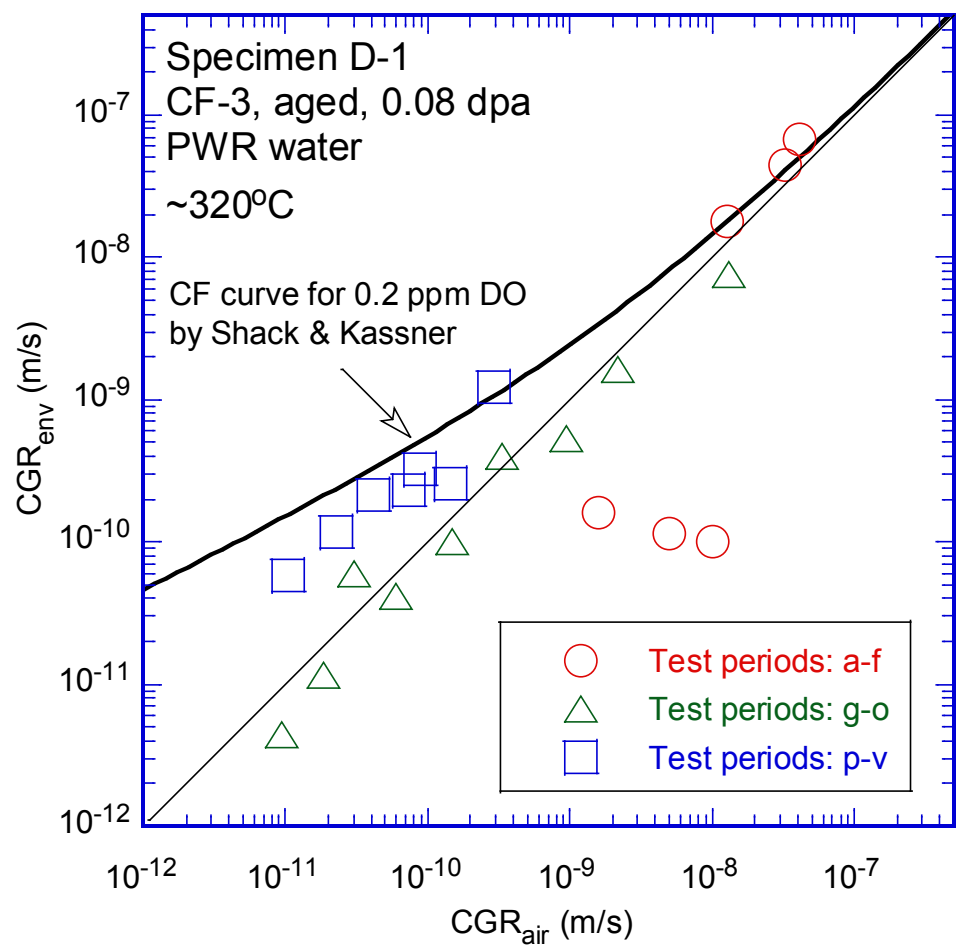

Figure 13. Cyclic CGRs of Specimen D-1, an aged 0.08-dpa CF-3 with 14\% ferrite tested in simulated PWR water.

After the cyclic CGR test, the sample was set to a constant load with PPU every 2 hours. A SCC CGR of $2.4 \mathrm{E}-11 \mathrm{~m} / \mathrm{s}$ was measured over $10 \mu \mathrm{m}$ crack extension. Despite the PPU, the measured CGR continued to decline over time. After the PPU was removed, the crack growth fell below the detection limit of the DCPD measurement. No crack extension was observed after $\sim 150 \mathrm{hr}$, and the CGR test was terminated.

\section{Fracture toughness JR curve test}

After the CGR test, a fracture toughness J-R curve test was performed in the test environment. The sample was pulled at a constant strain rate of $0.43 \mu \mathrm{m} / \mathrm{s}$, and the load and load-line displacement was recorded. The crack extension was also measured with DCPD method. The obtained J-R data are plotted in Figure 14. A correlation of $\mathrm{J}=419 \Delta \mathrm{a}^{0.80}$ was obtained with a curve fitting of the J-R data. The J value at the $0.2-\mathrm{mm}$ offset line is $\sim 161 \mathrm{~kJ} / \mathrm{m}^{2}$, similar to that of the unaged specimen, $\mathrm{C}-1$. Note that, this J-R curve test cannot be validated since data points outside the maximum measurement capacity were used for curve fitting. 


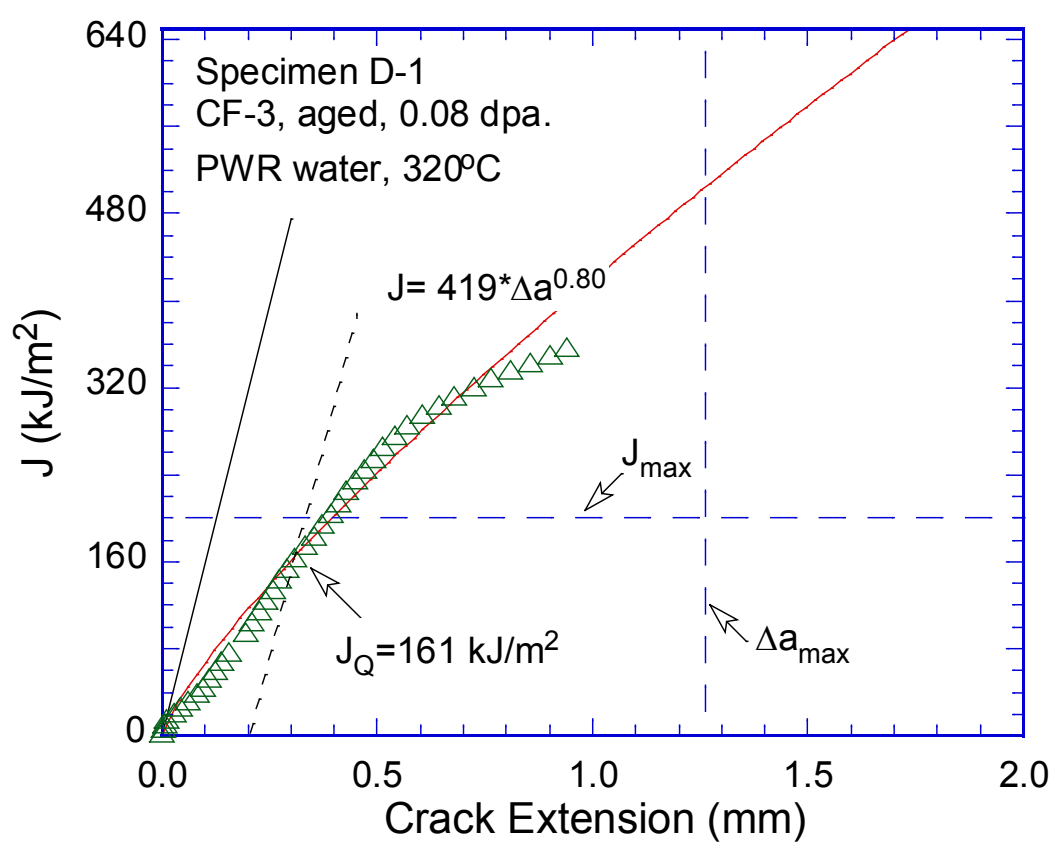

Figure 14. J-R curve of Specimen D-1, an aged 0.08-dpa CF-3 with 14\% ferrite tested in PWR water.

\section{$\underline{\text { Fractographic examination }}$}

Following the J-R curve test, the sample was broken open in air under cyclic loading at room temperature. The specimen was then cleaned and the replicas of the fracture surface were examined with a SEM. Figure 15 shows a global view of the entire fracture surface. The CGR front is relatively straight, indicating a well-controlled loading condition during the CGR test. The CGR region shows a TG morphology and the fracture surface is flat. In contrast, the surface of the J-R curve test is rough and the fracture mode is ductile dimple. Details of the initial fatigue region of this sample can be seen in Figure 16. As the test progressing, the fracture surface of the later stage of the CGR test became smoother, suggesting an increasing trend of environmental contribution to crack propagation. Delta ferrite can be seen in some areas on the fracture surface as shown in Figure 17. Figure 18 shows the transition region from the CGR to J$\mathrm{R}$ tests. While ductile dimples are the main fracture morphology in the J-R test region, some mixed-mode brittle fracture can also be seen as shown in Figure 19. Based on the SEM result, the final crack size was determined, and the DCPD results were scaled proportionally to match the final crack extension. 


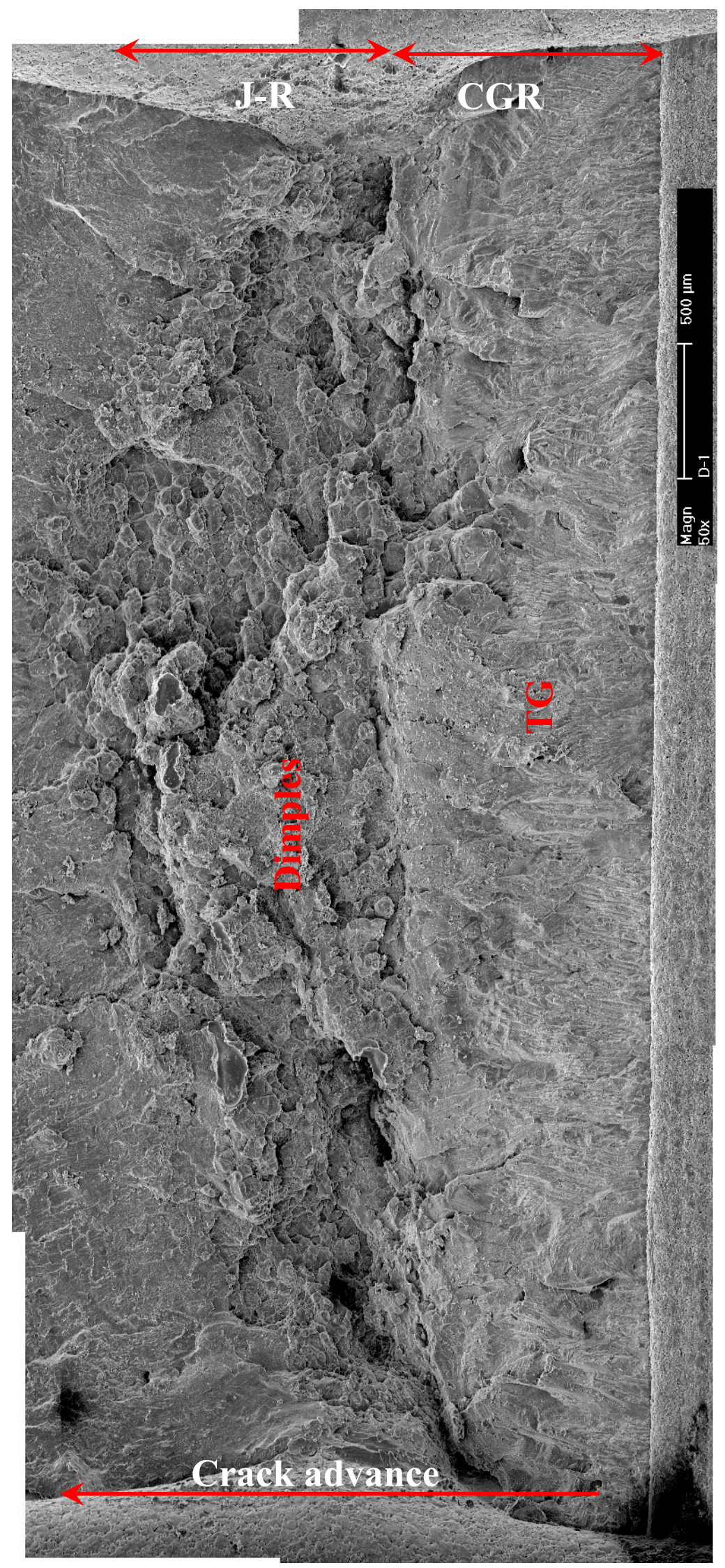

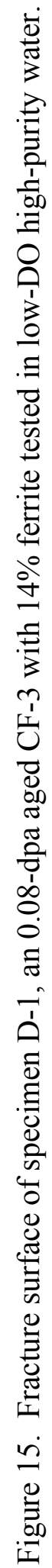




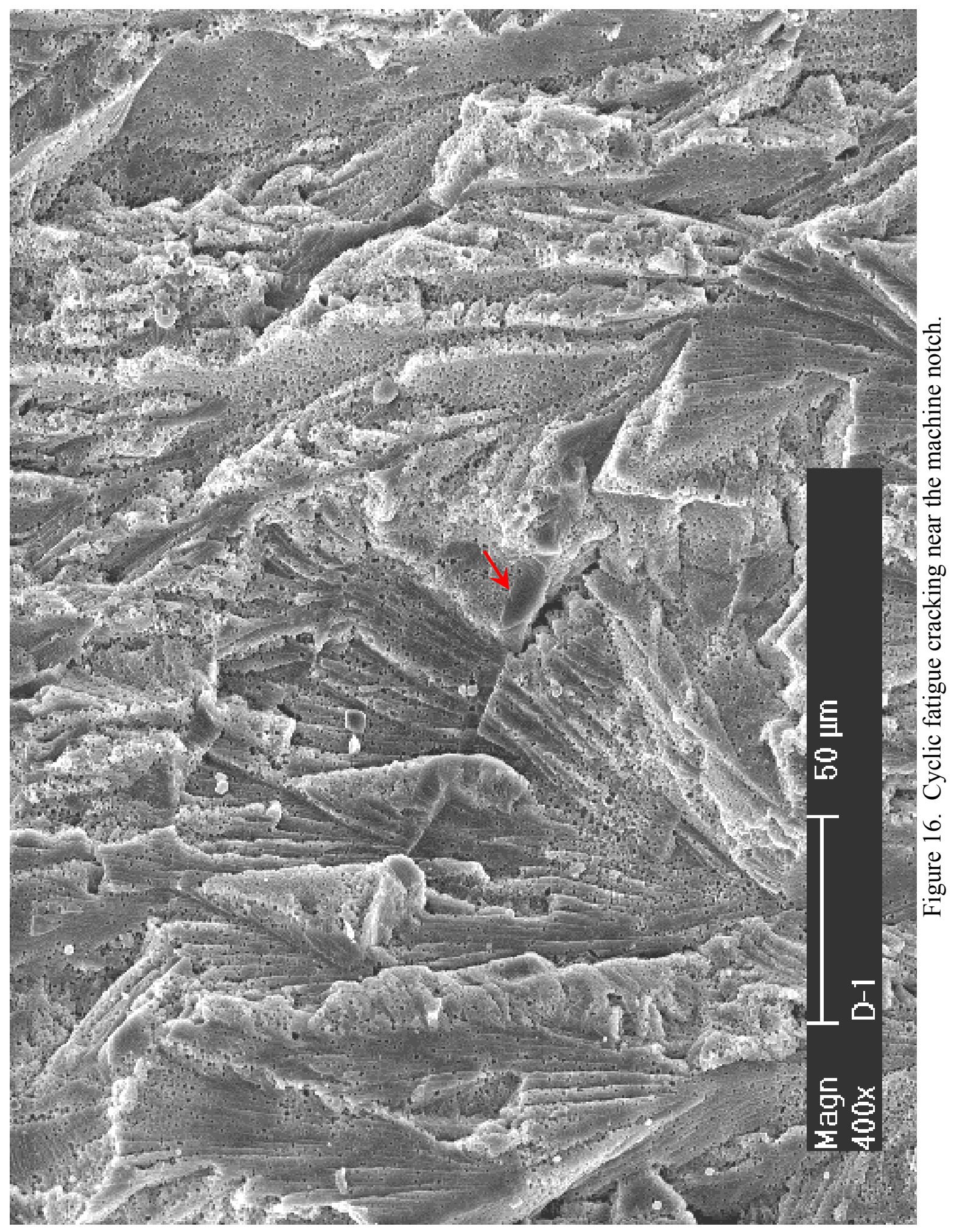




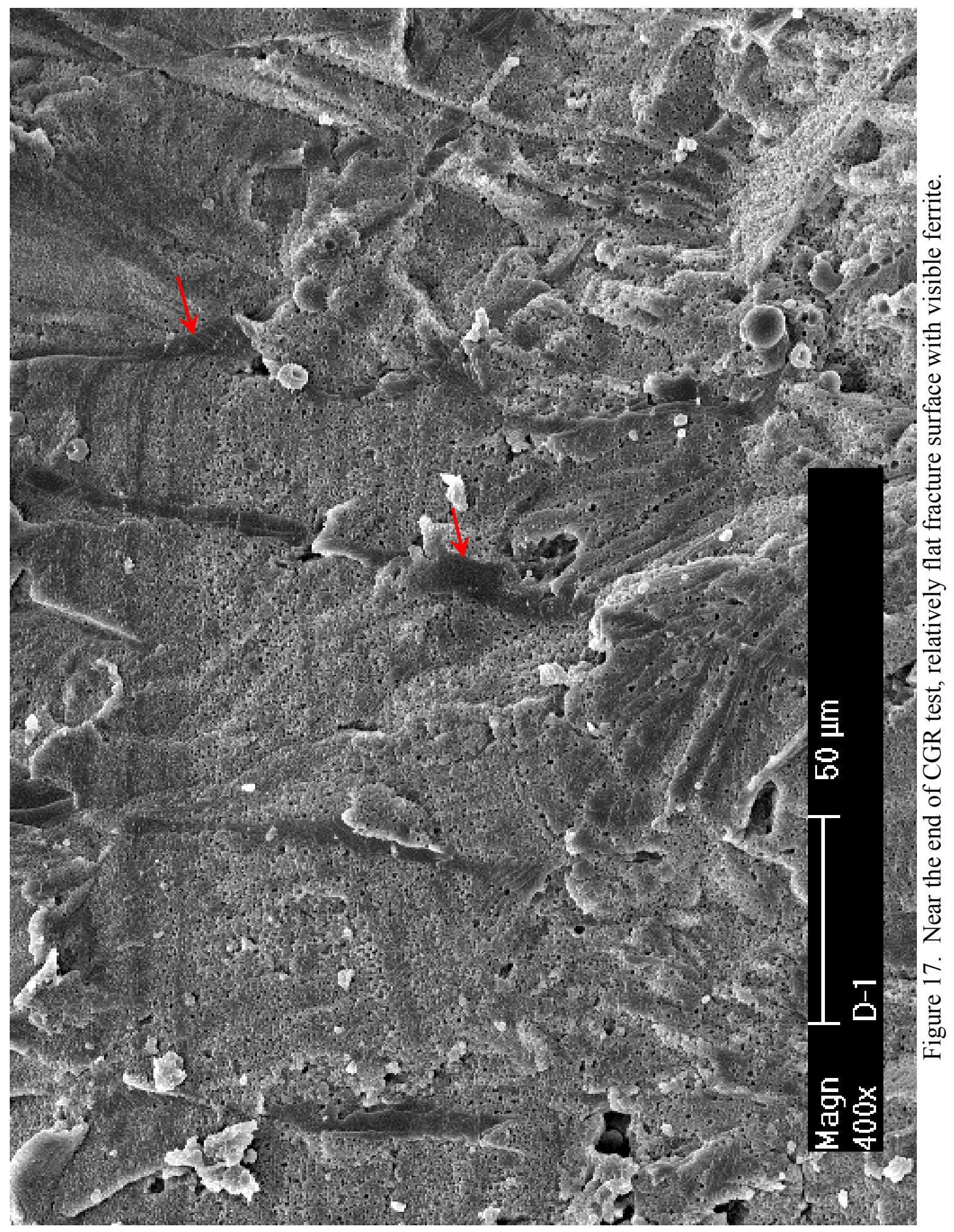




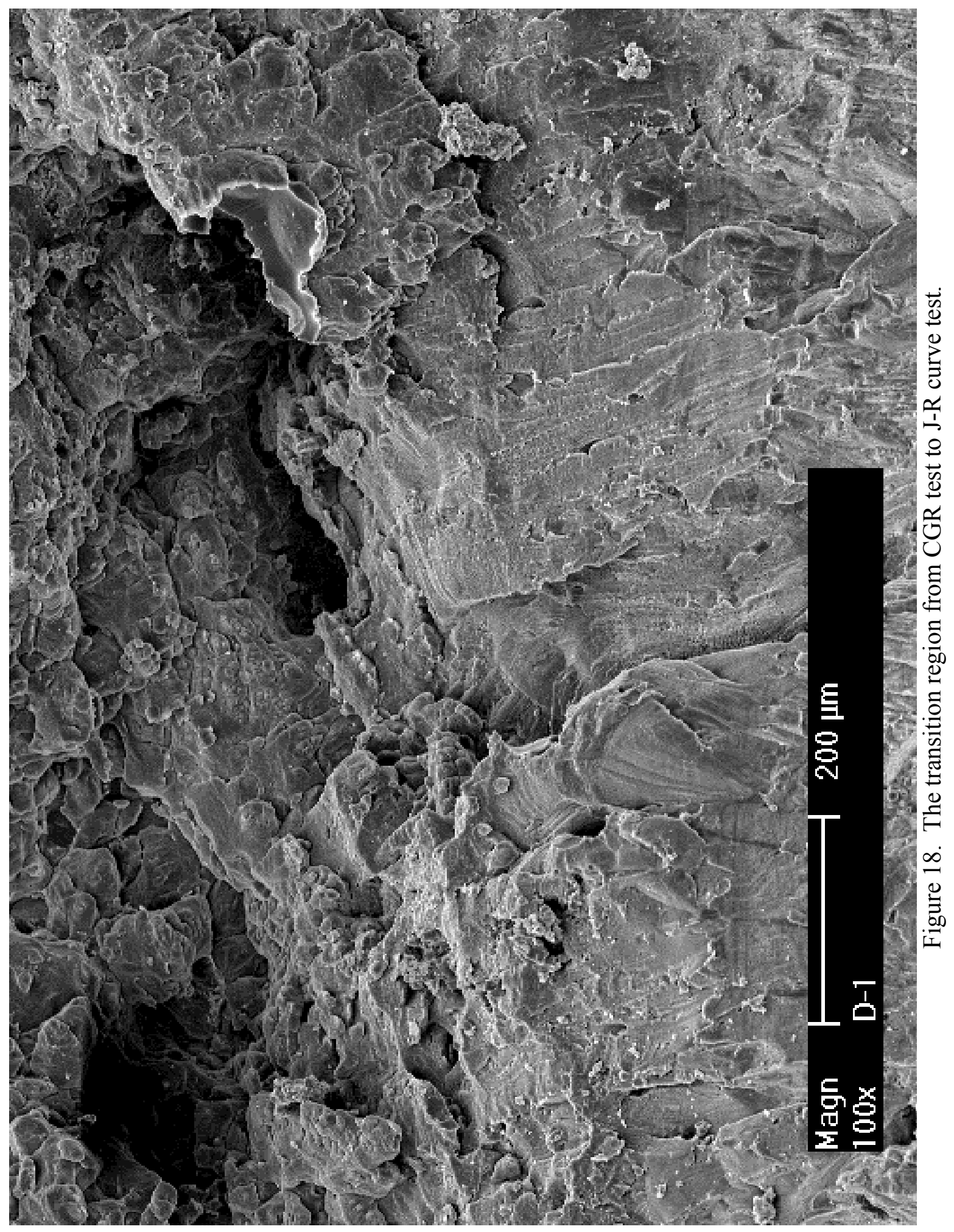




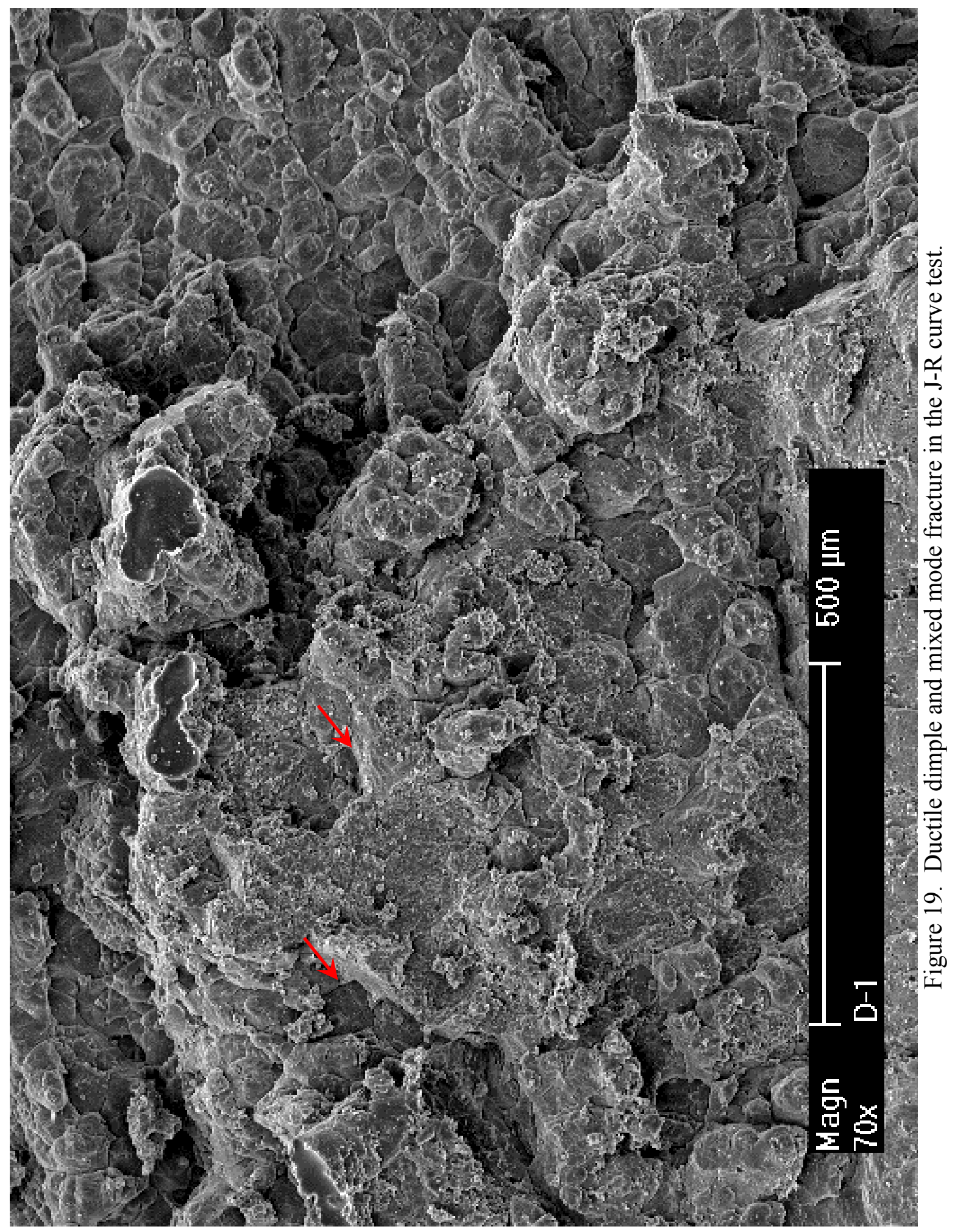




\subsection{CF-8 with $13 \%$ ferrite}

\subsubsection{Unaged Specimen, G-1}

\section{$\underline{\text { Crack growth rate test }}$}

Specimen G-1 was a CF-8 CASS with 13\% ferrite irradiated to 0.08 dpa. The sample was unaged and was tested in low-DO high-purity water at $\sim 320^{\circ} \mathrm{C}$. The test conditions and results are summarized in Table 5, and a crack-length history plot is shown in Figure 20.

Table 5. Crack growth rates of specimen G-1 (unaged CF-8 with 13\% ferrite) in low-DO highpurity water.

\begin{tabular}{|c|c|c|c|c|c|c|c|c|c|c|c|}
\hline $\begin{array}{l}\text { Test } \\
\text { Period }\end{array}$ & $\begin{array}{l}\text { Test } \\
\text { Time, } \\
\mathrm{h}\end{array}$ & $\begin{array}{l}\text { Test } \\
\text { Temp., } \\
{ }^{\circ} \mathrm{C}\end{array}$ & $\begin{array}{l}\text { Load } \\
\text { Ratio }\end{array}$ & $\begin{array}{l}\text { Rise } \\
\text { Time, } \\
\text { s }\end{array}$ & $\begin{array}{l}\text { Return } \\
\text { Time, } \\
\text { s }\end{array}$ & $\begin{array}{l}\text { Hold } \\
\text { Time, } \\
\text { s }\end{array}$ & $\begin{array}{l}\text { Kmax, } \\
\mathrm{MPa} \mathrm{m}^{1 / 2}\end{array}$ & $\begin{array}{l}\Delta \mathrm{K}, \\
\mathrm{MPa} \mathrm{m}^{1 / 2}\end{array}$ & $\begin{array}{l}\text { CGR in } \\
\text { Env., } \\
\mathrm{m} / \mathrm{s}\end{array}$ & $\begin{array}{l}\text { CGR } \\
\text { in Air, } \\
\mathrm{m} / \mathrm{s}\end{array}$ & $\begin{array}{l}\text { Crack } \\
\text { Length, } \\
\mathrm{mm}\end{array}$ \\
\hline Start & 0.2 & & & & & & & & & & 5.770 \\
\hline $\mathrm{a}^{\mathrm{a}}$ & 2.8 & 318 & 0.21 & 0.43 & 0.43 & 0.07 & 14.8 & 11.7 & 7.07E-08 & $3.99 \mathrm{E}-08$ & 5.995 \\
\hline $\mathrm{b}$ & 5.6 & 318 & 0.31 & 0.42 & 0.42 & 0.08 & 15.1 & 10.4 & $4.48 \mathrm{E}-08$ & $3.15 \mathrm{E}-08$ & 6.184 \\
\hline c & 7.9 & 318 & 0.41 & 0.40 & 0.40 & 0.10 & 15.0 & 8.9 & $1.55 \mathrm{E}-08$ & $2.15 \mathrm{E}-08$ & 6.244 \\
\hline $\mathrm{d}$ & 12.7 & 318 & 0.46 & 0.79 & 0.79 & 0.21 & 15.5 & 8.4 & 2.02E-08 & $9.35 \mathrm{E}-09$ & 6.375 \\
\hline $\mathrm{e}^{\mathrm{a}}$ & 23.7 & 318 & 0.51 & 1.93 & 1.93 & 0.57 & 15.3 & 7.5 & $2.90 \mathrm{E}-09$ & $2.86 \mathrm{E}-09$ & 6.423 \\
\hline$f$ & 48.0 & 318 & 0.56 & 3.75 & 3.75 & 1.25 & 15.7 & 6.9 & $2.98 \mathrm{E}-09$ & $1.15 \mathrm{E}-09$ & 6.510 \\
\hline g & 71.1 & 318 & 0.60 & 7.26 & 3.63 & 2.74 & 15.2 & 6.1 & $2.11 \mathrm{E}-11$ & $4.12 \mathrm{E}-10$ & 6.514 \\
\hline $\mathrm{h}$ & 95.5 & 318 & 0.61 & 3.58 & 1.43 & 1.42 & 15.1 & 5.8 & $7.40 \mathrm{E}-11$ & $7.28 \mathrm{E}-10$ & 6.520 \\
\hline $\mathrm{i}$ & 103.2 & 318 & 0.58 & 1.85 & 1.85 & 0.65 & 15.7 & 6.6 & $2.96 \mathrm{E}-09$ & $2.08 \mathrm{E}-09$ & 6.554 \\
\hline $\mathrm{j}$ & 146.7 & 318 & 0.64 & 7.05 & 1.41 & 2.95 & 15.4 & 5.6 & $8.36 \mathrm{E}-12$ & $3.25 \mathrm{E}-10$ & 6.554 \\
\hline $\mathrm{k}$ & 167.7 & 318 & 0.59 & 3.65 & 1.46 & 1.35 & 15.7 & 6.4 & $9.49 \mathrm{E}-10$ & $9.43 \mathrm{E}-10$ & 6.592 \\
\hline 1 & 176.4 & 318 & 0.59 & 7.30 & 1.46 & 2.70 & 15.9 & 6.5 & $2.81 \mathrm{E}-09$ & $4.95 \mathrm{E}-10$ & 6.643 \\
\hline $\mathrm{m}$ & 215.6 & 318 & 0.56 & 22.2 & 3.70 & 7.79 & 15.8 & 7.0 & $8.52 \mathrm{E}-10$ & $2.01 \mathrm{E}-10$ & 6.718 \\
\hline $\mathrm{n}$ & 263.9 & 318 & 0.55 & 44.6 & 8.92 & 15.4 & 16.1 & 7.2 & $2.95 \mathrm{E}-10$ & $1.09 \mathrm{E}-10$ & 6.760 \\
\hline $\mathrm{O}^{\mathrm{a}}$ & 291.6 & 318 & 0.55 & 111.5 & 8.92 & 38.5 & 16.4 & 7.3 & $7.51 \mathrm{E}-10$ & $4.72 \mathrm{E}-11$ & 6.833 \\
\hline $\mathrm{p}$ & 314.3 & 318 & 0.53 & 225.6 & 9.02 & 74.4 & 16.8 & 7.8 & $8.11 \mathrm{E}-10$ & $2.80 \mathrm{E}-11$ & 6.885 \\
\hline$q$ & 335.8 & 318 & 0.55 & 372.2 & 8.93 & 127.8 & 16.8 & 7.6 & $5.68 \mathrm{E}-10$ & $1.55 \mathrm{E}-11$ & 6.917 \\
\hline $\mathrm{r}$ & 384.2 & 318 & 0.54 & 746.3 & 8.96 & 253.7 & 16.7 & 7.7 & $2.05 \mathrm{E}-10$ & $8.19 \mathrm{E}-12$ & 6.947 \\
\hline $1 \mathrm{a}$ & 423.7 & 319 & 0.55 & 12 & 12 & 7200 & 16.8 & 7.5 & $1.03 \mathrm{E}-11$ & $7.95 \mathrm{E}-13$ & 6.950 \\
\hline $\mathrm{S}$ & $\begin{array}{c}531.1- \\
542.9 \\
\end{array}$ & 318 & 0.40 & 25.1 & 4.18 & 4.90 & 17.0 & 10.2 & 4.84E-09 & $5.29 \mathrm{E}-10$ & 7.106 \\
\hline $\mathrm{t}$ & 560.5 & 318 & 0.45 & 82.6 & 9.91 & 17.4 & 17.4 & 9.6 & $1.59 \mathrm{E}-09$ & $1.42 \mathrm{E}-10$ & 7.180 \\
\hline $\mathrm{u}$ & 584.4 & 318 & 0.49 & 203.4 & 9.76 & 46.6 & 17.7 & 9.0 & $6.60 \mathrm{E}-10$ & $4.77 \mathrm{E}-11$ & 7.226 \\
\hline $\mathrm{v}$ & 604.3 & 318 & 0.51 & 402.7 & 9.66 & 97.3 & 17.7 & 8.6 & $2.71 \mathrm{E}-10$ & $2.12 \mathrm{E}-11$ & 7.244 \\
\hline $\mathrm{W}$ & 628.4 & 318 & 0.54 & 797.2 & 9.57 & 202.8 & 18.0 & 8.3 & $5.48 \mathrm{E}-10$ & $9.62 \mathrm{E}-12$ & 7.280 \\
\hline $1 b^{a}$ & 720 & 319 & 0.55 & 12 & 12 & 7200 & 17.8 & 8.0 & $4.97 \mathrm{E}-11$ & $9.79 \mathrm{E}-13$ & 7.318 \\
\hline $1 \mathrm{c}$ & 845.1 & 319 & 1.0 & - & - & - & 18.2 & - & $4.80 \mathrm{E}-12$ & - & 7.321 \\
\hline
\end{tabular}

a The CGR value was obtained from the later part of the test period.

The cyclic CGR test was started with a triangle waveform of $1 \mathrm{~Hz}$ at a load ratio of $\sim 0.2$ and a $\mathrm{K}_{\max }$ of $\sim 15 \mathrm{MPa} \mathrm{m}^{1 / 2}$. A CGR comparable to the fatigue growth rate in air was established over $225-\mu \mathrm{m}$ crack extension. In the following test periods, the rise time and load ratio were increased gradually while the maximum stress intensity factor was kept the same. The measured CGRs continued to follow the expected fatigue growth rates closely. After about $750 \mu \mathrm{m}$ crack extension, the crack stalled at a load ratio of $\sim 0.6$. The crack was re-initiated successfully when 
the $\mathrm{K}_{\max }$ was raised slightly to $\sim 16 \mathrm{MPa} \mathrm{m}^{1 / 2}$. Environmentally enhanced cracking started to appear with a load ratio of $\sim 0.55$ and $30 \mathrm{~s}$ rise time. The enhancement was stabilized with further increases of rise time in the following test periods.

Next, the test was set to a constant-load with PPU every 2 hours. The measured CGR was $\sim 1.0 \mathrm{E}-11 \mathrm{~m} / \mathrm{s}$ over just $3 \mu \mathrm{m}$ crack extension. Unexpectedly, a steam leak was developed at the high-pressure section of the recirculation loop, and the test had to be interrupted for about $100 \mathrm{hr}$. After the test was resumed, several cyclic loading test periods were repeated to re-establish environmentally assisted cracking. The crack responded quickly to the cyclic loading and a CGR much higher than the fatigue growth rate in air was obtained. After some $310 \mu \mathrm{m}$ crack extension, the rise time and load ratio were increased slowly in the following test periods to stabilize the environmental effect. By the end of the cyclic test, the measured CGR was more than 50 times higher than the estimated fatigue growth rate.

(a)

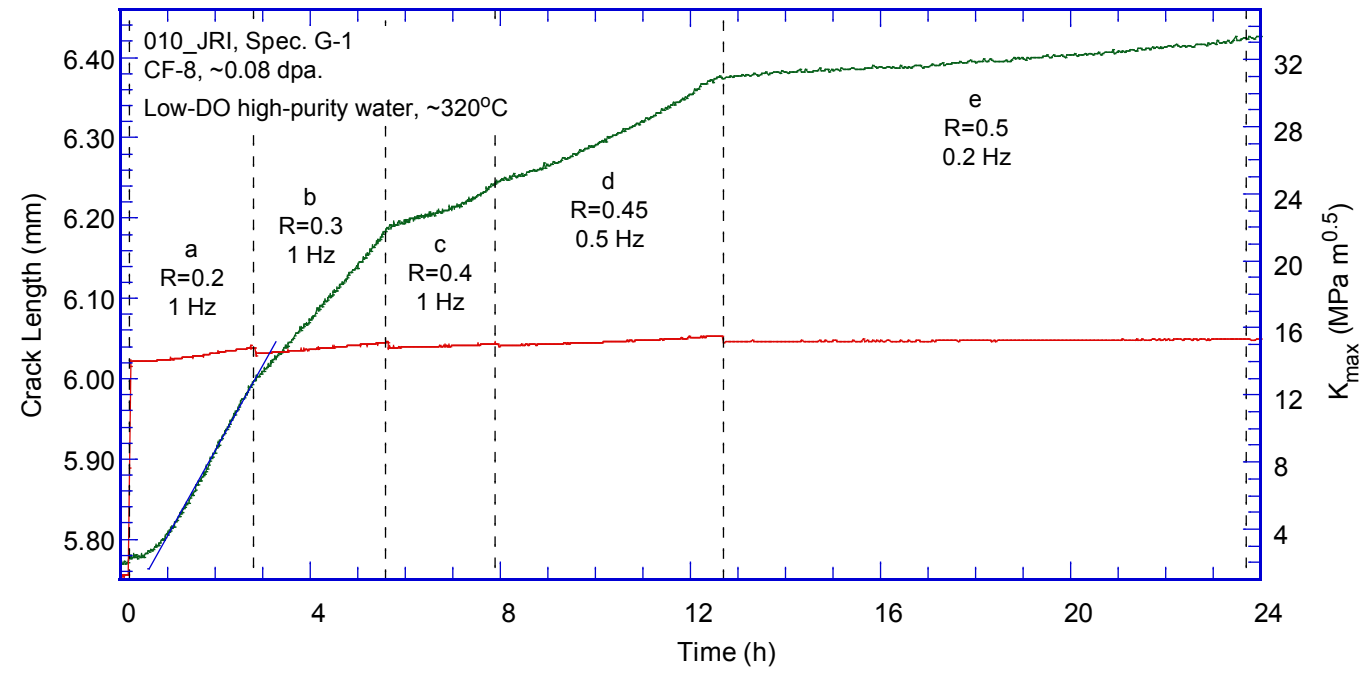

(b)

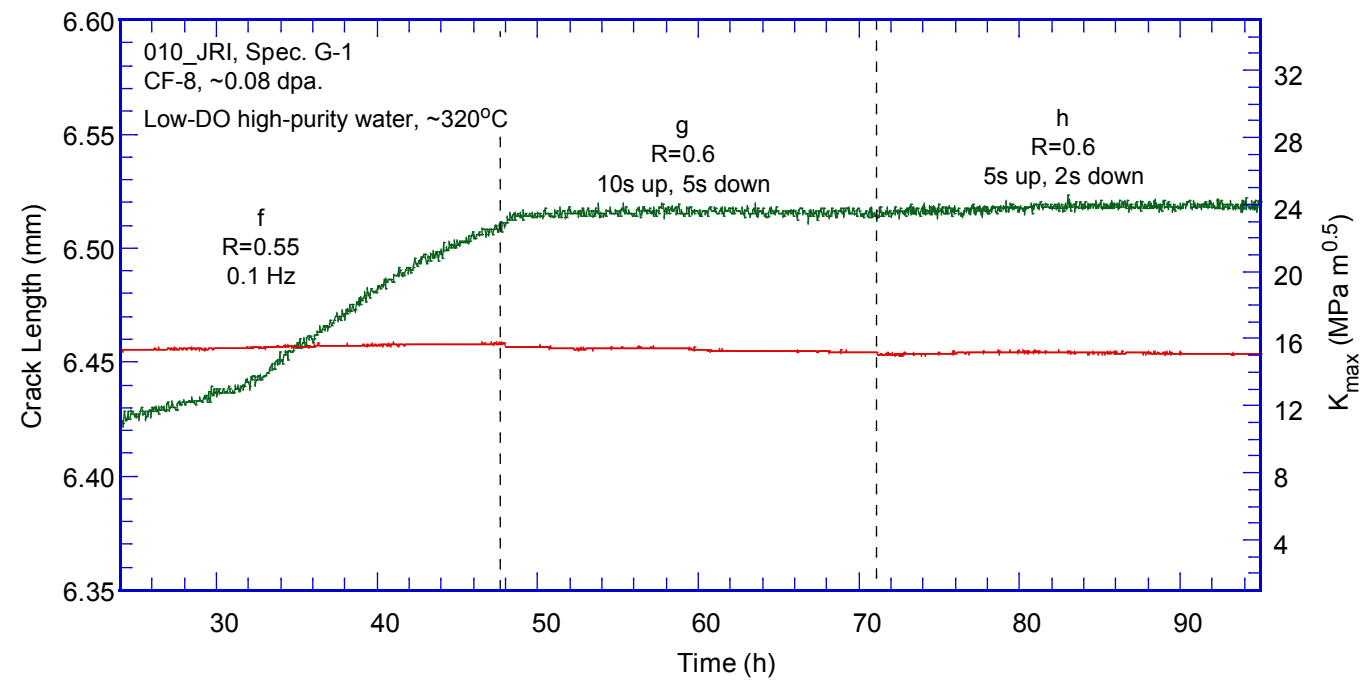

Figure 20. Crack-length-vs.-time plot of specimen G-1 (unaged 0.08-dpa CF-8 with 13\% ferrite): test periods (a) a-e, (b) f-h, (c) i-l, (d) m-o, (e) p-r, (f) 1a, (g) v-w, (h) 1b-1c. 
(c)

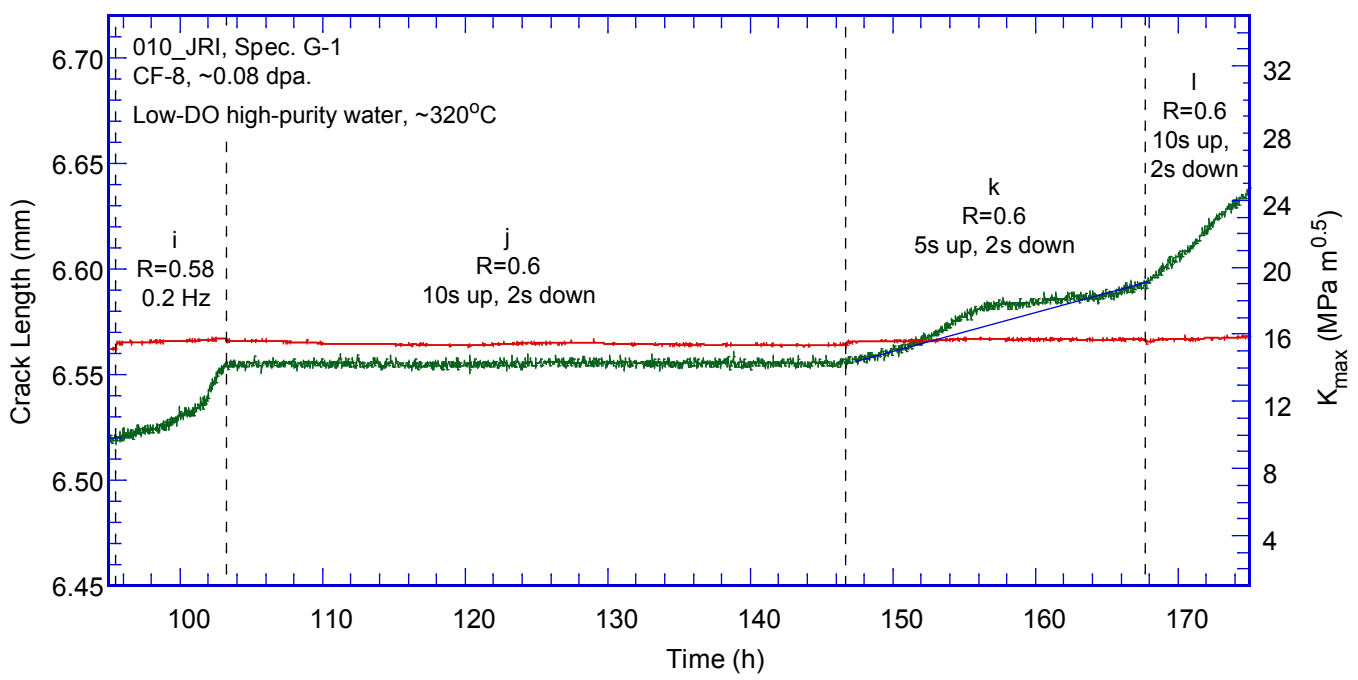

(d)

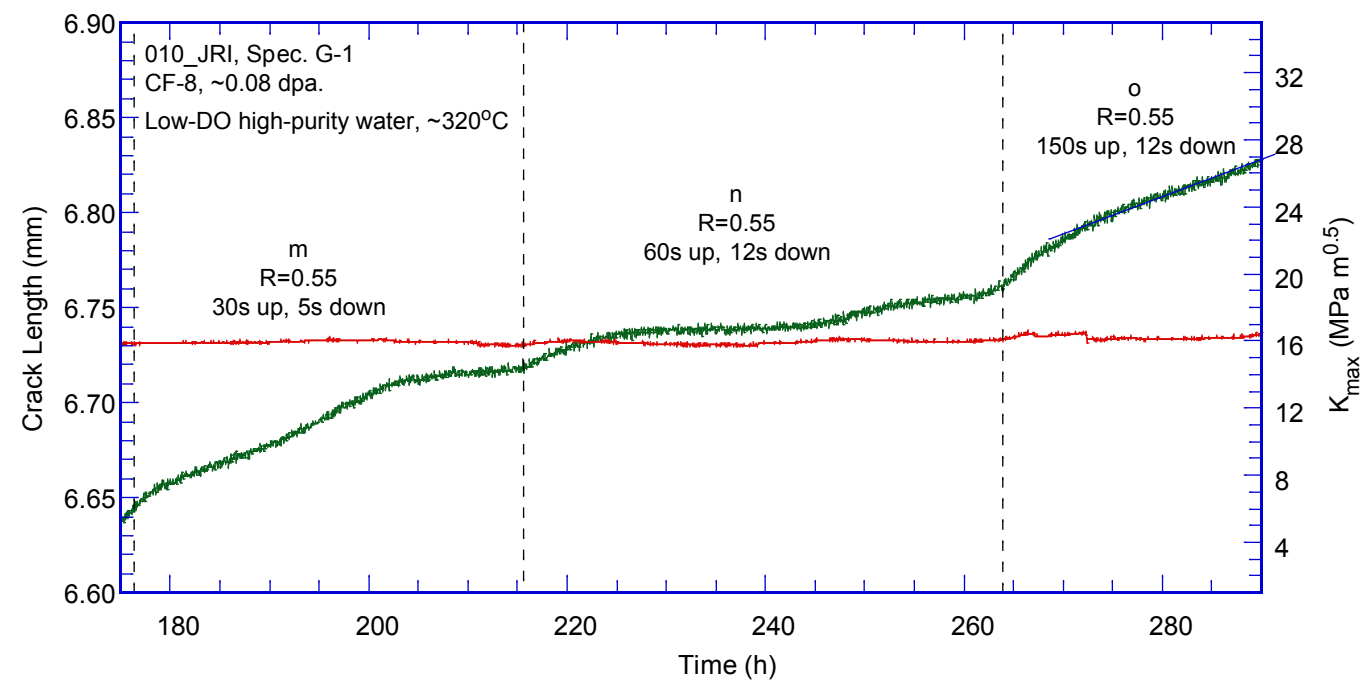

(e)

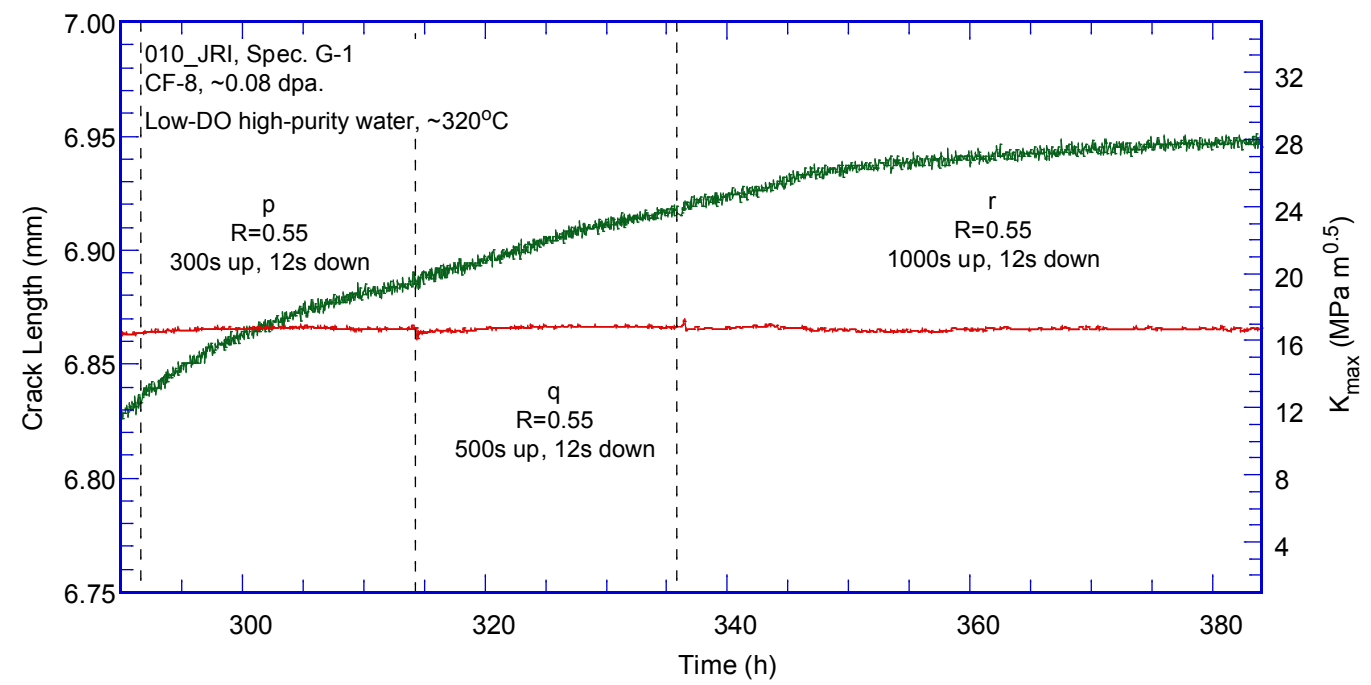

Figure 20. (Cont'd) 
(f)

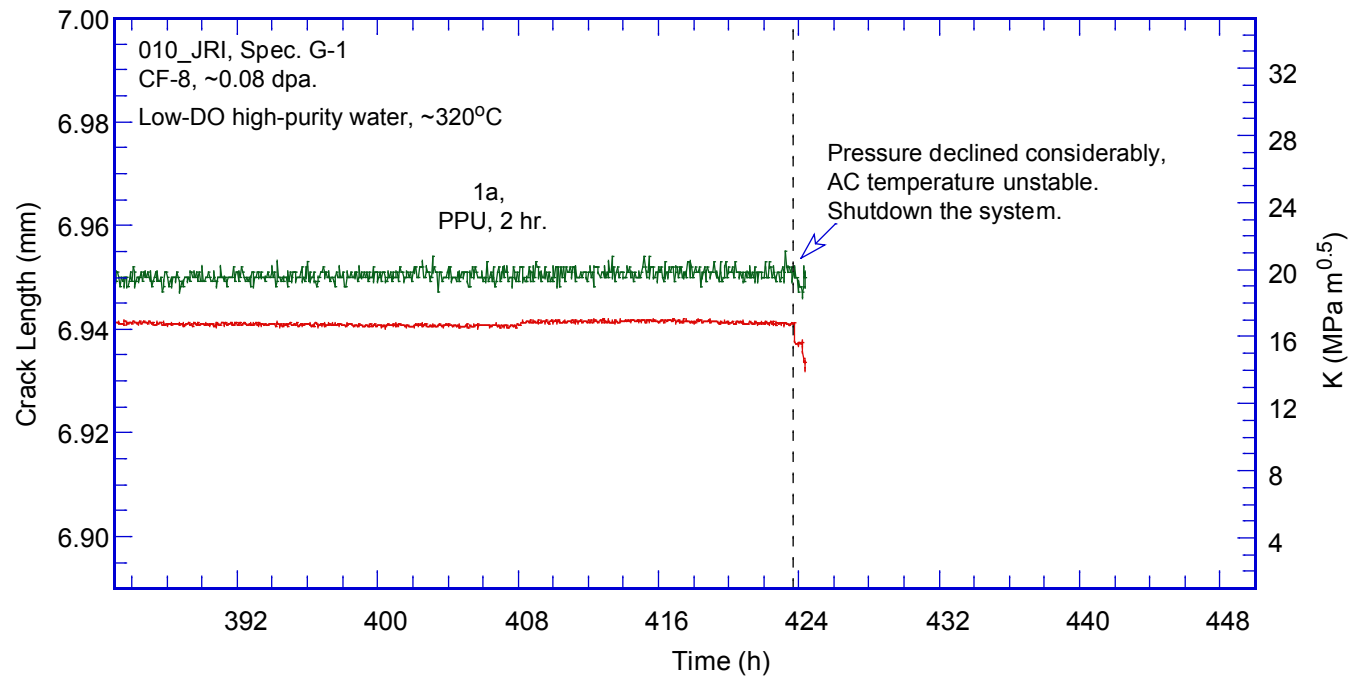

(g)

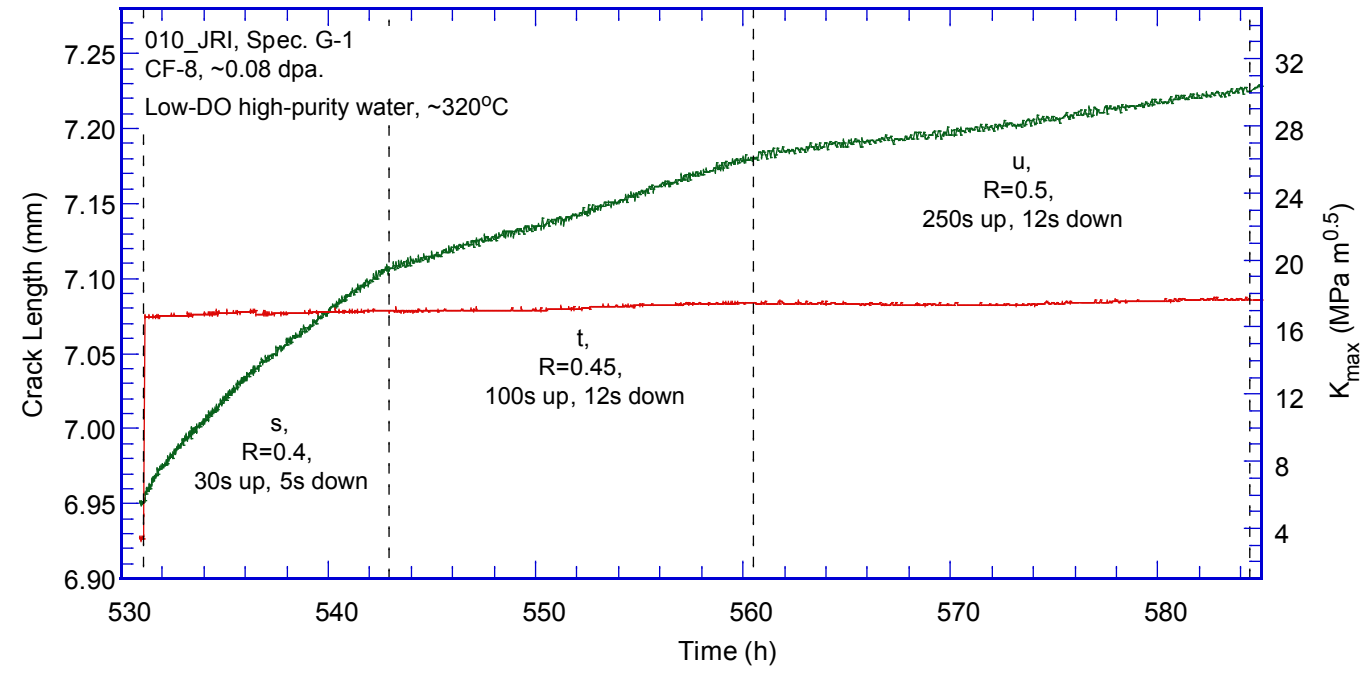

(h)

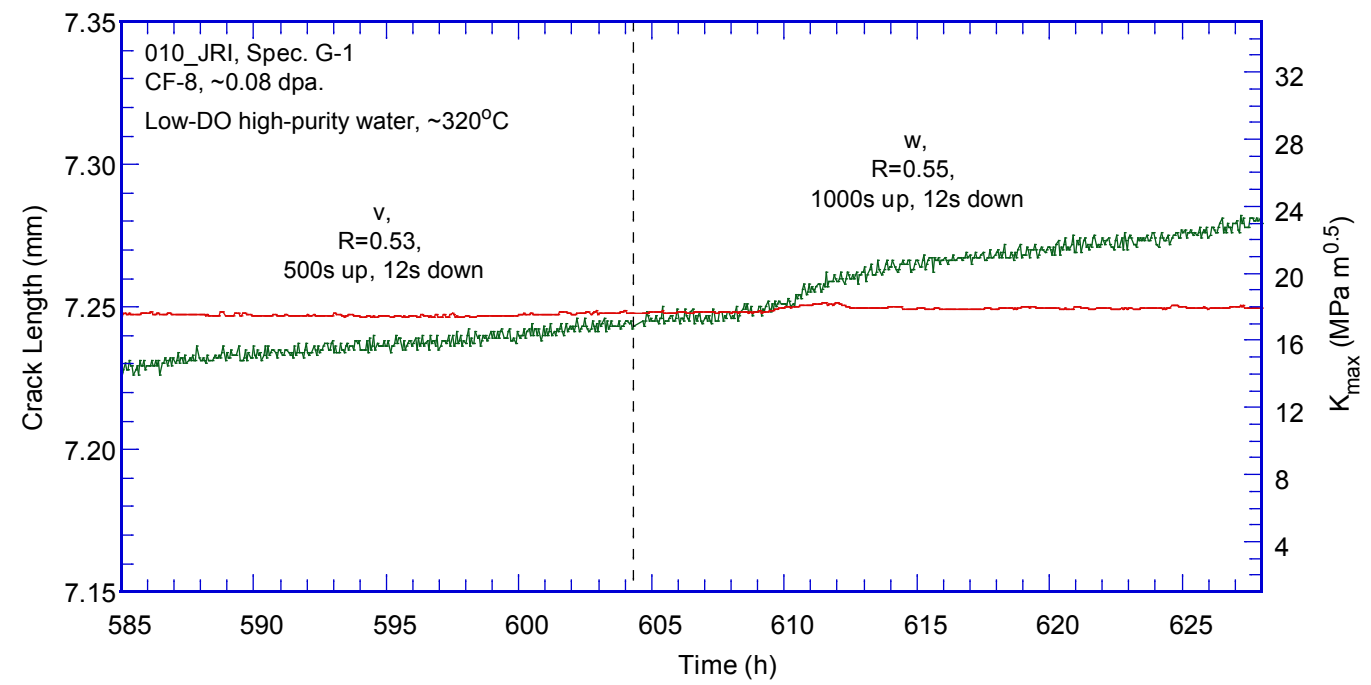

Figure 20. (Cont'd) 
(i)

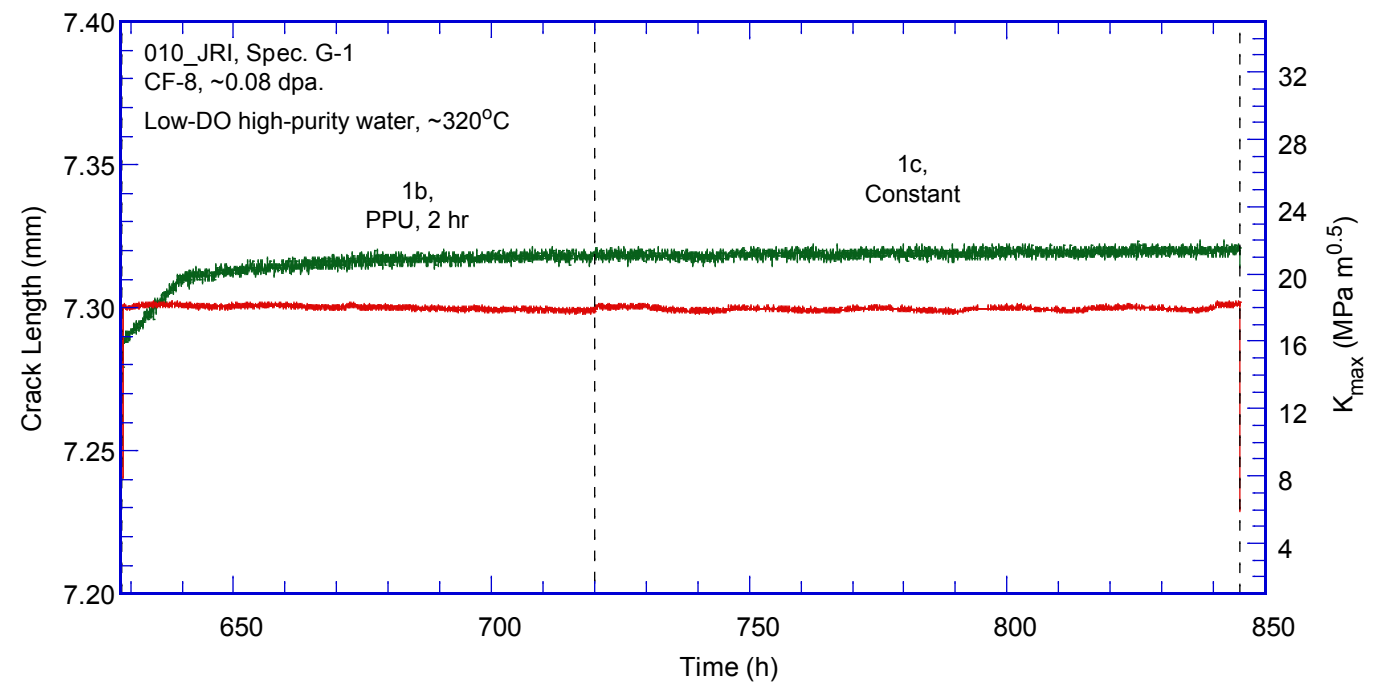

Figure 20. (Cont'd)

Figure 21 shows the cyclic CGRs of this test as a function of the fatigue growth rate in air. While these cyclic CGRs may have been affected by the restart of the test, there is no doubt that the corrosion-fatigue response of this specimen is much worse than that of CF-3 shown in previous the sections.

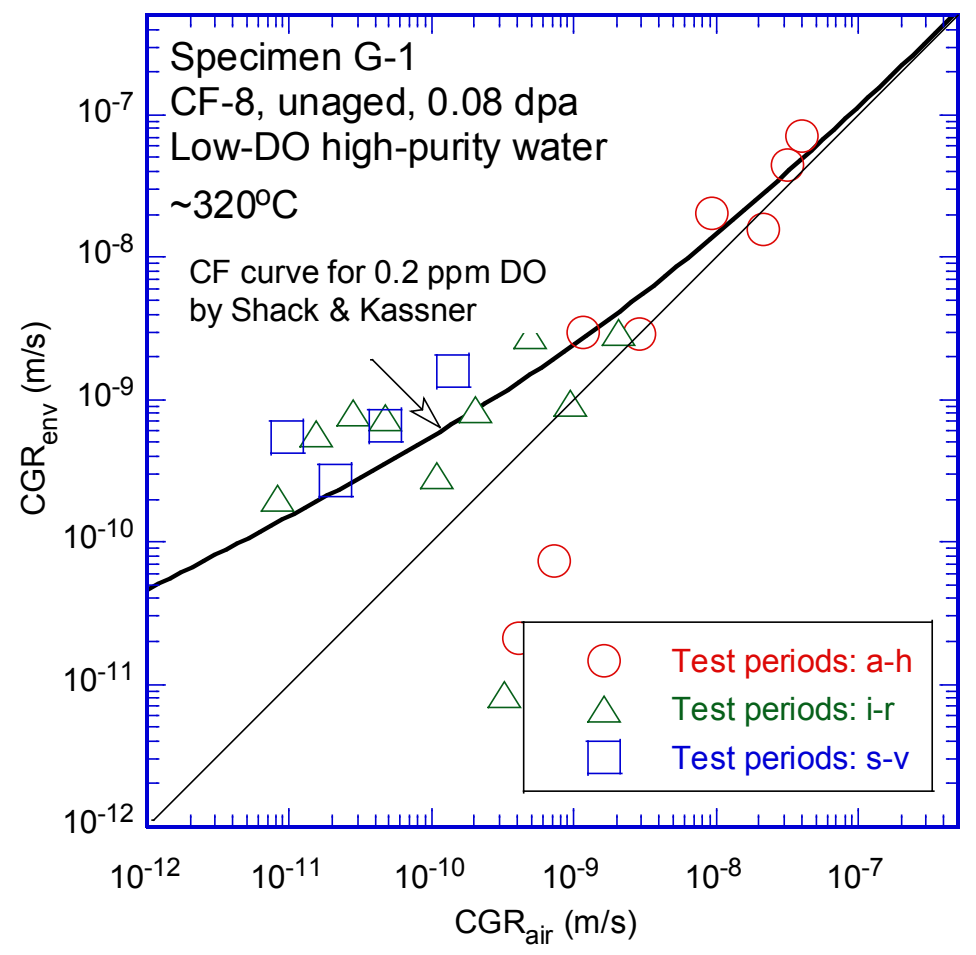

Figure 21. Cyclic CGRs of Specimen G-1, an unaged 0.08-dpa CF-8 with 13\% ferrite tested in low-DO high-purity water. 
The test was transitioned to a constant-load SCC CGR test at the similar stress intensity level $\left(\sim 18 \mathrm{MPa} \mathrm{m}^{1 / 2}\right)$ with PPU every 2 hours. After an initial stage of rapid growth, the observed CGR slowed down to about $5.0 \mathrm{E}-11 \mathrm{~m} / \mathrm{s}$, which was about a factor of five higher than that measured before the system was shut down. The reason of the initial rapid growth is not clear. Finally, the test was set to a near constant-K condition at $\sim 18 \mathrm{MPa} \mathrm{m}^{1 / 2}$. A CGR of $4.8 \mathrm{E}-12 \mathrm{~m} / \mathrm{s}$ was measured over $\sim 13 \mu \mathrm{m}$ crack extension.

\section{Fracture toughness JR curve test}

After the CGR test, a fracture toughness J-R curve test was conducted on the specimen in the same test environment. The test was performed with a constant strain rate of $0.43 \mu \mathrm{m} / \mathrm{s}$. During the test, the load and load-line displacement was recorded continuously, and the crack extension was measured with DCPD method. The obtained J-R data are shown in Figure 22. A power-law correlation of $\mathrm{J}=870 \Delta \mathrm{a}^{0.92}$ was fitted to the data, and the $\mathrm{J}$ value at the $0.2-\mathrm{mm}$ offset line was $\sim 452 \mathrm{~kJ} / \mathrm{m}^{2}$. Note that, due to the small crack extension obtained in this test, only a few data points at the end of the test were qualified for the analysis. The data points used for the curve fitting were also much higher than the maximum fracture toughness could be measured with this specimen size.

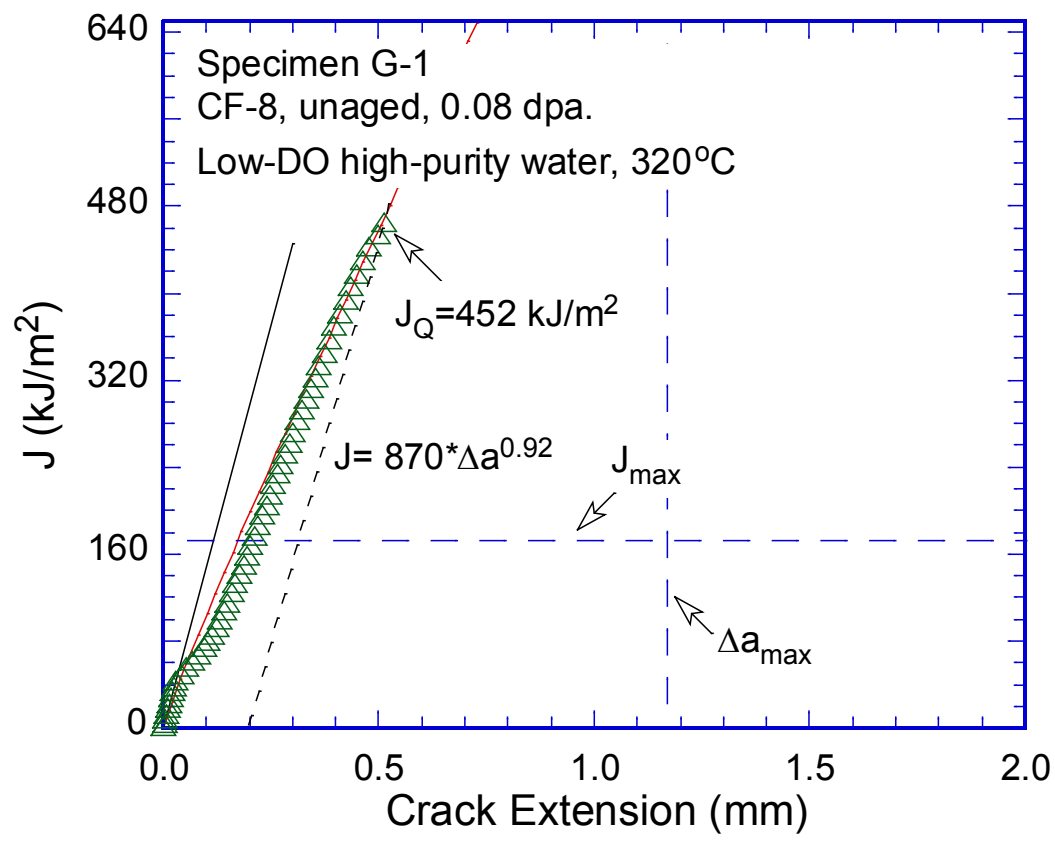

Figure 22. J-R curve of Specimen G-1, an unaged 0.08-dpa CF-8 with 13\% ferrite tested in lowDO high-purity water.

\section{$\underline{\text { Fractographic examination }}$}

After the test, the specimen was broken in air at room temperature for fractographic examination. Figure 23 shows a global view of the entire fracture surface of specimen G-1. The CGR front is not straight, and the crack extension is larger on the left hand side of the image than the right. A very small crack extension can also be seen for the J-R curve test. Apparently, the alignment of 
loading train was disturbed by the interruption of the test, leading to a loading problem during this J-R curve test.

While the CGR region shows a TG morphology, the failure mode for the J-R curve test is ductile dimple. Details of the initial fatigue region of this sample can be seen in Figure 24. The fracture surface of the later stage of the CGR test is much smoother (as shown in Figure 25), indicating an increasing trend of environmental contribution as the test progressing. Delta ferrite can be seen in some areas on the fracture surface. Figure 26 shows the transition region from the CGR to J-R curve tests. A clear contrast can be seen on the fracture surface between the TG fracture in the CGR test and the ductile dimple morphology in the J-R curve test. The fracture mode in the J-R curve test is fully ductile as shown in Figure 27. 


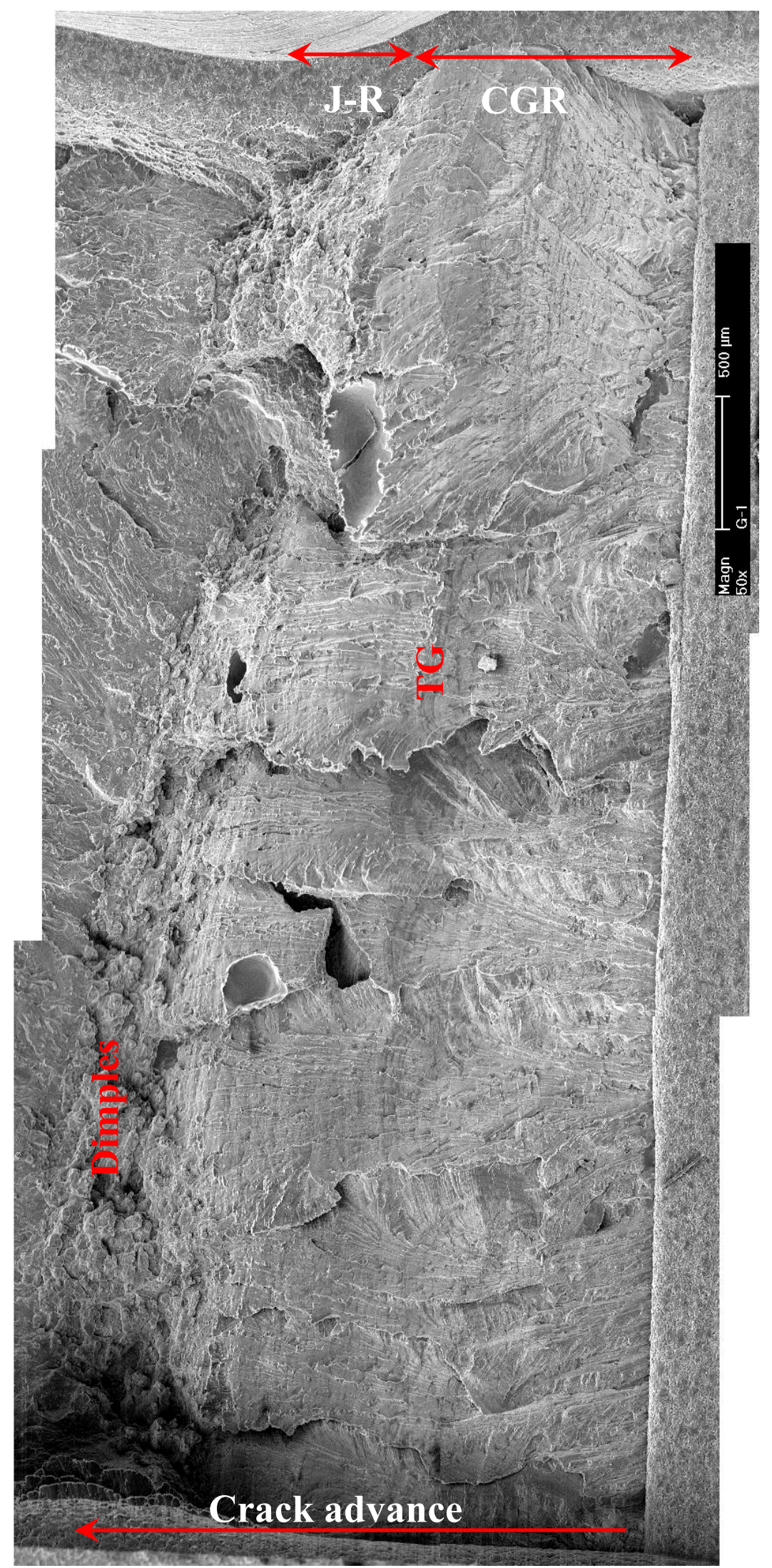

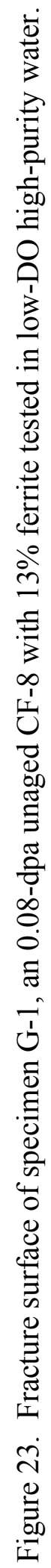




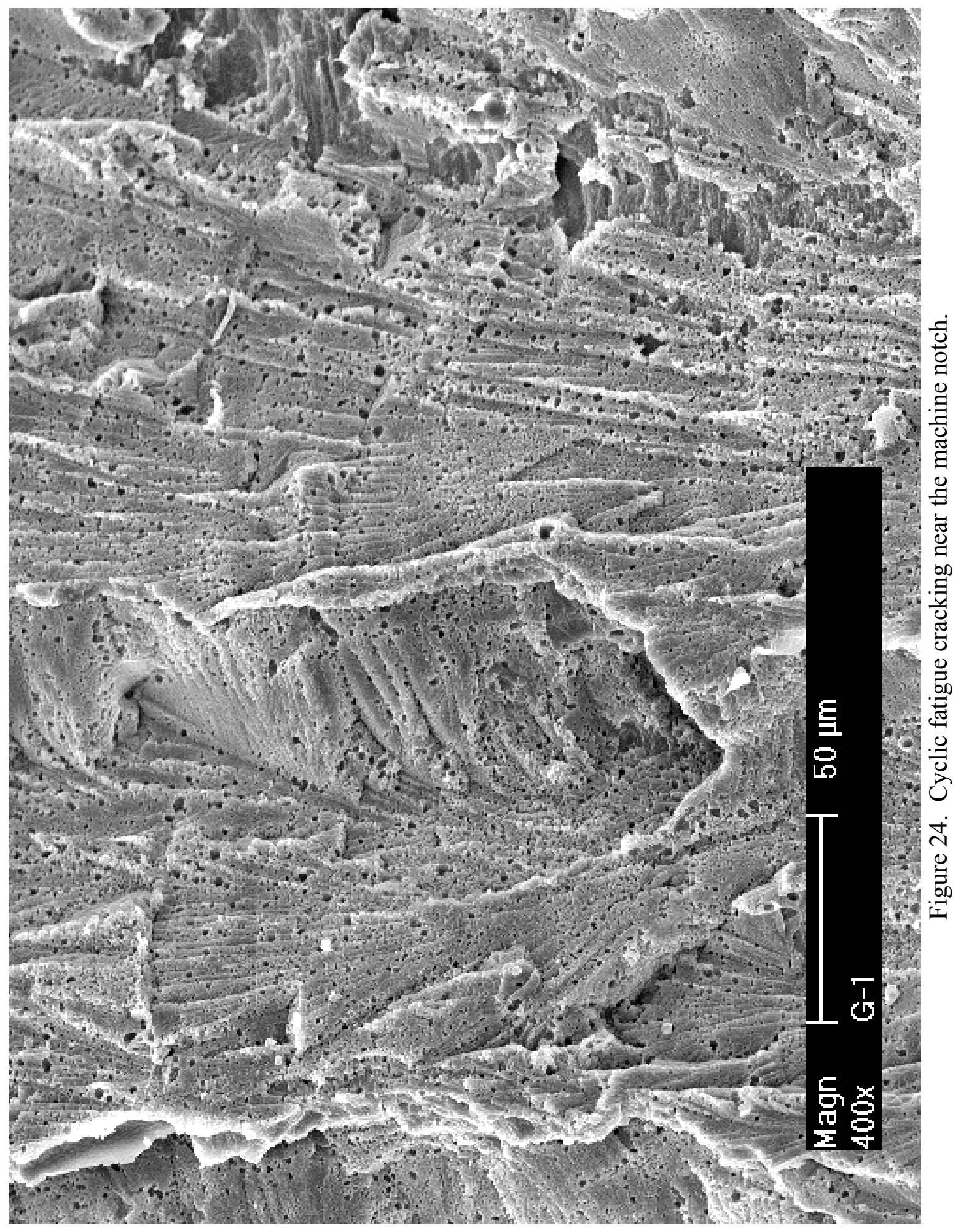




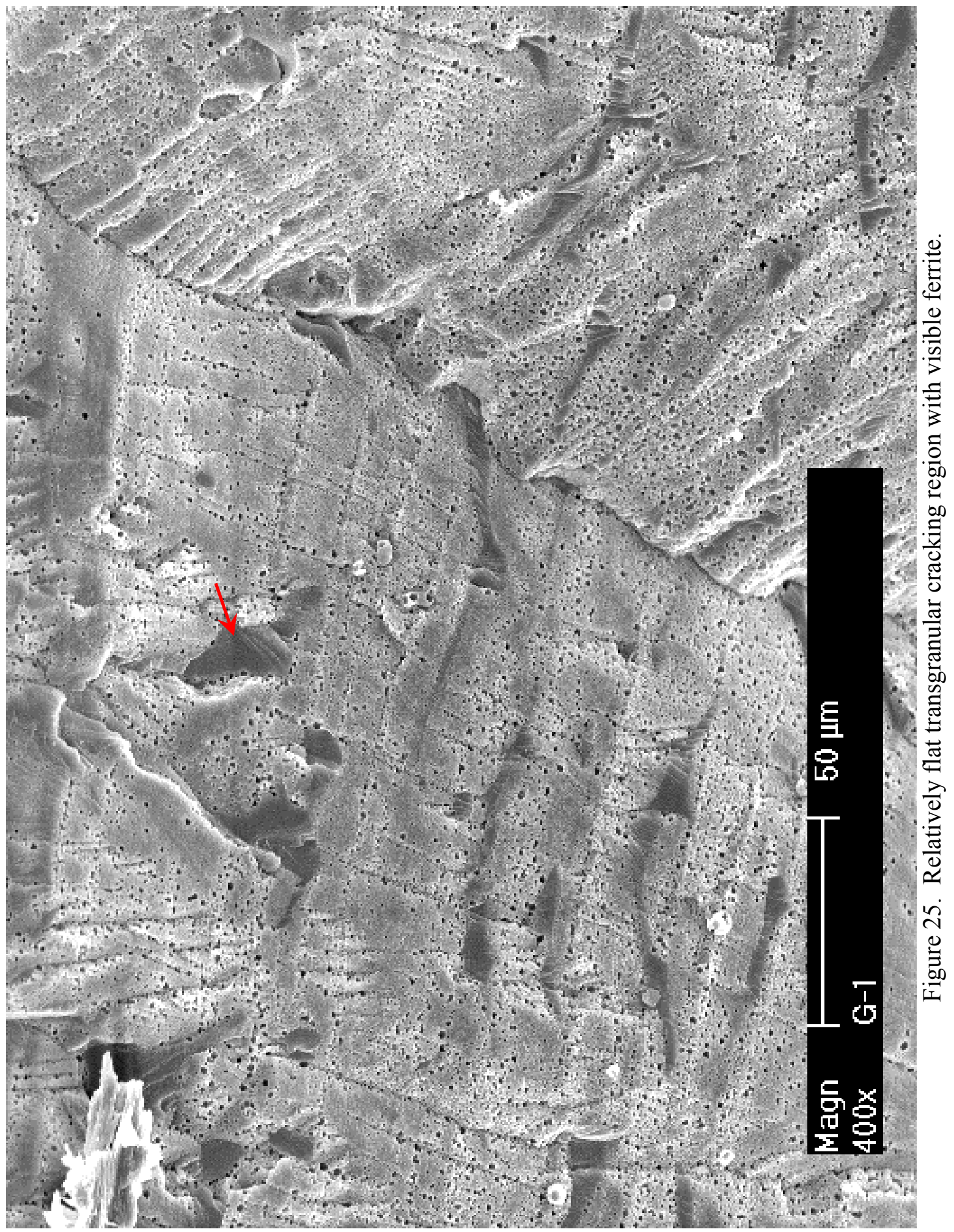




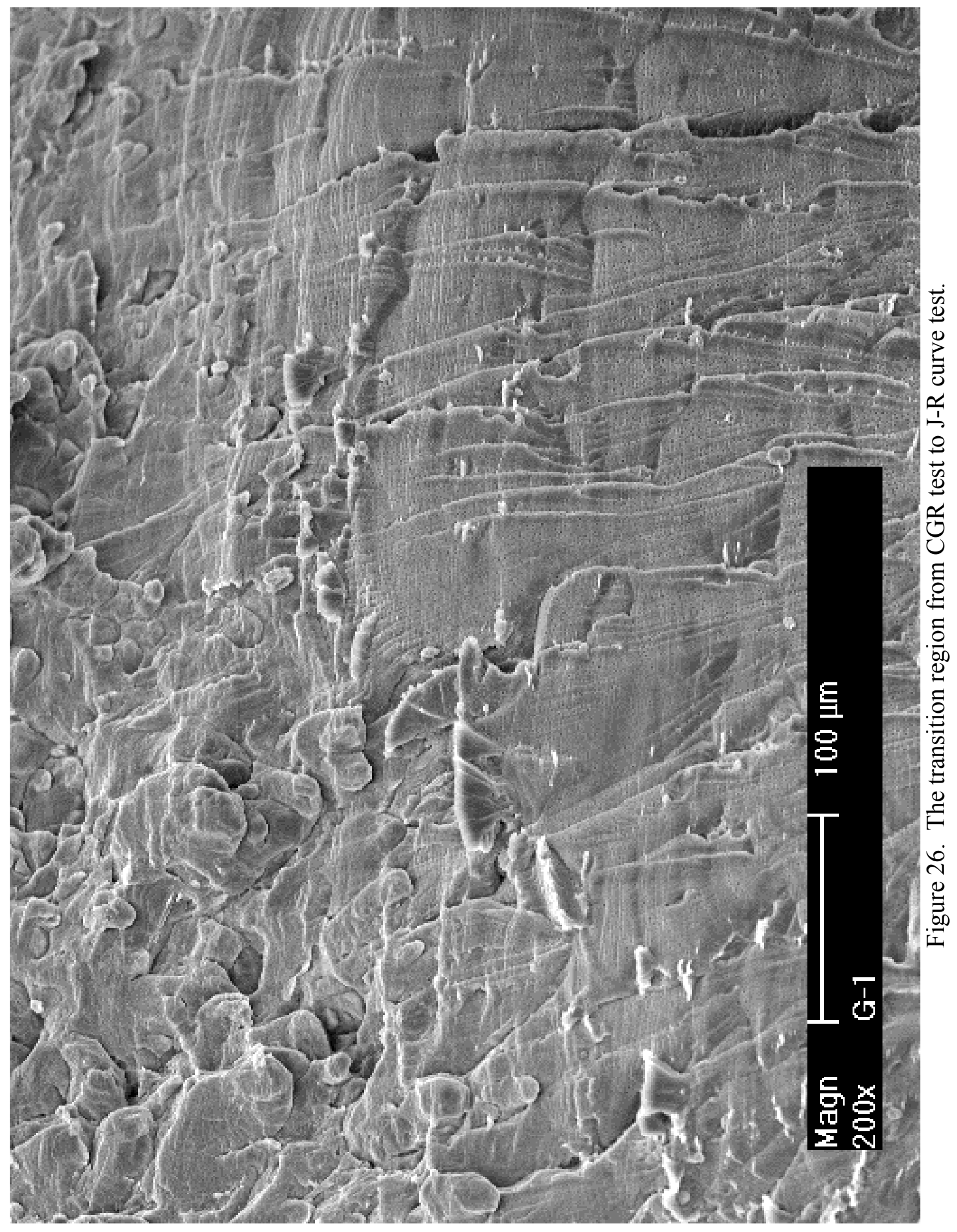




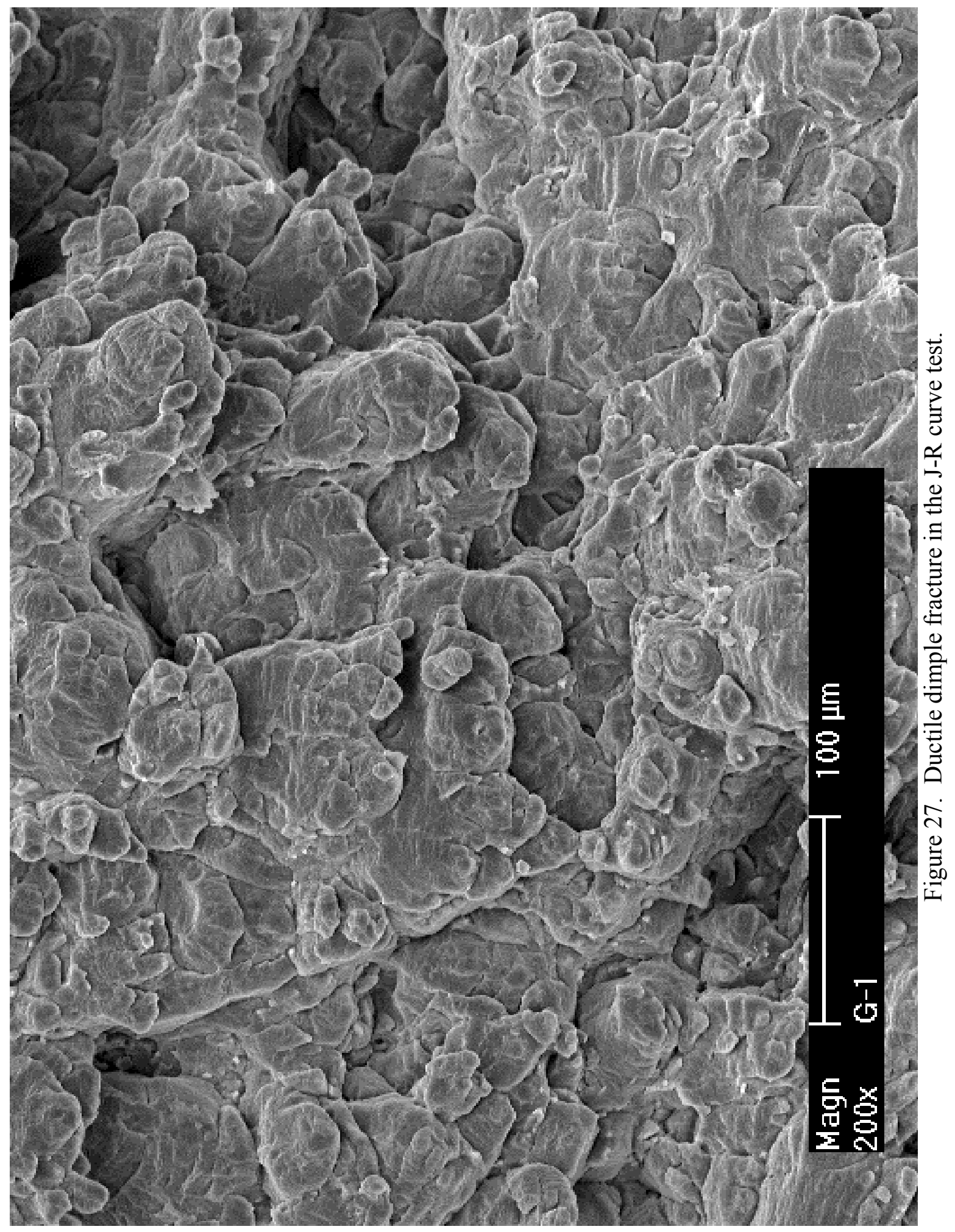




\subsubsection{Aged Specimen, $\mathrm{H}-1$}

Crack growth rate test

Specimen H-1 was an aged CF-8 with $13 \%$ ferrite irradiated to 0.08 dpa. The sample was aged at $400^{\circ} \mathrm{C}$ for $5,900 \mathrm{hr}$ prior to the irradiation. The test was conducted in low-DO high-purity water at $320^{\circ} \mathrm{C}$. The test conditions and results are summarized in Table 6 , and a crack-length history plot is shown in Figure 28.

Table 6. Crack growth rates of specimen H-1 (aged CF-8 with 13\% ferrite) in low-DO highpurity water.

\begin{tabular}{|c|c|c|c|c|c|c|c|c|c|c|c|}
\hline $\begin{array}{l}\text { Test } \\
\text { Period }\end{array}$ & $\begin{array}{l}\text { Test } \\
\text { Time, } \\
\mathrm{h} \\
\end{array}$ & $\begin{array}{l}\text { Test } \\
\text { Temp., } \\
{ }^{\circ} \mathrm{C} \\
\end{array}$ & $\begin{array}{l}\text { Load } \\
\text { Ratio }\end{array}$ & $\begin{array}{l}\text { Rise } \\
\text { Time, } \\
\mathrm{s} \\
\end{array}$ & $\begin{array}{l}\text { Return } \\
\text { Time, } \\
\mathrm{s} \\
\end{array}$ & $\begin{array}{l}\text { Hold } \\
\text { Time, } \\
\text { s }\end{array}$ & $\begin{array}{l}\text { Kmax, } \\
\mathrm{MPa} \mathrm{m}^{1 / 2}\end{array}$ & $\begin{array}{l}\Delta \mathrm{K}, \\
\mathrm{MPa} \mathrm{m}^{1 / 2}\end{array}$ & $\begin{array}{l}\text { CGR in } \\
\text { Env., } \\
\mathrm{m} / \mathrm{s}\end{array}$ & $\begin{array}{l}\text { CGR } \\
\text { in Air, } \\
\mathrm{m} / \mathrm{s} \\
\end{array}$ & $\begin{array}{l}\text { Crack } \\
\text { Length, } \\
\mathrm{mm}\end{array}$ \\
\hline Start & 0.2 & & & & & & & & & & 5.857 \\
\hline$a^{a}$ & 2.9 & 318 & 0.20 & 0.43 & 0.43 & 0.07 & 14.5 & 11.6 & $5.21 \mathrm{E}-08$ & $3.75 \mathrm{E}-08$ & 6.029 \\
\hline $\mathrm{b}$ & 7.0 & 318 & 0.30 & 0.84 & 0.84 & 0.16 & 14.6 & 10.2 & $1.68 \mathrm{E}-08$ & $1.43 \mathrm{E}-08$ & 6.144 \\
\hline $\mathrm{c}$ & 21.1 & 318 & 0.40 & 4.06 & 4.06 & 0.94 & 14.3 & 8.7 & $3.20 \mathrm{E}-09$ & $1.91 \mathrm{E}-09$ & 6.210 \\
\hline $\mathrm{d}$ & 29.6 & 317 & 0.47 & 7.89 & 1.58 & 2.11 & 14.1 & 7.5 & $1.16 \mathrm{E}-10$ & $6.69 \mathrm{E}-10$ & 6.213 \\
\hline $\mathrm{e}$ & 44.9 & 317 & 0.48 & 3.92 & 1.57 & 1.08 & 14.1 & 7.4 & $1.50 \mathrm{E}-10$ & $1.26 \mathrm{E}-09$ & 6.220 \\
\hline $\mathrm{f}^{\mathrm{a}}$ & 57.2 & 317 & 0.45 & 3.99 & 3.99 & 1.01 & 14.7 & 8.0 & 4.44E-09 & $1.62 \mathrm{E}-09$ & 6.272 \\
\hline $\mathrm{g}$ & 92.8 & 318 & 0.47 & 7.89 & 1.58 & 2.11 & 14.4 & 7.7 & $1.08 \mathrm{E}-10$ & 7.14E-10 & 6.289 \\
\hline $\mathrm{h}^{\mathrm{a}}$ & 129.2 & 318 & 0.48 & 11.8 & 1.58 & 3.15 & 15.4 & 8.0 & $2.91 \mathrm{E}-09$ & $5.55 \mathrm{E}-10$ & 6.433 \\
\hline i & 149.6 & 318 & 0.49 & 23.5 & 3.92 & 6.48 & 15.5 & 7.9 & $1.34 \mathrm{E}-09$ & $2.68 \mathrm{E}-10$ & 6.501 \\
\hline $\mathrm{j}$ & 174 & 318 & 0.50 & 46.8 & 9.36 & 13.2 & 15.6 & 7.8 & $8.68 \mathrm{E}-10$ & $1.32 \mathrm{E}-10$ & 6.554 \\
\hline $\mathrm{k}$ & 199.1 & 318 & 0.50 & 93.1 & 9.31 & 26.9 & 15.7 & 7.8 & $9.60 \mathrm{E}-10$ & $6.56 \mathrm{E}-11$ & 6.616 \\
\hline 1 & 238.9 & 318 & 0.49 & 195.0 & 9.36 & 55.0 & 15.6 & 8.0 & $3.26 \mathrm{E}-10$ & $3.43 \mathrm{E}-11$ & 6.652 \\
\hline $\mathrm{m}$ & 268.7 & 320 & 0.50 & 387.8 & 9.31 & 112.2 & 15.8 & 7.9 & $4.61 \mathrm{E}-10$ & $1.68 \mathrm{E}-11$ & 6.692 \\
\hline $\mathrm{n}$ & 333.1 & 320 & 0.49 & 777.9 & 9.34 & 222.1 & 16.0 & 8.2 & $2.34 \mathrm{E}-10$ & $9.05 \mathrm{E}-12$ & 6.735 \\
\hline $1 \mathrm{a}$ & 486.8 & 320 & 0.50 & 12 & 12 & 7200 & 15.8 & 7.9 & $2.05 \mathrm{E}-11$ & $8.94 \mathrm{E}-13$ & 6.748 \\
\hline $1 b$ & 670 & 321 & 1.0 & - & - & - & 15.6 & - & $7.81 \mathrm{E}-12$ & - & 6.753 \\
\hline
\end{tabular}

a The CGR value was obtained from the later part of the test period.

The test was started with cyclic loading of $1 \mathrm{~Hz}$ at a load ratio of $\sim 0.2$ and a $\mathrm{K}_{\max }$ of $\sim 14.5 \mathrm{MPa}$ $\mathrm{m}^{1 / 2}$. Like the unaged sample (specimen G-1), a CGR similar to that of fatigue growth rate in air was quickly established. After about $80 \mu \mathrm{m}$ crack extension, the load ratio was increased to $\sim 0.3$ and then to $\sim 0.4$ in the next two test periods. The measured CGRs decreased accordingly along the line of the fatigue growth rate in air. After the load ratio was increased to $\sim 0.5$, the CGR dropped significantly below the expected fatigue growth rate in air. The crack growth was stalled and did not respond to a reduction in rise time in the following test period.

The crack was re-activated with a slightly higher $\mathrm{K}_{\max }$ at a load ratio of $\sim 0.45$ and $0.1 \mathrm{~Hz}$ frequency. After the loading was changed to a slow-fast sawtooth waveform, the crack stalled again. The $\mathrm{K}_{\max }$ was increased again to $\sim 15.5 \mathrm{MPa} \mathrm{m}^{1 / 2}$. After an initial slow growth period, the observed CGR started to increase. Finally, environmentally enhanced cracking started to appear and was stabilized with increasing rise time in the following test periods while the load ratio was maintained at around $\sim 0.5$. The cyclic CGR results are shown in Figure 29 along with a reference corrosion-fatigue curve for SSs. Similar to that observed in the unaged CF-8, this heat showed a significantly worse corrosion-fatigue behavior than that of CF-3. 
(a)

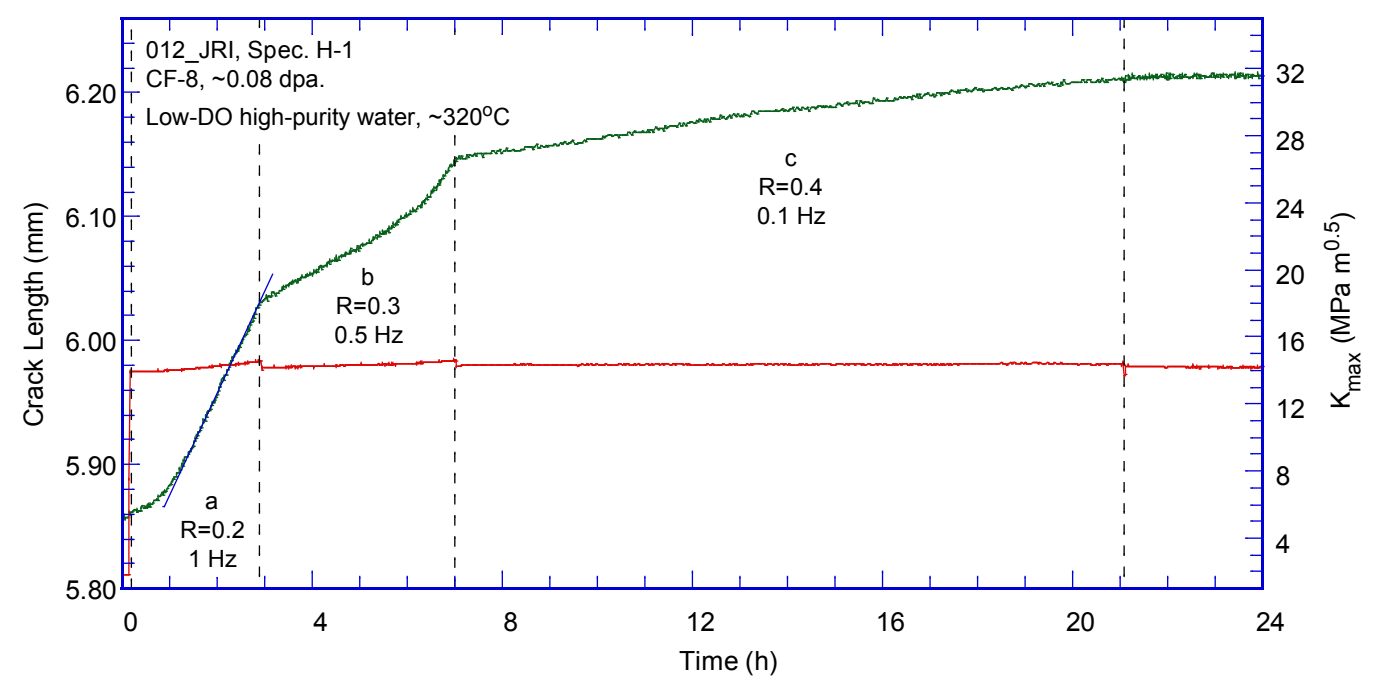

(b)

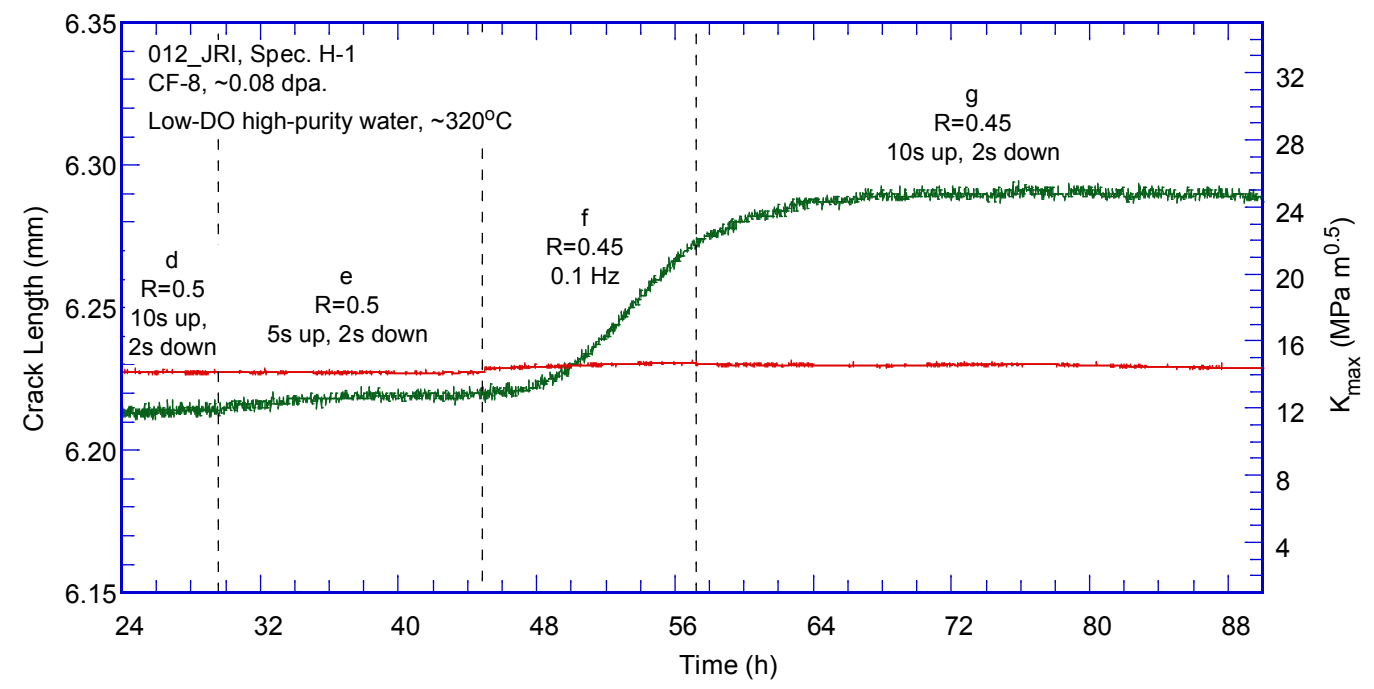

(c)

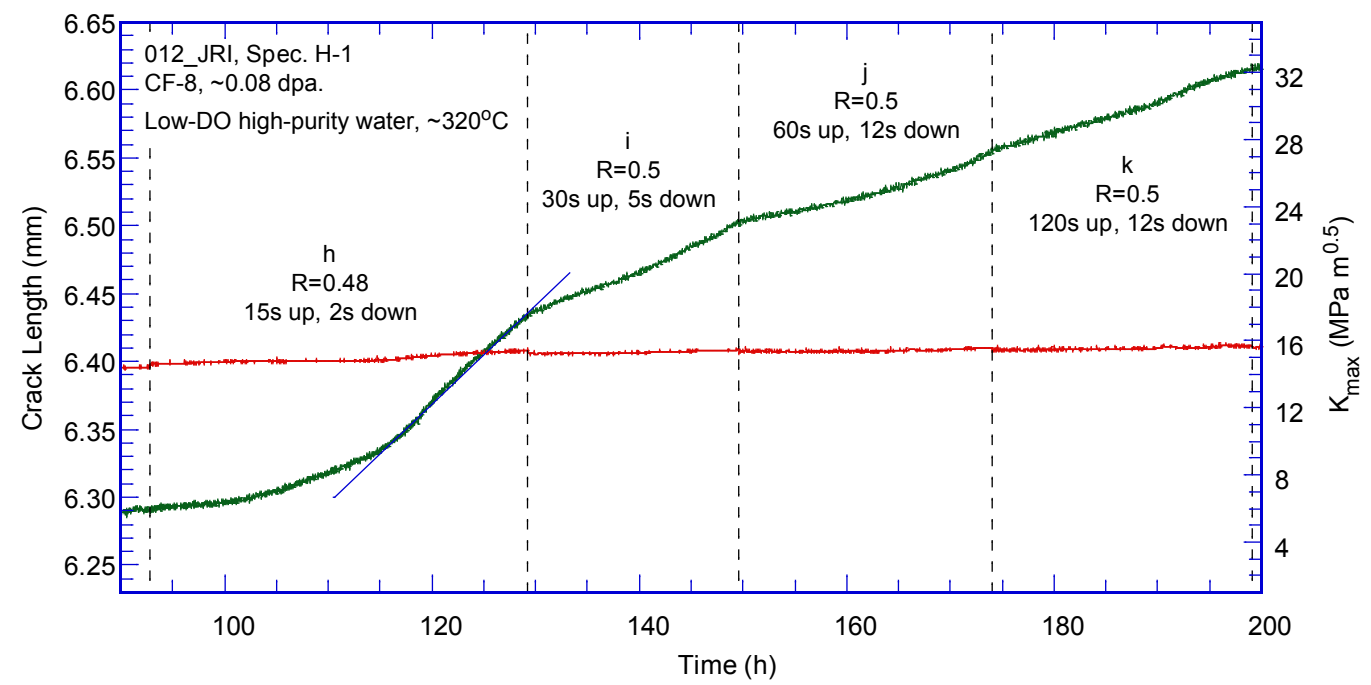

Figure 28. Crack-length-vs.-time plot of specimen H-1 (aged 0.08-dpa CF-8 with 13\% ferrite): test periods (a) a-c, (b) d-g, (c) 1-n, (d) h-k, and (e) 1a-1b. 
(d)

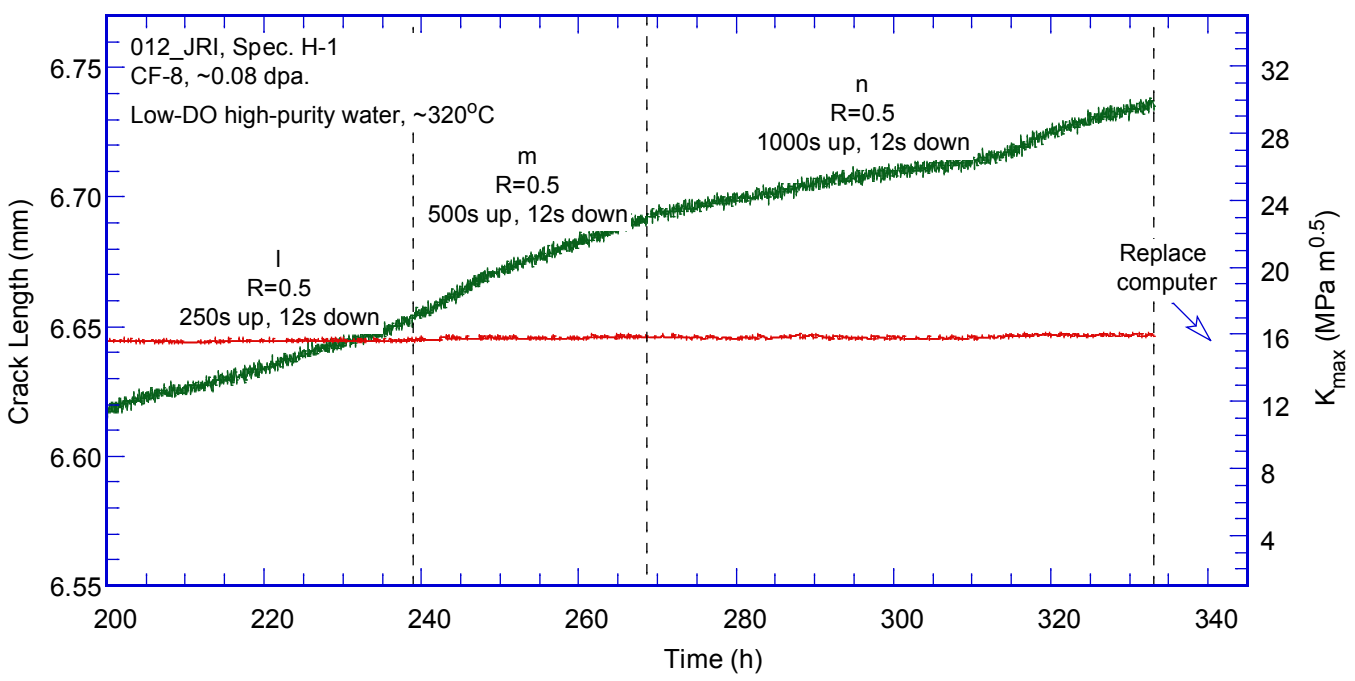

(e)

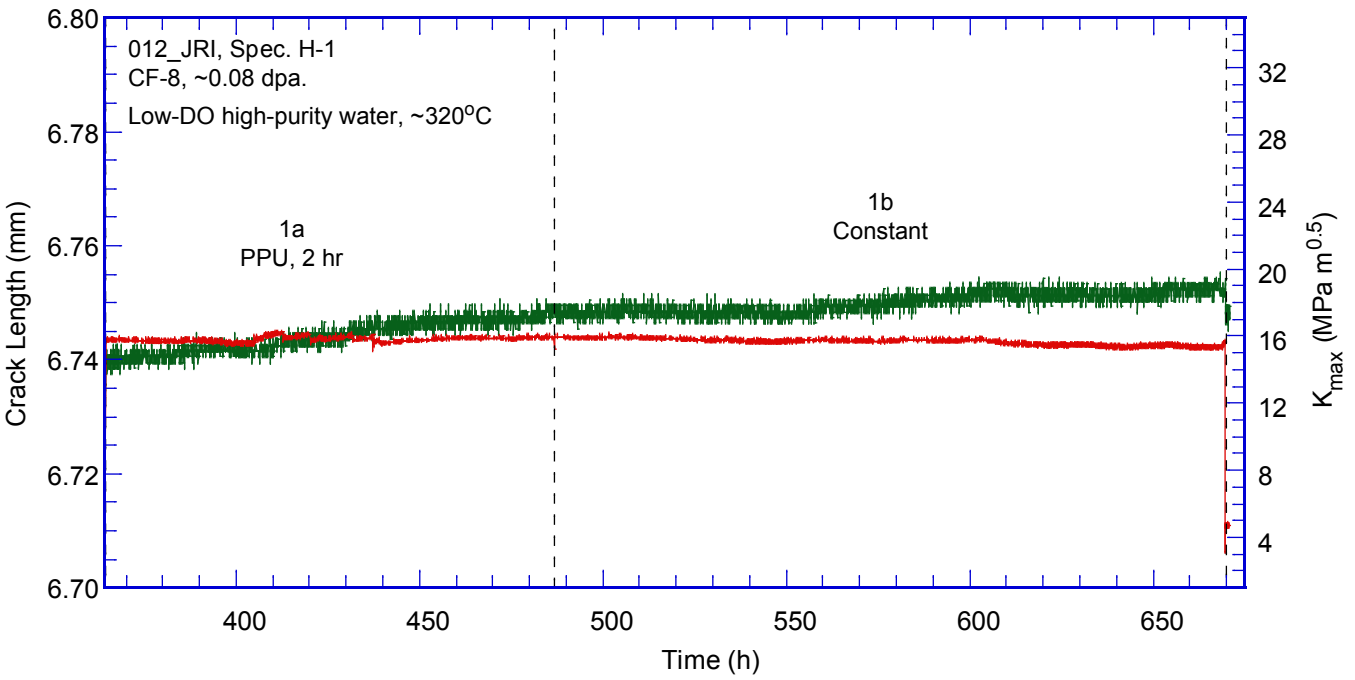

Figure 28. (Cont'd)

After the environment enhancement was stabilized, the test was set to a constant-load with PPU every $2 \mathrm{hr}$. A SCC CGR of $2.0 \mathrm{E}-11 \mathrm{~m} / \mathrm{s}$ was measured over $13 \mu \mathrm{m}$ crack extension. After the PPU was removed, the observed CGR decreased to about $7.8 \mathrm{E}-12 \mathrm{~m} / \mathrm{s}$ over $5 \mu \mathrm{m}$ crack extension. The CGR test was then terminated to prepare for a J-R curve test.

\section{$\underline{\text { Fracture toughness JR curve test }}$}

A fracture toughness J-R curve test was performed on the sample in the test environment after the CGR test. The test was carried out with a constant strain rate of $0.43 \mu \mathrm{m} / \mathrm{s}$, and the load and load-line displacement was recorded. The obtained J-R data are shown in Figure 30. A power law correlation of $J=406 \Delta \mathrm{a}^{0.60}$ was fitted to the $J-R$ data, and the $J$ value at the $0.2-\mathrm{mm}$ offset line was $\sim 205 \mathrm{~kJ} / \mathrm{m}^{2}$. Due to the small size of the specimen and high ductility, this J-R curve test cannot be validated. Data points outside the measurement capacity for this sample size were used for the curve fitting. 


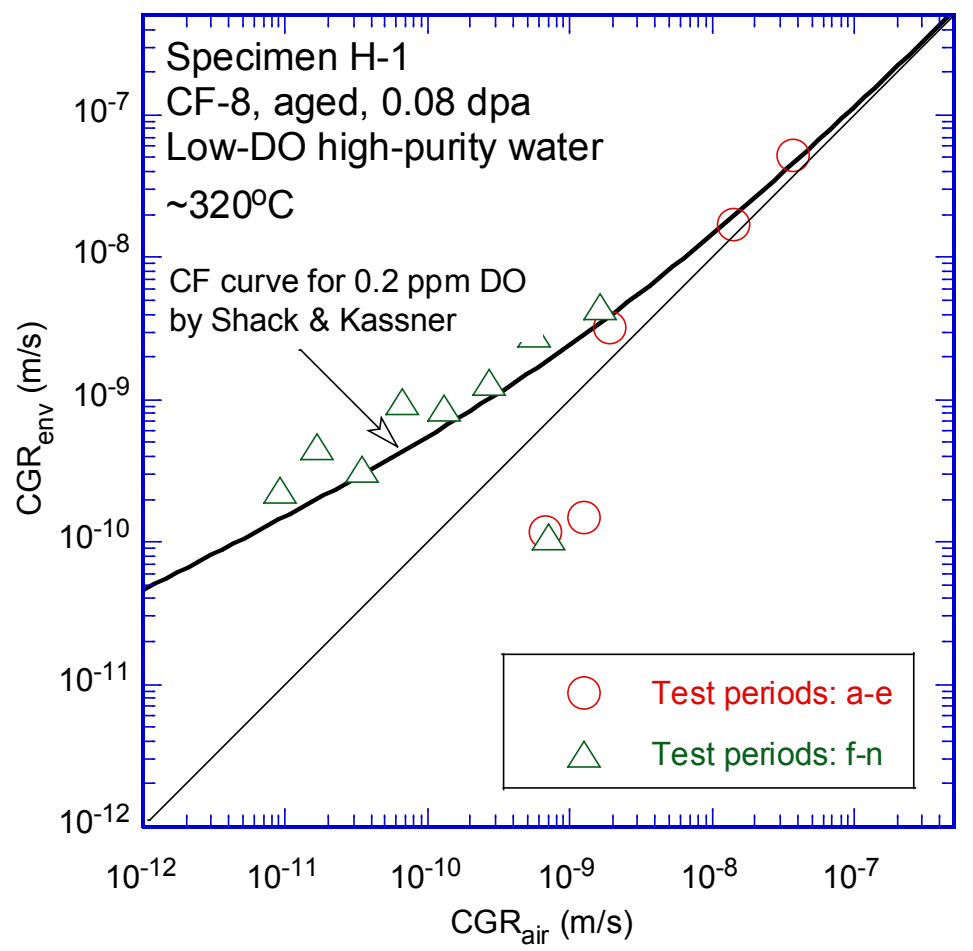

Figure 29. Cyclic CGRs of Specimen H-1, an aged 0.08-dpa CF-8 with 13\% ferrite tested in low-DO high-purity water.

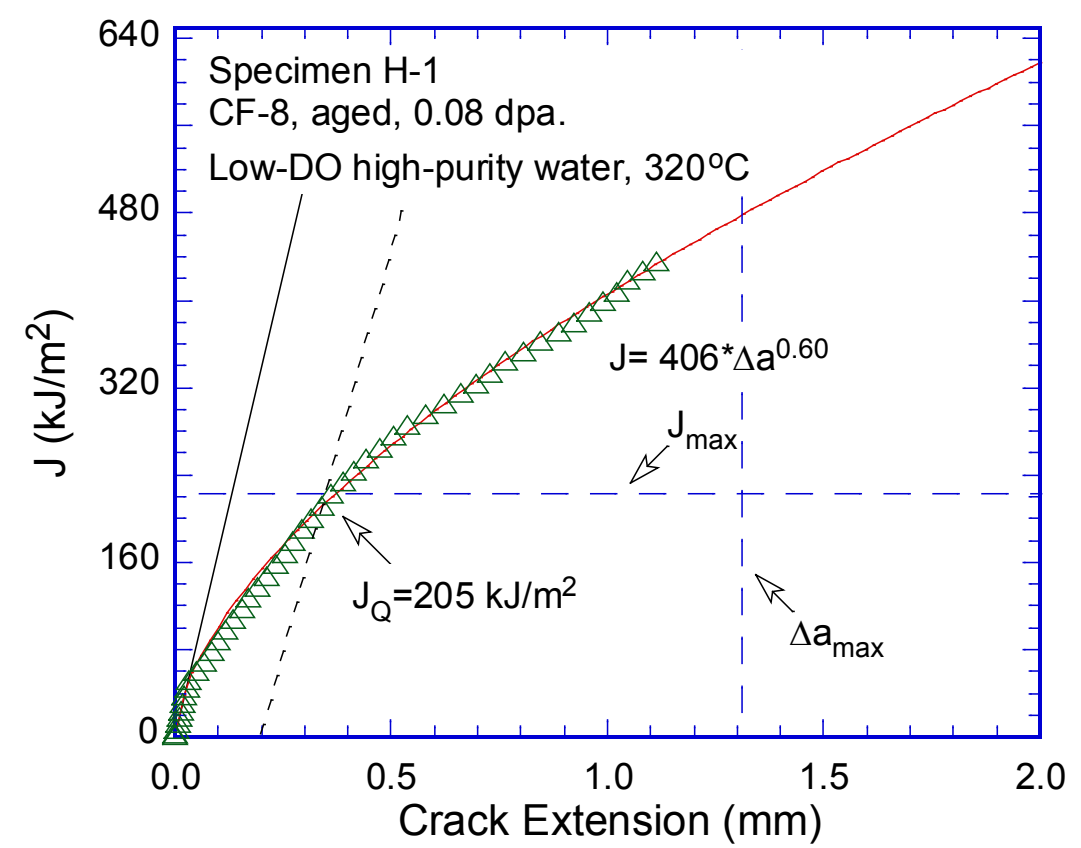

Figure 30. J-R curve of Specimen H-1, an aged 0.08-dpa CF-8 with $13 \%$ ferrite tested in lowDO high-purity water. 


\section{Fractographic examination}

After the J-R curve test, the sample was broken with cyclic loading in air at room temperature. Replicas of the fracture surface were examined with a SEM. Figure 31 shows a global view of the entire fracture surface of specimen $\mathrm{H}-1$. The CGR and J-R test regions can be easily identified at this magnification. The CGR test region is relatively flat, while the J-R curve test region is much rougher. The CGR front is pretty straight, indicating a good loading condition during the test. The final crack front resulting from J-R test is curved, suggesting an inadequate constraint at the crack tip.

An enlarged view along the sample centerline can be seen in Figure 32. While the CGR region shows a TG morphology, the failure mode for the J-R curve test is ductile dimple. Heavy deformation ledges resulting from fatigue loading can be seen near the machined notch as shown in Figure 33. The fracture surface of the later stage of the CGR test becomes smoother (as shown in Figure 34), indicating an increasing trend of environmental contribution as the test progressing. Delta ferrites are visible beyond the initial fatigue region on the fracture surface. Figure 35 shows the transition region from the CGR to J-R curve tests. A clear contrast can be seen between the TG fracture in the CGR test and the ductile dimple morphology in the J-R curve test. The ductile dimple fracture in the J-R curve test can be seen in Figure 36. 


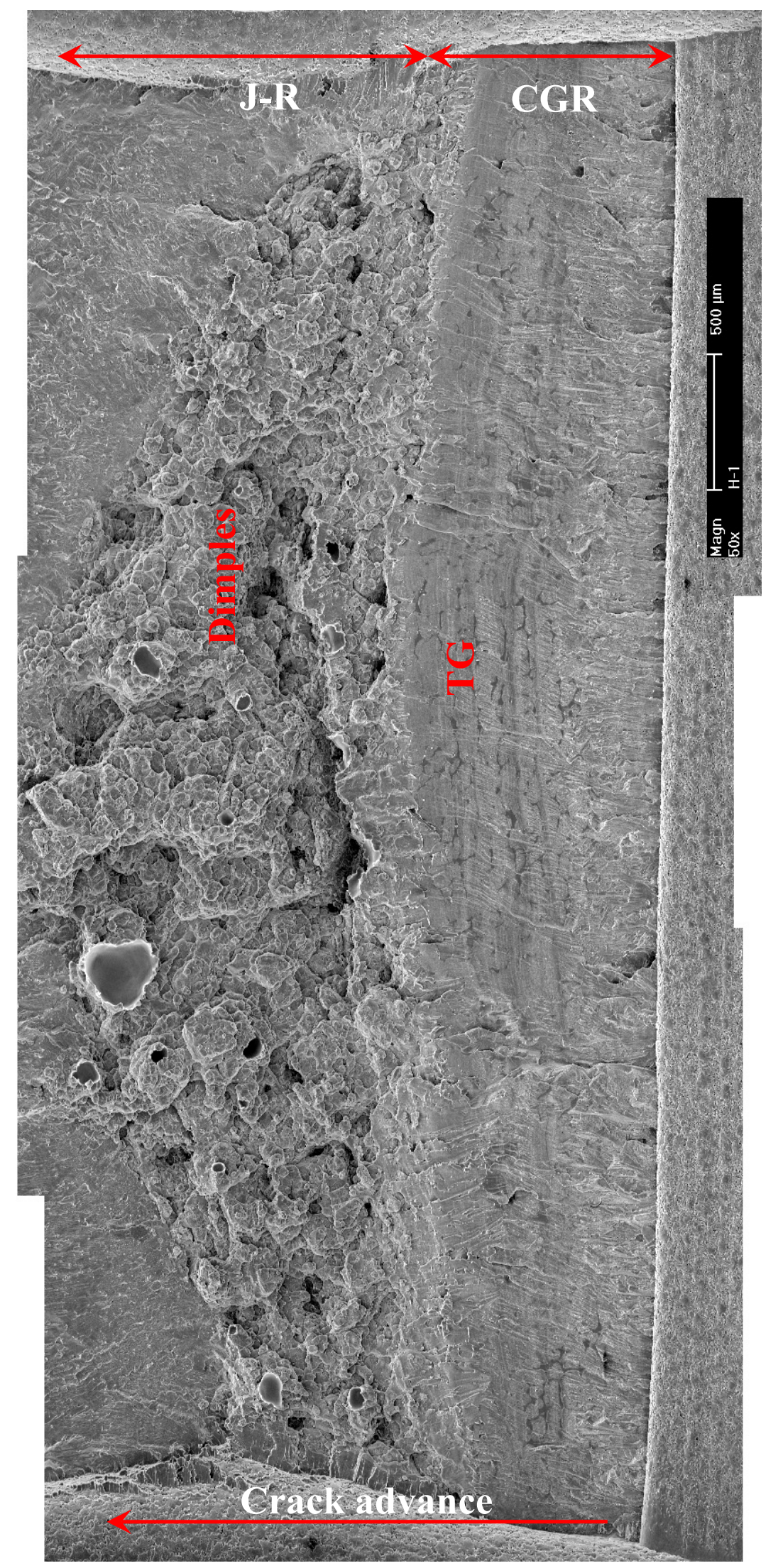

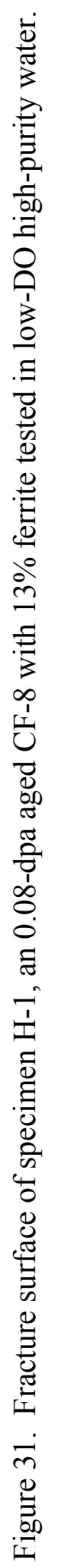




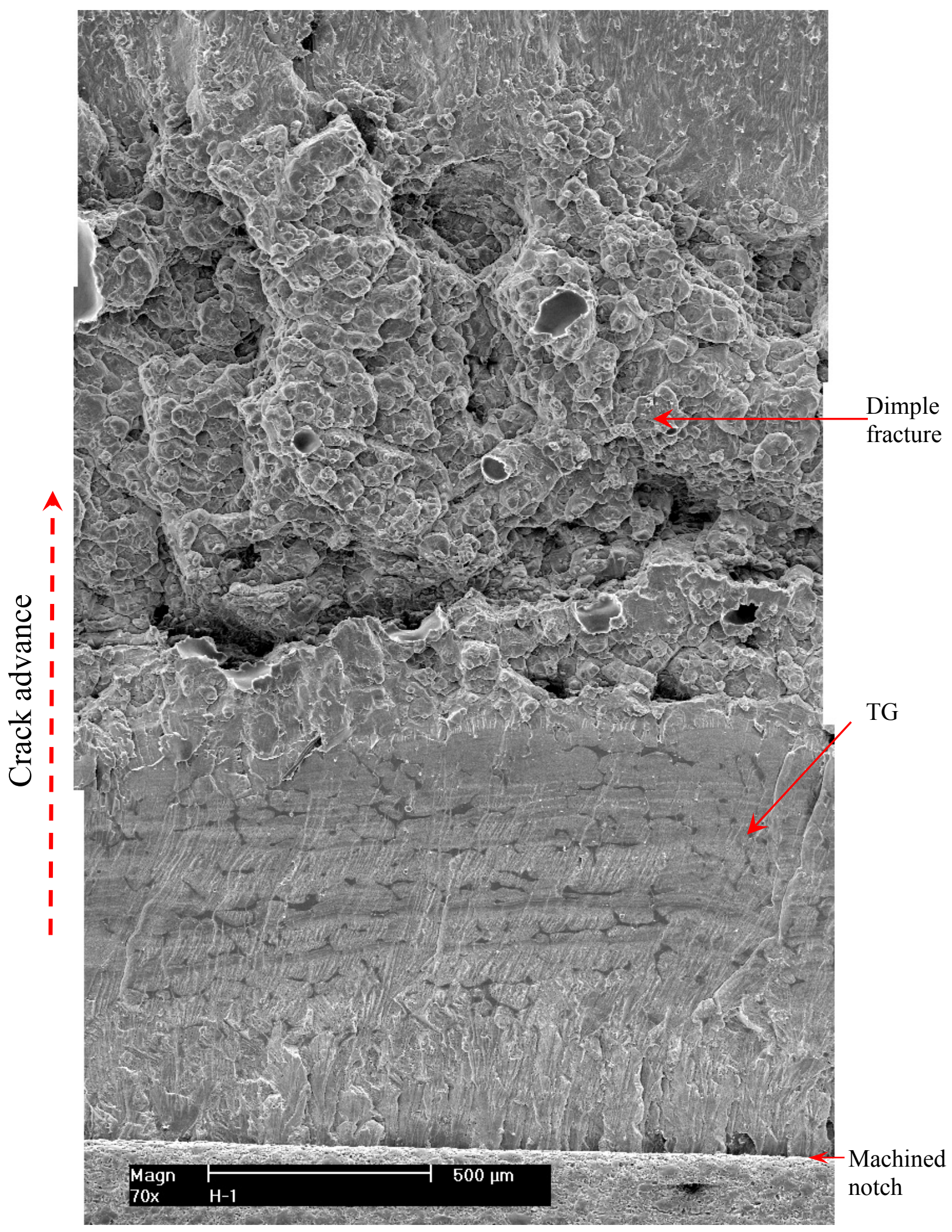

Figure 32. Fracture surface of specimen H-1 along the sample central line. 


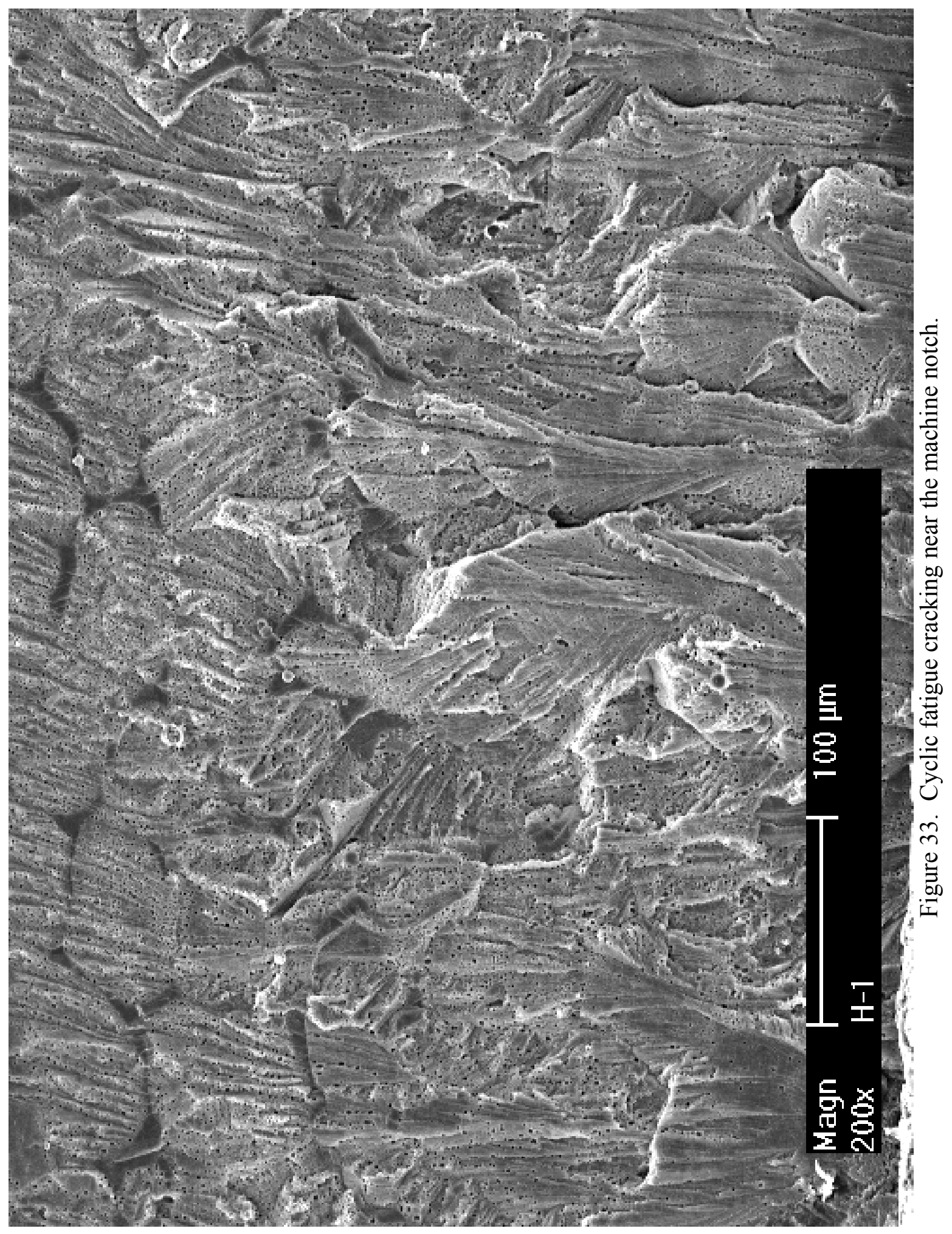




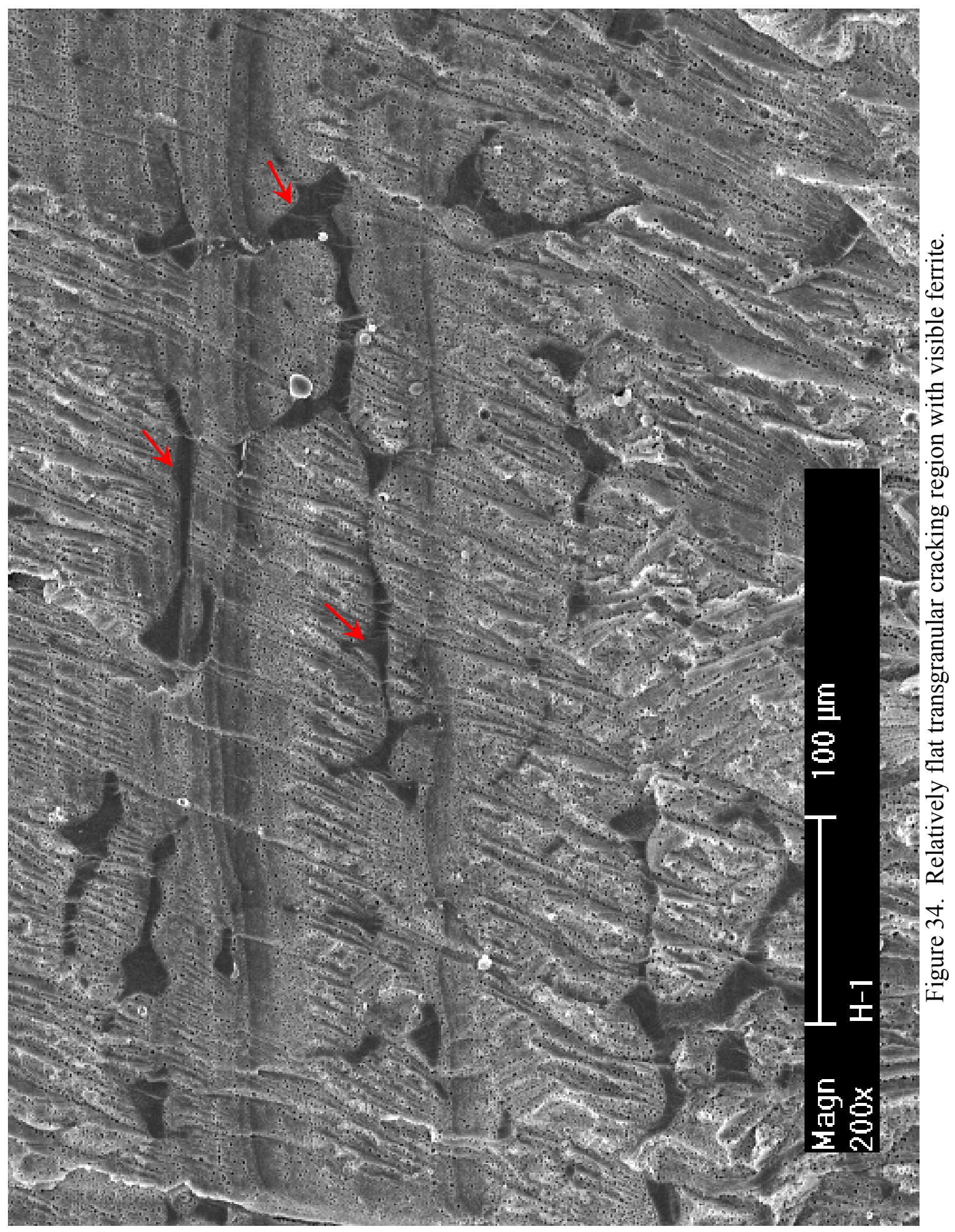




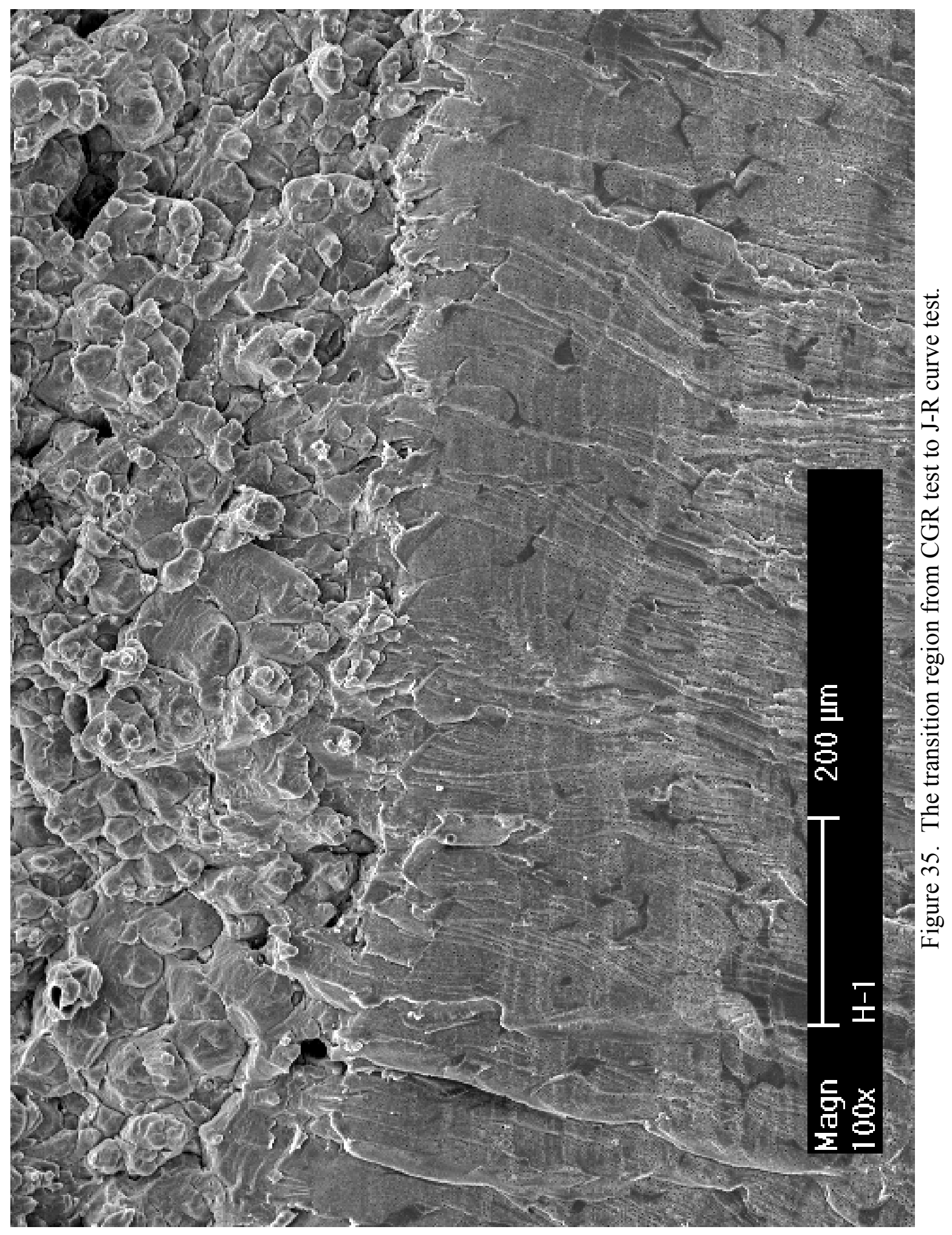




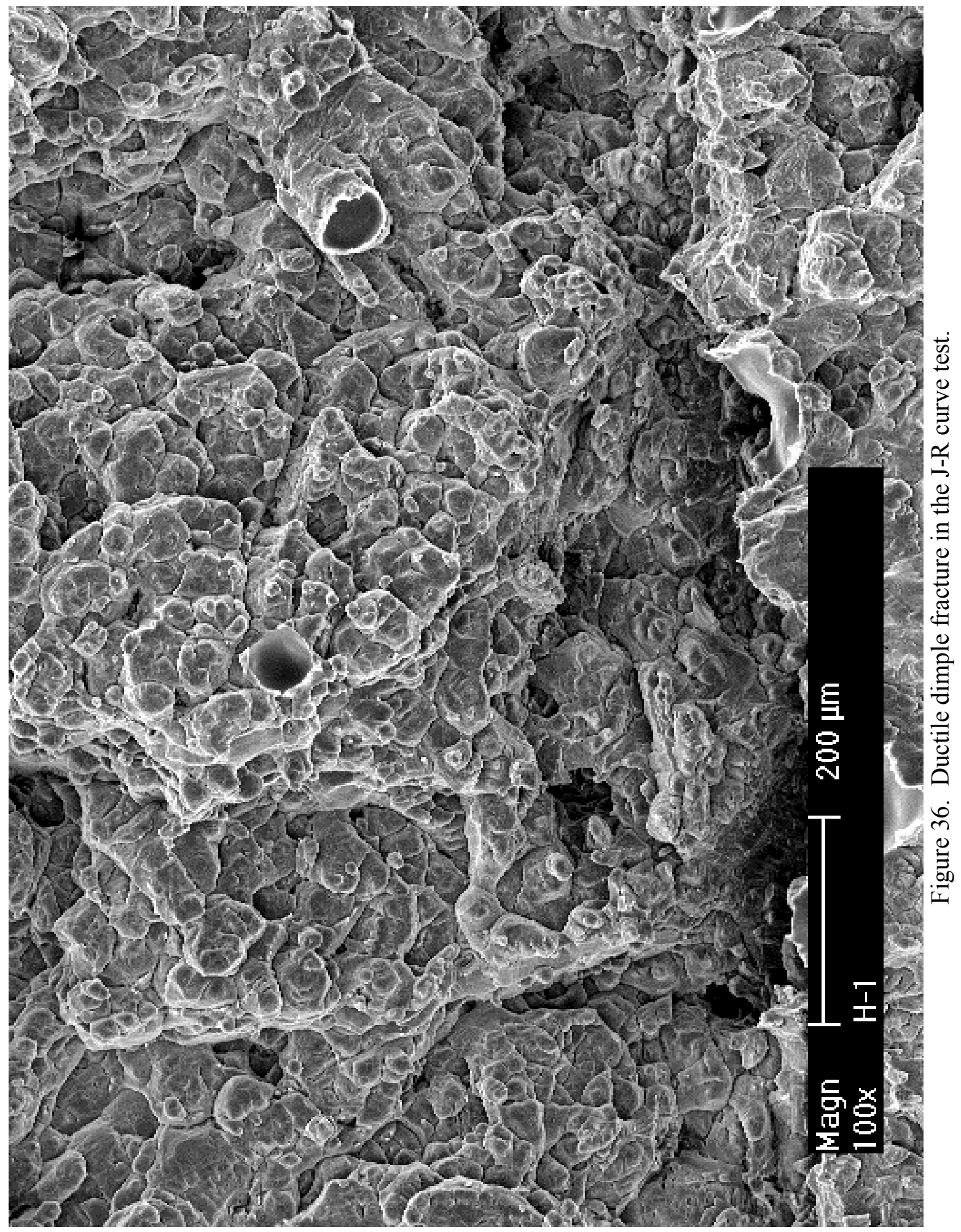




\section{DISCUSSION}

\subsection{Crack Growth Behavior of the Low-Ferrite CASS Specimens}

In the current study, the measured cyclic and SCC CGRs of the CASS specimens were relatively low owning to the beneficial effect of delta ferrite and the low-corrosion-potentials of the test environments. Environmentally enhanced cracking was difficult to establish and stabilize among these samples. Stalled crack growth was often observed during the tests, and significant data scatter could be seen with the test results. To compare the cracking behavior of different samples, cyclic CGR data were analyzed with a superposition model developed by Shack and Kassner. ${ }^{18}$ By assuming that the environmental contribution to cyclic CGR is related to fatigue crack growth rate in air, Shack and Kassner determined a corrosion-fatigue curve of unirradiated wrought and CASS SSs in high-purity water containing $0.2 \mathrm{ppm}$ and $8 \mathrm{ppm}$ DO.

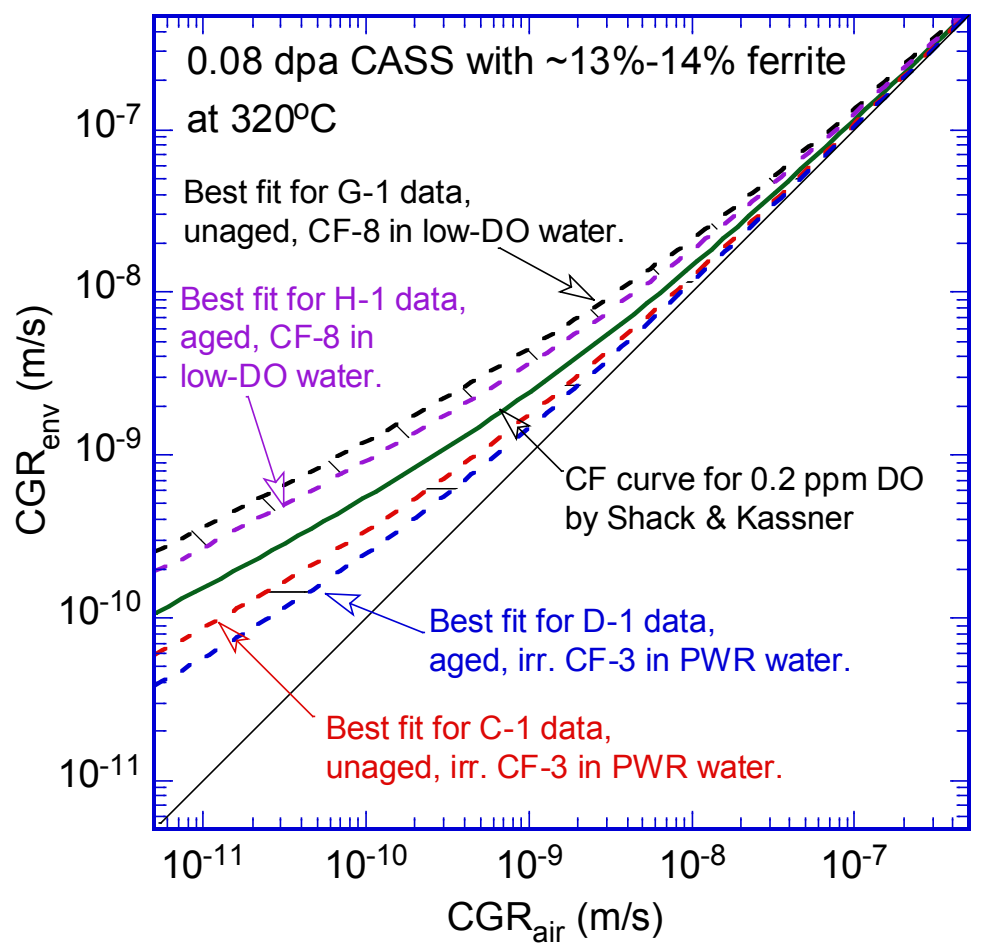

Figure 37. Best fit curves for cyclic CGR data with a superposition model.

Using the corrosion-fatigue curve of $0.2 \mathrm{ppm} \mathrm{DO}$ as a reference, the best fit curves for each data set of the CASS specimens are compared in Figure 37. Note that only the test segments with significant crack extensions were selected for the data fitting. The fitting results clearly show that the corrosion-fatigue response of CF-3 is better than that of CF-8. At 0.08 dpa, no elevated cracking susceptibility can be seen for CF-3, while much higher CGRs were observed for CF-8. The effect of ferrite content on the cyclic cracking response is insignificant for CF-3. For CF-8, the best fit curves of the low-ferrite heat are above the reference line of $0.2 \mathrm{ppm}$ DO. This is different from what observed previously in the high-ferrite CF-8 whose best fitting curves are below the reference line. ${ }^{16}$ A lower ferrite content seems to worsen the corrosion-fatigue 
response of CF-8 significantly. It is not clear, however, if there is a threshold of ferrite content, below which the beneficial effect of delta ferrite may be lost in CF-8. Also, for both CF-3 and CF-8 specimens, the cyclic CGRs are higher in unaged than in aged specimens, suggesting a better corrosion-fatigue performance of the latter. This observation is consistent with that shown in the previous study on high-ferrite CASS alloys. ${ }^{16}$ However, given the large scatter in the CGR data, the observed differences between aged and unaged CASS may not be statistically significant.

Table 7 shows the SCC CGRs obtained in this study (shaded in grey) along with the previous results from the CASS alloys with $\sim 24 \%$ ferrite. ${ }^{16}$ These results are plotted in Figure 38 as a function of applied stress intensity factor. No distinguish is made between the unirradiated or irradiated specimens in the figure. The red and green symbols are for high- and low-ferrite specimens, respectively. The open and close symbols represent unaged and aged conditions, respectively. While a large scatter can be seen among the SCC CGRs, all data points are below the NUREG-0313 curve, ${ }^{19}$ indicating good SCC responses. Neutron irradiation up to 0.08 dpa does not elevate the cracking susceptibility of these CASS alloys significantly in low-corrosionpotential environments. The cracking behaviors of low- and high-ferrite specimens are very similar, and no effect of ferrite content can be seen among these tests.

Table 7. CGR test results of CASS specimens at $\sim 320^{\circ} \mathrm{C}$.

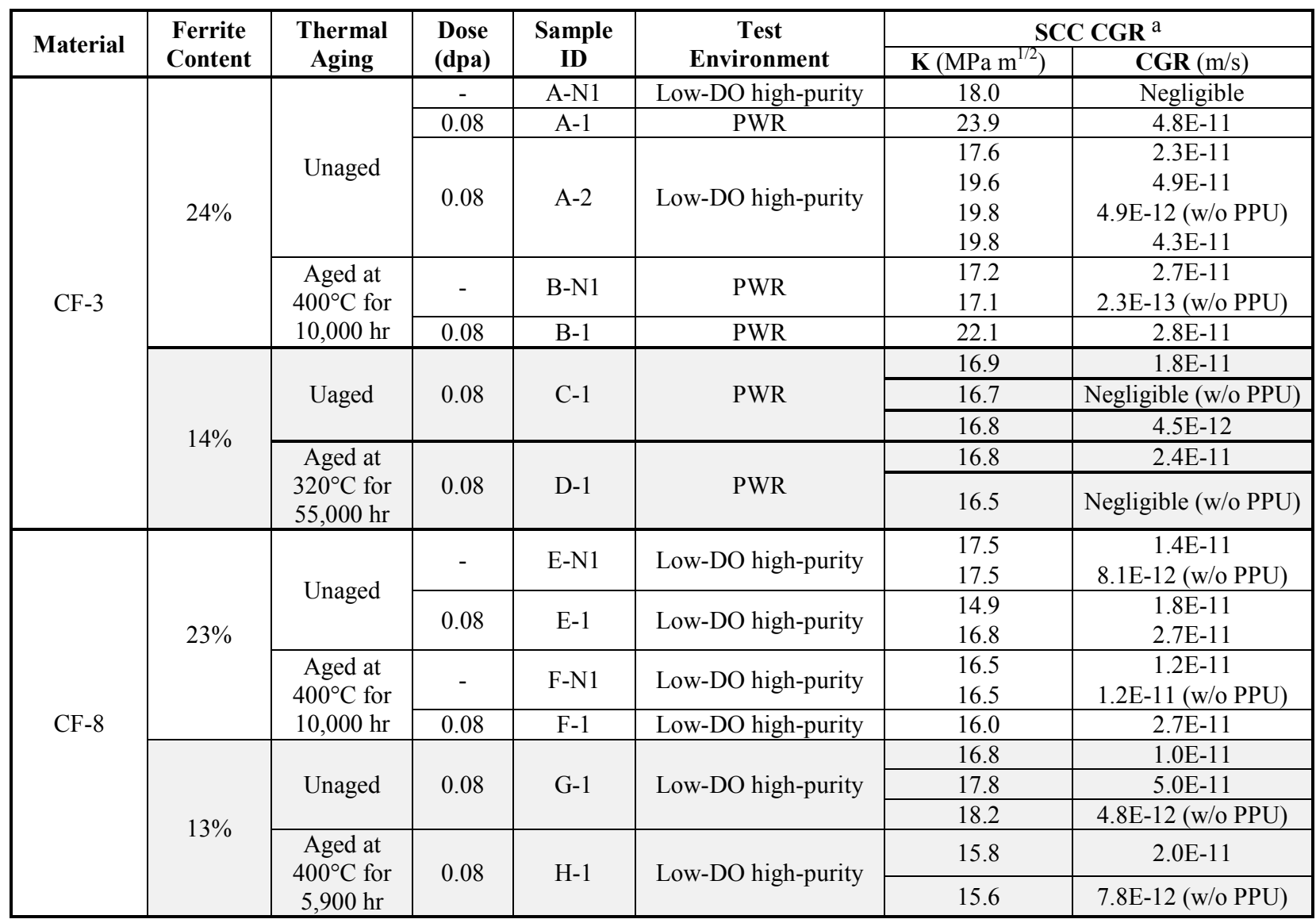

a Unless otherwise noted, SCC CGRs were measured under constant loads with PPU every 1 or 2 hours. 


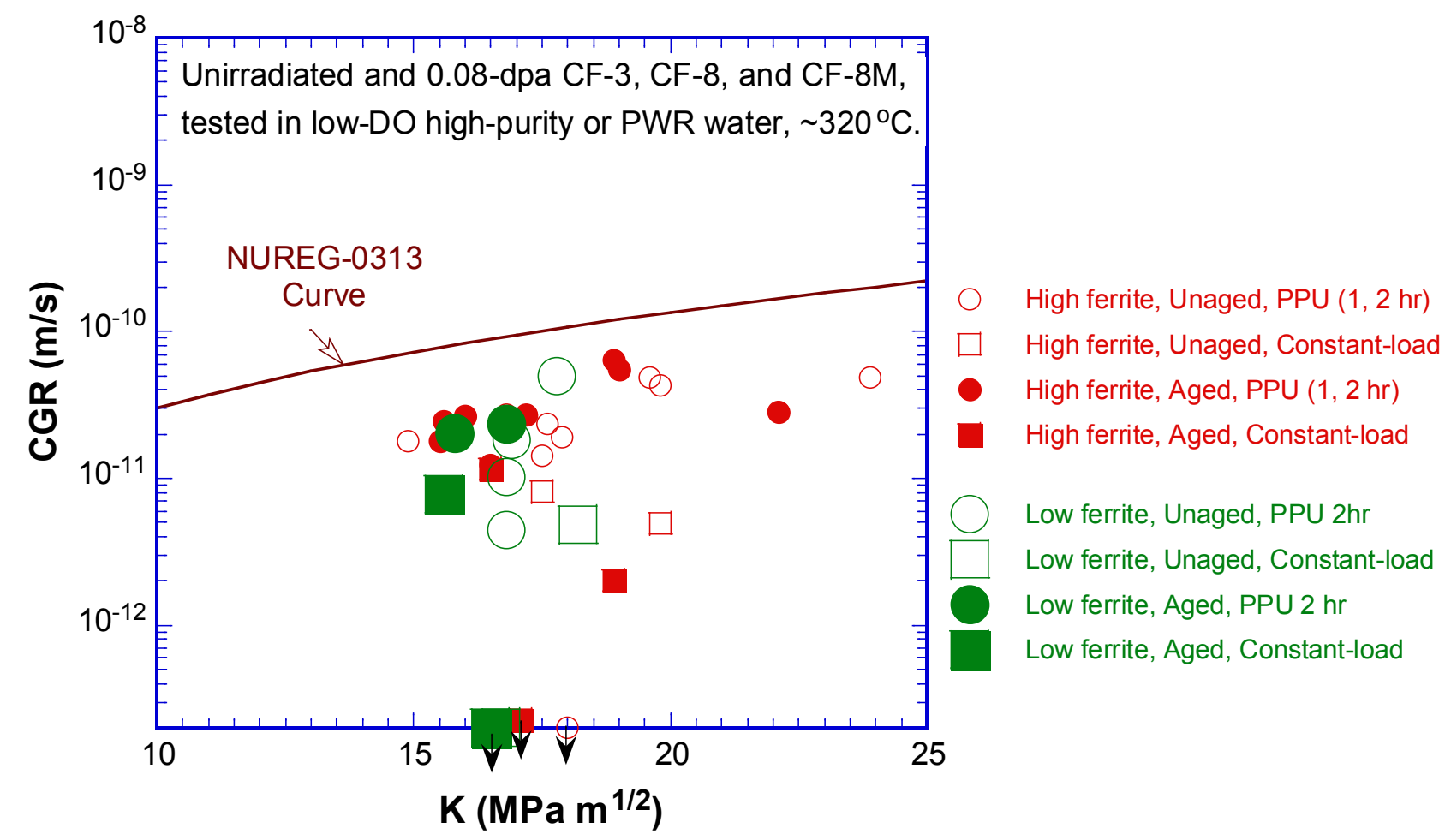

Figure 38. SCC crack growth rates of CASS alloys tested in low-DO high-purity water or PWR water at $\sim 320^{\circ} \mathrm{C}$

\subsection{Fracture Toughness}

The fracture toughness results obtained in the current study are summarized in Table 8 (also shaded in grey). The previous results on high ferrite content CASS alloys ${ }^{16}$ are included in the table along with some unirradiated fracture toughness values obtained at $290^{\circ} \mathrm{C}$ in air. Note that the unirradiated specimens tested in air are 1T-CT, much larger than the specimens used in the current study and in reference [16]. Since the low-ferrite heats are not tested in unirradiated conditions, their fracture toughness values are calculated based on a method proposed in [20]. The room-temperature Charpy impact energies reported in [21] are used in the calculations. Please refer to the references [20] and [21] for experimental details of the unirradiated tests.

Figure 39 shows the comparisons between unirradiated and irradiated tests, and the low- and high-ferrite specimens. The blue and brick bars are for the high- and low-ferrite samples, respectively. For the unirradiated CF-3 (Figure 39-a), the unaged J values of the high- and lowferrite heats are very similar, both slightly above $300 \mathrm{~kJ} / \mathrm{m}^{2}$. After thermal aging and/or irradiation, the J value of high-ferrite heat (blue bars) was reduced considerably, to 100-200 $\mathrm{kJ} / \mathrm{m}^{2}$. A similar reduction in J value can be seen for the low-ferrite CF-3 after irradiation with or without thermal aging. Thermal aging alone, however, does not yield the same extent of embrittlement (see the $3^{\text {rd }}$ brick bar from the left). The dominant effect of neutron irradiation on embrittlement is evident. This observation implies that, while lowering the ferrite content can help reduce thermal aging embrittlement, it is not effective to mitigate irradiation-induced 
embrittlement. Note that the CF-3 specimen was aged at $320^{\circ} \mathrm{C}$ for $55,000 \mathrm{hr}$, a thermal aging condition that may have not produced fully saturated embrittlement for this $\mathrm{CF}-3$ material.

However, even with an aging condition of $400^{\circ} \mathrm{C}$ for $10,000 \mathrm{hr}$ (a fully saturated aging condition), the estimated $\mathrm{J}$ value based on the Charpy impact energy is still above $275 \mathrm{~kJ} / \mathrm{cm}^{2}$, considerably higher than that of irradiated $\mathrm{J}$ values. Thus, the significant decline in $\mathrm{J}$ value observed in CF-3 (more than $100 \mathrm{~kJ} / \mathrm{m}^{2}$ ) must be attributed to neutron irradiation. It is clear that irradiation plays a dominant role in causing embrittlement in CF-3 under a combined condition of thermal aging and neutron irradiation.

Table 8. Fracture toughness J-R curve test results for CASS alloys.

\begin{tabular}{|c|c|c|c|c|c|c|c|c|c|c|c|}
\hline \multirow{2}{*}{ Material $^{\mathrm{a}}$} & \multirow{2}{*}{$\begin{array}{l}\text { Ferrite } \\
\text { content }\end{array}$} & \multirow{2}{*}{$\begin{array}{l}\text { Thermal } \\
\text { aging }\end{array}$} & \multirow{2}{*}{$\begin{array}{c}\text { Sample } \\
\text { Size }\end{array}$} & \multirow{2}{*}{ Test Env. $^{\text {b }}$} & \multirow{2}{*}{$\begin{array}{c}\text { Test Temp. }{ }^{\mathrm{b}} \\
\left({ }^{\circ} \mathrm{C}\right)\end{array}$} & \multicolumn{3}{|c|}{ Unirradiated } & \multicolumn{3}{|c|}{ Irradiated (0.08 dpa) } \\
\hline & & & & & & $\mathrm{C}$ & $\mathrm{n}$ & $\mathrm{J}_{\mathrm{Q}}\left(\mathrm{kJ} / \mathrm{m}^{2}\right)$ & $\mathrm{C}$ & $\mathrm{n}$ & $\mathrm{J}_{\mathrm{Q}}\left(\mathrm{kJ} / \mathrm{m}^{2}\right)$ \\
\hline \multirow{8}{*}{$\mathrm{CF}-3$} & \multirow{4}{*}{$24 \%$} & \multirow{2}{*}{ Unaged } & $1 / 4 \mathrm{~T}$ & Water & $\sim 320$ & 536 & 0.68 & 320 & 430 & 0.64 & 204 \\
\hline & & & $1 \mathrm{~T}$ & Air & $\sim 290$ & 756 & 0.31 & 700 & - & - & - \\
\hline & & \multirow{2}{*}{ Aged } & $1 / 4 \mathrm{~T}$ & Water & $\sim 320$ & 353 & 0.66 & 170 & 362 & 0.85 & 116 \\
\hline & & & $1 \mathrm{~T}$ & Air & $\sim 290$ & 296 & 0.51 & 167 & - & - & - \\
\hline & \multirow{4}{*}{$14 \%$} & \multirow{2}{*}{ Unaged } & $1 / 4 \mathrm{~T}$ & Water & $\sim 320$ & - & - & - & 347 & 0.65 & 168 \\
\hline & & & - & - & - & $(477)^{\mathrm{e}}$ & $(0.46)$ & (318) & - & - & - \\
\hline & & \multirow{2}{*}{ Aged } & $1 / 4 \mathrm{~T}$ & Water & $\sim 320$ & - & - & - & 419 & 0.80 & 161 \\
\hline & & & - & - & - & $(472)$ & $(0.46)$ & (313) & - & - & - \\
\hline \multirow{8}{*}{$\mathrm{CF}-8$} & \multirow{4}{*}{$23 \%$} & \multirow{2}{*}{ Unaged } & $1 / 4 \mathrm{~T}$ & Water & $\sim 320$ & - & - & $>500^{c}$ & 359 & 0.57 & 183 \\
\hline & & & $1 \mathrm{~T}$ & Air & $\sim 290$ & 783 & 0.27 & 753 & - & - & - \\
\hline & & \multirow{2}{*}{ Aged } & $1 / 4 \mathrm{~T}$ & Water & $\sim 320$ & 395 & 0.58 & 220 & 372 & 0.62 & 171 \\
\hline & & & $1 \mathrm{~T}$ & Air & $\sim 290$ & 396 & 0.51 & 242 & - & - & - \\
\hline & \multirow{4}{*}{$13 \%$} & \multirow{2}{*}{ Unaged } & $1 / 4 \mathrm{~T}$ & Water & $\sim 320$ & - & - & - & $870^{d}$ & $0.92^{d}$ & $452^{d}$ \\
\hline & & & - & - & - & $(479)$ & $(0.43)$ & $(331)$ & - & - & - \\
\hline & & \multirow{2}{*}{ Aged } & $1 / 4 \mathrm{~T}$ & Water & $\sim 320$ & - & - & - & 406 & 0.60 & 205 \\
\hline & & & - & - & - & (411) & $(0.40)$ & $(276)$ & - & - & - \\
\hline
\end{tabular}

${ }^{a}$ Irradiated unaged and aged materials were exposed to the irradiation temperature $\left(\sim 315^{\circ} \mathrm{C}\right)$ for approximately $4320 \mathrm{hr}$. The aging parameter P defined in reference [20] is 1.66, 1.82, and 2.07 for Material CF-3, CF-8, and CF-8M, respectively. Thus, the extent of embrittlement caused by the reactor temperature is negligible during the course of the irradiation.

$\mathrm{b}$ All 1/4T-CT specimens were tested in low-corrosion-potential water environments at $\sim 320^{\circ} \mathrm{C}$. All $1 \mathrm{~T}$-CT specimens were tested in an air atmosphere at $\sim 290^{\circ} \mathrm{C}$ in a previous study (NUREG/CR 4744, No.7, [21]).

$\mathrm{c}$ The last data point measured at the end of the test. A J value of $\sim 700 \mathrm{~kJ} / \mathrm{m}^{2}$ was estimated by extrapolating the available data to the 0.2 -mm offset line.

$\mathrm{d}$ The results may have been affected by an interruption during the CGR test.

e The values in parentheses are estimated from room temperature Charpy impact energies.

For CF-8, the comparison between high- and low-ferrite specimens is complicated by a questionable data point of the unaged irradiated test (the $2^{\text {nd }}$ brick bar in Figure 39-b). Very little crack extension was obtained in this test, and only a few data points at the end of the test were qualified for the curve fitting. The fractographic examination also showed that the sample was strained more severely on one side than the other. This loading misalignment may be caused by the interruption of the test due to a steam leak (see section 3.2.1). Excluding this data point (i.e., the unaged and irradiated condition), the $\mathrm{J}$ value of the low-ferrite CF-8 decreases from an initial 
$\sim 330 \mathrm{~kJ} / \mathrm{m}^{2}$ to $276 \mathrm{~kJ} / \mathrm{m}^{2}$ after aging, and to $205 \mathrm{~kJ} / \mathrm{m}^{2}$ after aging plus irradiation. This decreasing trend is consistent with that observed in the high-ferrite CF-8. Comparing the results under the aged condition (the four bars on the right in Figure 39-b), the irradiation-induced embrittlement of the high-ferrite specimen (i.e., the difference of the two blue bars) is nearly identical to that of low-ferrite specimen (i.e., the difference of the two brick bars). It appears that, by lowering the ferrite content from $\sim 24 \%$ to $\sim 14 \%$, the extent of irradiation-induced embrittlement was not reduced.

The mechanism of thermal aging embrittlement of CASS has been studied extensively. ${ }^{4} 21$ Precipitations and microchemical changes in ferrite phase are believed to be responsible for thermal aging embrittlement. Thus, the degree of thermal aging embrittlement can be affected by ferrite content. If the same embrittlement mechanism also operates under irradiation, a similar effect of ferrite content should be observed for irradiation-induced embrittlement. However, the current results from both CF-3 and CF-8 specimens do not support this hypothesis. While some of the tests on irradiated and unirradiated CASS alloys need to be repeated and confirmed, the initial results suggest that the embrittlement of CASS could evolve more rapidly with irradiation. The embrittlement mechanism that operates under irradiations need to be investigated thoroughly. Under a combined condition of thermal aging and irradiation, neutron irradiation is the main factor contributing to the embrittlement of CASS. Without doubt, this dominant role of irradiation will become even more important at high doses.

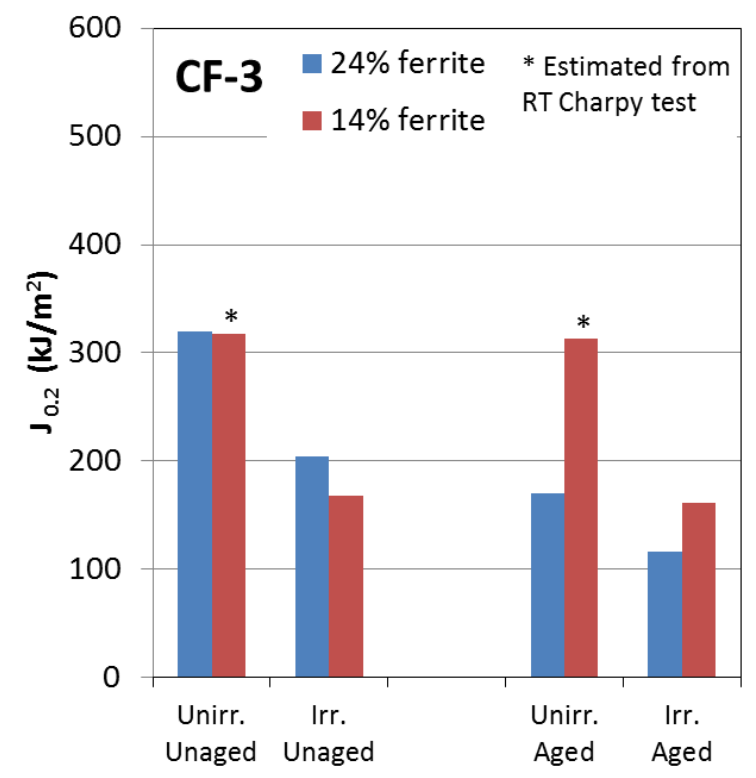

(a)

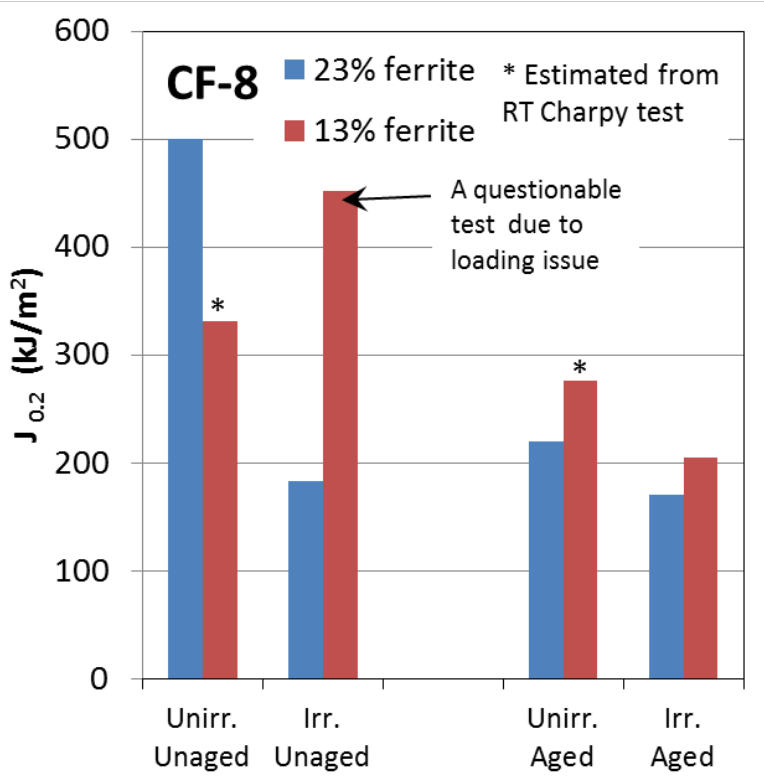

(b)

Figure 39. $\mathrm{J}_{0.2}$ values of high- and low-ferrite CASS: (a) for CF-3, and (b) CF-8. 
Crack growth rate and fracture toughness J-R curve tests were performed on CF- 3 and CF-8 cast austenite stainless steels (CASS) with $13-14 \%$ of ferrite. The tests were conducted at $\sim 320^{\circ} \mathrm{C}$ in either high-purity water with low dissolved oxygen or in simulated pressurized reactor water. All specimens were precracked in the test environments, and cyclic and SCC CGRs were measured to assess their cracking behaviors under low-corrosion-potential environments. The cyclic CGRs of CF-8 were higher than that of CF-3, and the differences between the aged and unaged specimens were small. No elevated SCC susceptibility was seen in these tests, and the SCC CGRs of these materials were comparable to those of CASS alloys with $>23 \%$ ferrite. The fracture toughness values of unirradiated CF-3 were similar between the unaged and aged specimens, and neutron irradiation reduced the fracture toughness significantly. The fracture toughness of CF-8 was reduced after thermal aging, and declined further after irradiation. It appears that while lowering ferrite content may help reduce the tendency of thermal aging embrittlement, it is not very effective to mitigate irradiation-induced embrittlement. Under a combined condition of thermal aging and irradiation, neutron irradiation plays a dominant role in inducing embrittlement. 


\section{REFERENCES}

1. U.S. NRC, "Expert Panel Report on Proactive Materials Degradation Assessment," NUREG/CR-6923, 2006.

2. Blair, M., and T. L. Steven, Steel Castings Handbook, Sixth Edition, Steel Founders' Society of America and ASM International, 1995.

3. ASTM International, "Standard Specification for Castings, Austenitic, for PressureContaining Parts," A351/A351M-10, Annual Book of ASTM Standards, 2012.

4. Chopra, O. K., and A. Sather, "Initial Assessment of the Mechanisms and Significance of Low-Temperature Embrittlement of Cast Stainless Steels in LWR Systems," NUREG/CR5385, ANL-89/17, 1990.

5. Mills, W. J., "Fracture Toughness of Type 304 and 316 Stainless Steels and Their Welds," International Materials Reviews, 4, No. 2 (1997): 45.

6. Beck, F. H., E. A. Schoefer, J. W. Flowers, and M. G. Fontana, "New Cast High-Strength Alloy Grades by Structure Control," in Advances in the Technology of Stainless Steels and Related Alloys, ASTM STP 369, 1965.

7. Floreen, S., and H. W. Hayden, "The Influence of Austenite and Ferrite on the Mechanical Properties of Two-phase Stainless Steels Having Microduplex Structures," ASM Transactions Quarterly, 61, No. 3 (1968): 489-499

8. Beck, F. H., J. Juppenlatz, and P. F. Wieser, "Effects of Ferrite and Sensitization on Intergranular and Stress Corrosion Behavior of Cast Stainless Steels," in Stress Corrosion New Approaches, H. L. Craig, Jr., ed., ASTM STP 610, 1976.

9. Hughes, N. R., W. L. Clarke, and D. E. Delwiche, "Intergranular Stress-Corrosion Cracking Resistance of Austenitic Stainless Steel Castings," in Stainless Steel Castings, V. G. Behal and A. S. Melilli, eds., ASTM STP 756, 1982.

10. Fisher, R. M, E. J. Dulis, and K. G. Carroll, "Identification of the Precipitate Accompanying 885F Embrittlement in Chromium Steels,” Transactions of AIME, 197 No. 5 (1953): 690695.

11. Grobner, P. J., "The $885^{\circ} \mathrm{F}\left(475^{\circ} \mathrm{C}\right)$ Embrittlement of Ferritic Stainless Steels," Metallurgical and Materials Transactions B, 4, No. 1 (1973): 251-260.

12. Nichol, T. J., A. Datta, and G. Aggen, "Embrittlement of Ferritic Stainless Steels," Metallurgical and Materials Transactions A, 11, No. 4 (1980): 573-585.

13. Trautwein, A., and W. Gysel, "Influence of Long-time Aging of CF8 and CF8M Cast Steel at Temperatures Between 300 and $500^{\circ} \mathrm{C}$ on Impact Toughness and Structural Properties," in Stainless Steel Castings, ASTM STP 756 (1982): 165-189.

14. Wollenberger, H., "Phase Transformations under Irradiation," Journal Nuclear Materials, 216 (1994) 63.

15. Averback, R. S., “Atomic Displacement Processes in Irradiated Metals,” Journal Nuclear Materials, 216 (1994): 49. 
16. Chen, Y., B Alexandreanu, and K. Natesan, "Crack Growth Rate and Fracture Toughness Tests on Irradiated Cast Stainless Steels," NUREG/CR-7184, ANL-12/56, 2015.

17. Andresen, P. L., F. P. Ford, S. M. Murphy, and J. M. Perks, "State of Knowledge of Radiation Effects on Environmental Cracking in Light Water Reactor Core Materials," Proc. 4th Intl. Symp. on Environmental Degradation of Materials in Nuclear Power Systems -Water Reactors, NACE, Houston, TX, pp. 1.83-1.121, 1990.

18. Shack, W. J., and T. F. Kassner, "Review of Environmental Effects on Fatigue Crack Growth of Austenitic Stainless Steels,” NUREG/CR-6176, 1994.

19. Hazelton, W. S., and W. H. Koo, "Technical Report on Material Selection and Processing Guidelines for BWR Coolant Pressure Boundary Piping,” NUREG-0313, Rev. 2, 1988.

20. Chopra, O. K., "Estimation of Fracture Toughness of Cast Stainless Steels During Thermal Aging in LWR Systems,” NUREG/CR-4513, ANL-93/22, Rev.1, 1994.

21. Chopra, O. K., "Long-Term Embrittlement of Cast Duplex Stainless Steels in LWR Systems,” NUREG/CR-4744, Vol. 6, No. 1, ANL-91/22, 1992. 